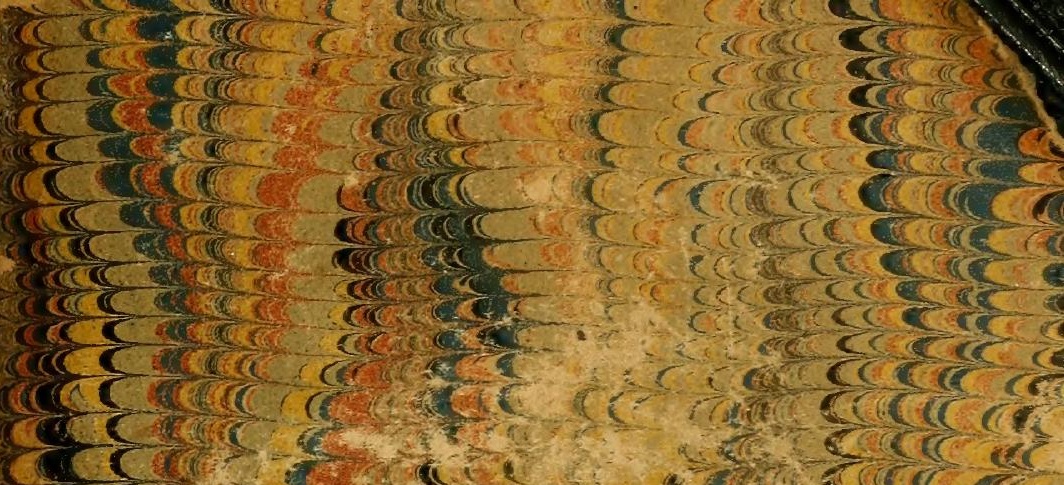

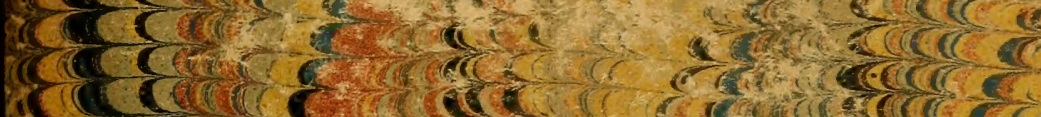

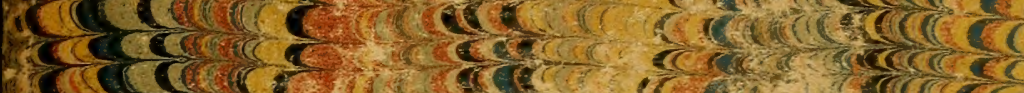

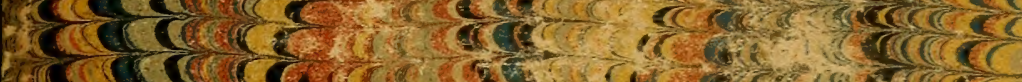

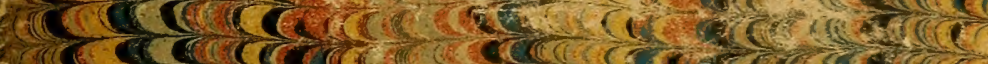

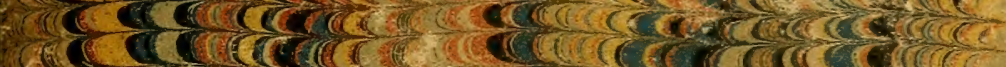

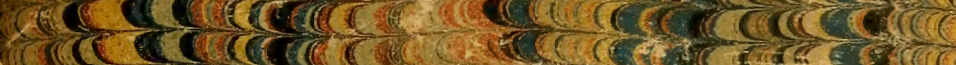

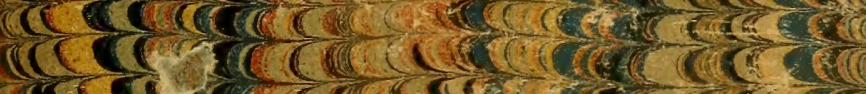

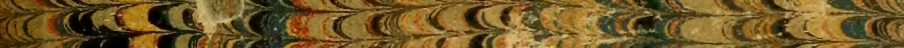

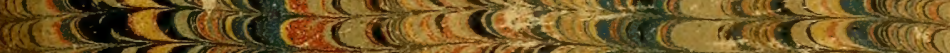

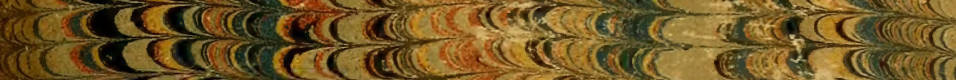

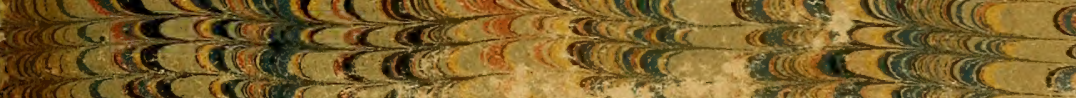

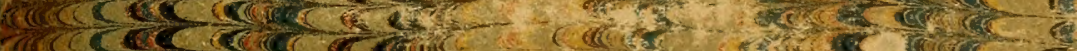

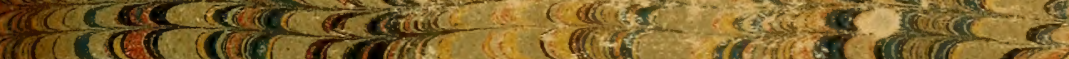

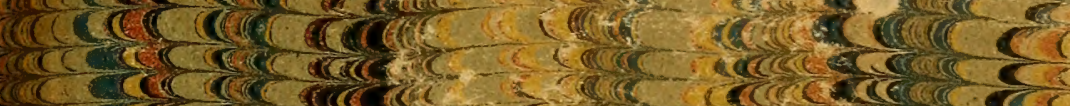

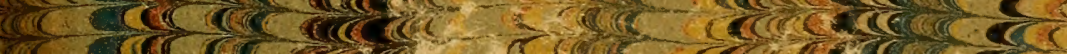

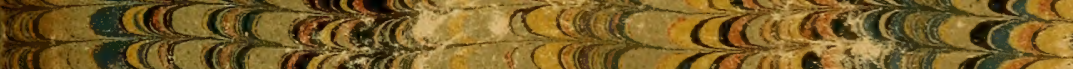

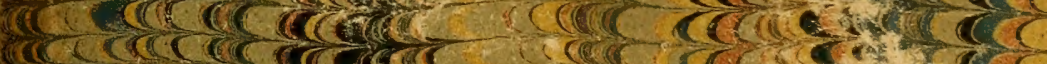

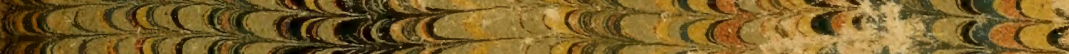
-

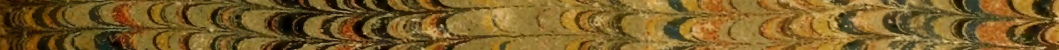

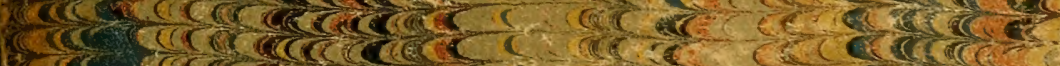

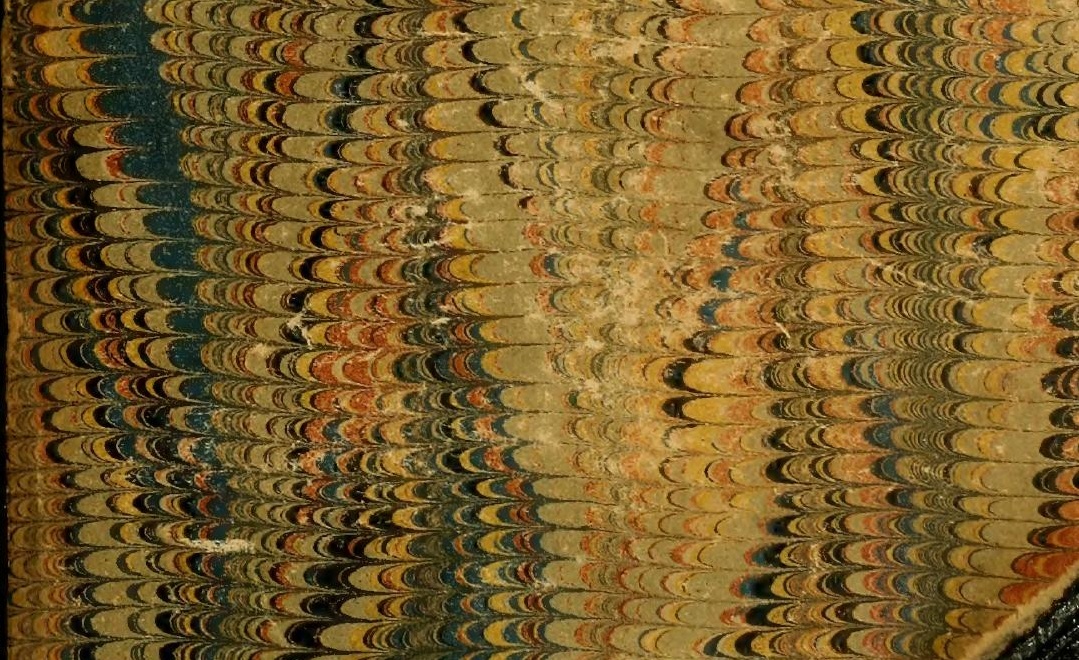




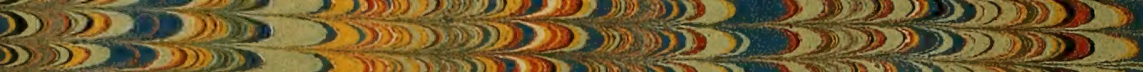

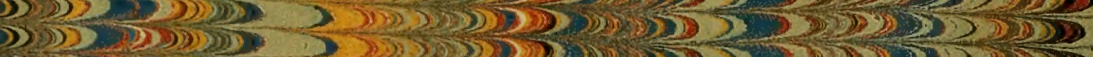

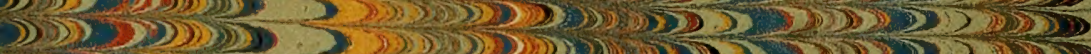

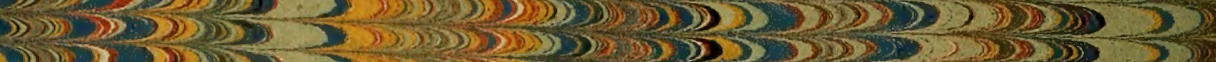

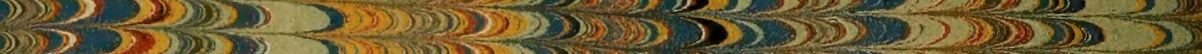
$3(25) 2$ (2)

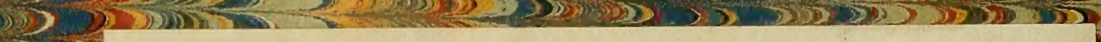

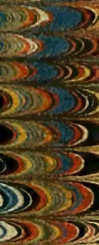
D) 5 D) $>$ D) $D>$ 3 (P) 2$)$ D) $\rightarrow$ (D) 353 DDS 3) 2 D) 35) 55

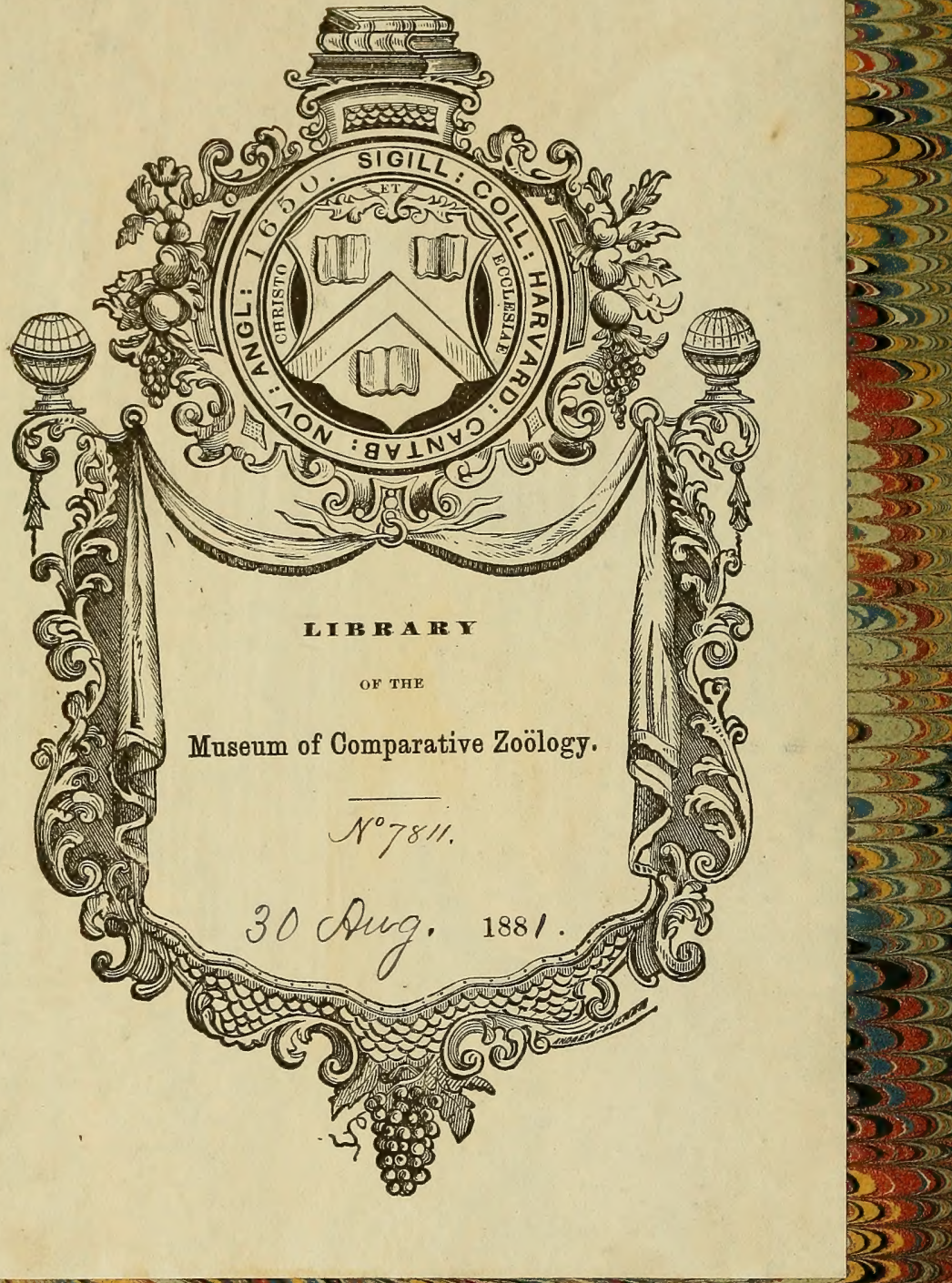

(D) $) 20$

3 (3)

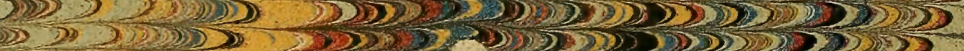

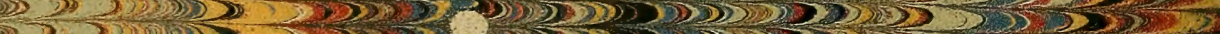

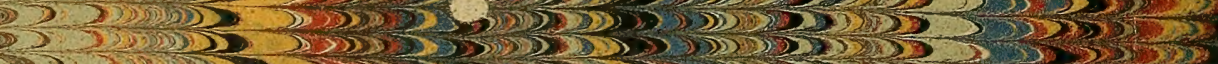

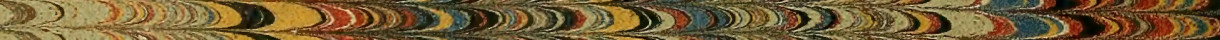

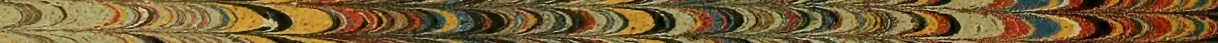

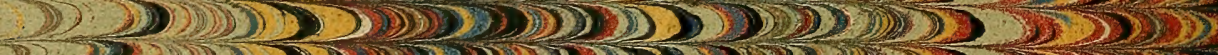

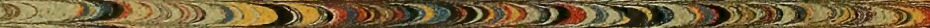








\title{
A SELECTION OF THE
}

\section{B I R D S}

OF

\section{BR A IL A ND MEXICO.}

\author{
THE DRAWINGS
}

BY

\section{WILLIAM SWAINSON, ESQ. A.C.G.}

FELLOW OF THE ROYAL AND LINN. SOCIETIES OF LONDON ; HON. MEMBER OF THE CAMBRIDGE PHIL. SOC. ; MEMBER OF THE WERNERIAN SOC. OF EDINBORGH; THE NAT. HIST. SOC. OF PARIS ; THE ACademY OF SCIENCES, PHILAdELPHia; THE Hist. SOC. OF NEW YORK; THE SO. AFRICAN AND LIVERPOOL ROYAL INSTITUTIONS, ETC. ETC.

\section{O N D O N :}

HENRY G. BOHN, YORK STREET, COVENT GARDEN. 
AUG 3018\%1

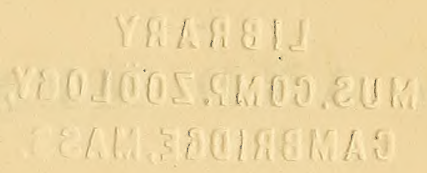




\section{LIST OF PLATES}

\section{N \\ SWAINSON'S BIRDS OF BRAZIL.}

PLATE.

English Names.

1. Crimson-rump'd Oriole.

2. Greater Crimson-rump'd Cassican. Cassicus affinis.

3. Yellow-backed Cassican.

4. Black Cassican.

5. Blue-headed Tanager.

6. Citron-headed Tanager.

7. Chesnut-cap'd Tanager.

8. Blue-winged Tanager.

9. Long-bill'd Puff Bird.

10. White-ear'd Puff Bird.

11. Spotted Puff Bird.

12. White-bearded Puff Bird.

13. Tropical Wren.

14. Red-breasted Wren.

15. Bar-throated Wren.

16. Long-bill'd Wren.

17. Black masked Tanager.
Latin Names.

Icterus hæmorrhous.

Cassicus icteronotus.

Cassicus nigerrimus.

Aglaia cyanocephala.

Aglaia citrinella.

Aglaia cucullata.

Aglaia cyanoptera.

Tamatia somnolenta.

Tamatia leucotus.

Tamatia maculata.

Tamatia leucops.

Thryothorus Aquinoctialis

Thryothorus carinatus.

Thryothorus rutilans

Thryothorus striolatus.

Ramphopis nigro-gularis. 
English Names.

Latin Names.

PLATE.

18. Crimson Tanager.

Ramphopis coccineus.

19. Crimson Tanager, Female.

Ramphopis coccineus.

20. Marone Tanager.

Ramphopis atro-coccineus.

21. Green and Blue-crested Humming Bird. Trochilus cristatus.

22. Delalande's Humming Bird.

23. Helmet Manakin.

24. Short-tailed Manakin.

25. Striped Manakin.

26. Bearded Manakin.

27. Mango Humming Bird, Young.

28. Mango Humming Bird

29. Violet-ear'd Humming Bird.

30. Ruby Topaz Humming Bird.

31. Black-backed Tanager.

32. Great-crested Cassican.

33. Sharp-tailed Wren.

34. Striped Puff Bird.

35. Red-breasted Puff Bird.

36. Swallow Puff Bird.

37. Blue shouldered Tanager.

38. Olive-grey Tanager.

39. Bishop Tanager.

40. Olive-flanked Tanager.

41. Blue-grey Tanager.

42. Yellow-shouldered Tanager.

43. Black-backed Tanager.
Trochilus Delalandix.

Pipra galeata.

Calyptura cristata.

Pipra strigilata.

Pipra manacus

Lampornis mango.

Lampornis mango.

Trochilus auritus.

Trochilus moschitus.

Aglaia melanotus.

Cassicus cristatus.

Lochmias squamulata.

Lypornix striata.

Lypornix rubicula.

Lypornix tenebrosa.

Tanagra cana.

Tanagra olivascens.

Tanagra Episcopus.

Tanagra inornata.

Tanagra cœlestes.

Tanagra ornata.

Aglaia melanotis 
English Names.

PLATE.

44. Blue-backed Manakin.

45. Long-tailed Manakin.

46. White-eyebrowed Flycatcher.

47. Great-headed Flycatcher.

48. Round-winged Flycatcher.

49. Straw-crested Flycatcher.

50. Little Tyrant Flycatcher.

51. Royal Tody.

52. Royal Tody.

53. Crested-rufous Flycatcher.

54. Short-footed Flycatcher.

55 Knob-fronted Wren, Male.

56. Knob-fronted Wren, Female.

57. Red-breast Wren.

58. Brazilian Shrike.

59. Cinereous Bush Shrike.

60. Red-eyed Shrike.

61. Green-breasted Trogon, Male.

62. Green-breasted Trogon, Female.

63. Purple-breasted Trogon, Male.

64. Purple-breasted Trogon, Female.

65. Red-backed Bush Shrike, Male.

66. Red-backed Bush Shrike, Female.

67. Rufous-crowned Flatbill, Male.

68. Rufous crowned Flatbill, Female.
Latin Names.

Pipra pareola.

Pipra caudata.

Tyrannula superciliosá.

Tyrannula megacephala.

Tyrannula modesta.

Tyrannula caniceps.

Tyrannus circumcinctus.

Megalophus regius.

Megalophus regius.

Tyrannula ferruginea.

Tyrannula curtipes.

Platyurus corniculatus.

Platyurus corniculatus.

Platyurus affinis.

Cyclarhis Guianensis.

Thamnophilus nævius.

Thamnophilus bicolor.

Trogon auratus.

Trogon auratus.

Trogon purpuratus.

Trogon purpuratus.

Thamnophilus baảius.

Thamnophilus badius

Conopophaga ruficeps.

Conopophaga ruficeps. 


\section{BIRDS OF MEXICO.}

English Names.

PIATE.

69. Sooty Flycatcher.

70. Black-tailed Flycatcher.

71. Yellow-tailed Flycatcher.

72. Pimple-faced Oriole.

73. Mexican Imperial Eagle.

74. Mexican Amethyst Humming Bird. Trochilus montanus.

75. Green-tailed Humming Bird.

76. Sapphire-crowned Humming Bird

77. Mexican-star Humming Bird.

78. Pigmy Humming Bird.
Latin Names.

Tyrannula

Tyrannula Sayii ?

Setophaga

Icterus Pustulatus.

Thrasäetos Harpyia, G. R. Gray.

Troçhilus Anais.

Trochilus Rivoli.

Trochilus cyanopogon.

Trochilus pygmæus. 



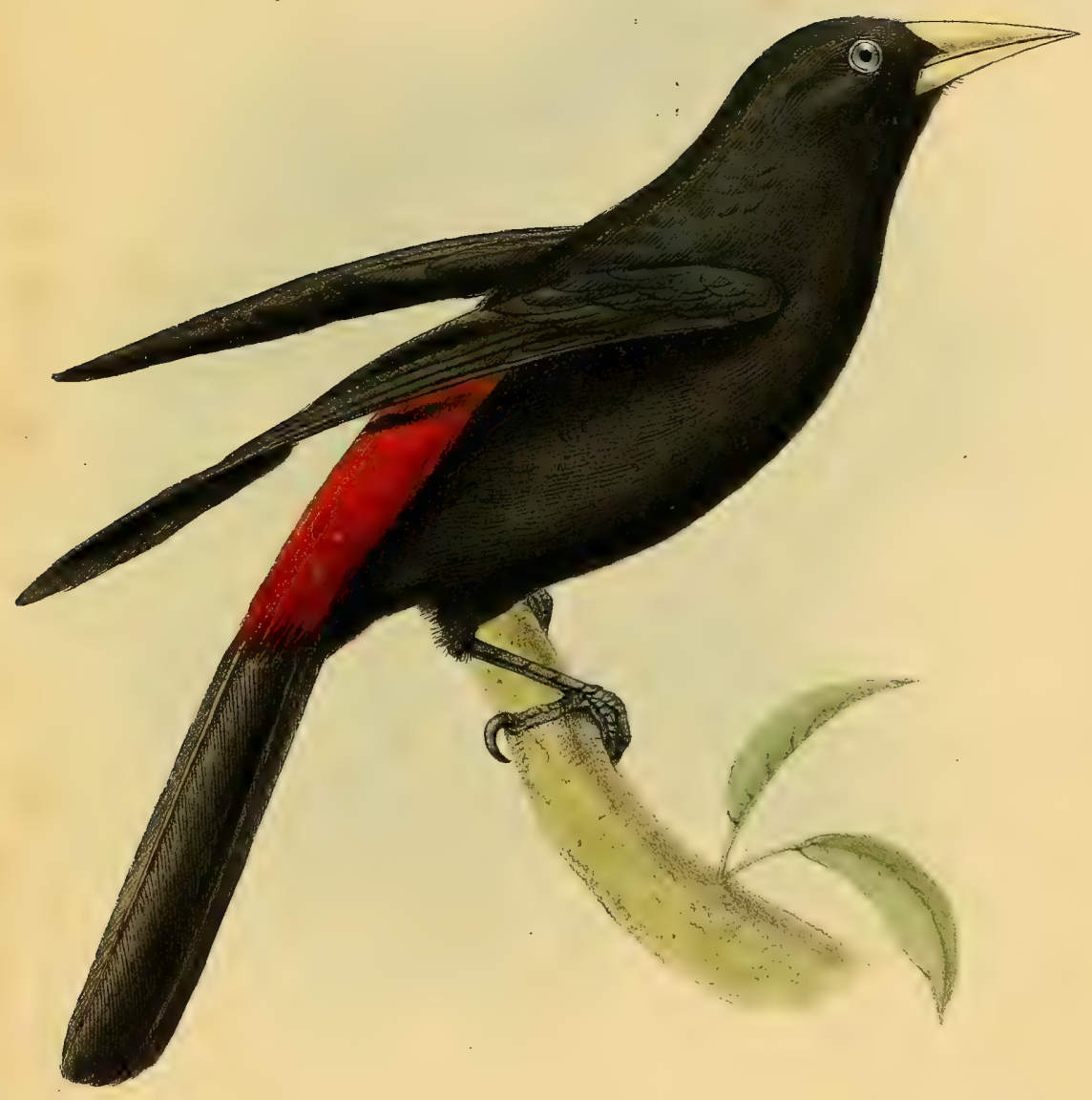

Crimson-rump'd Oriole

I. hamorrhous . 





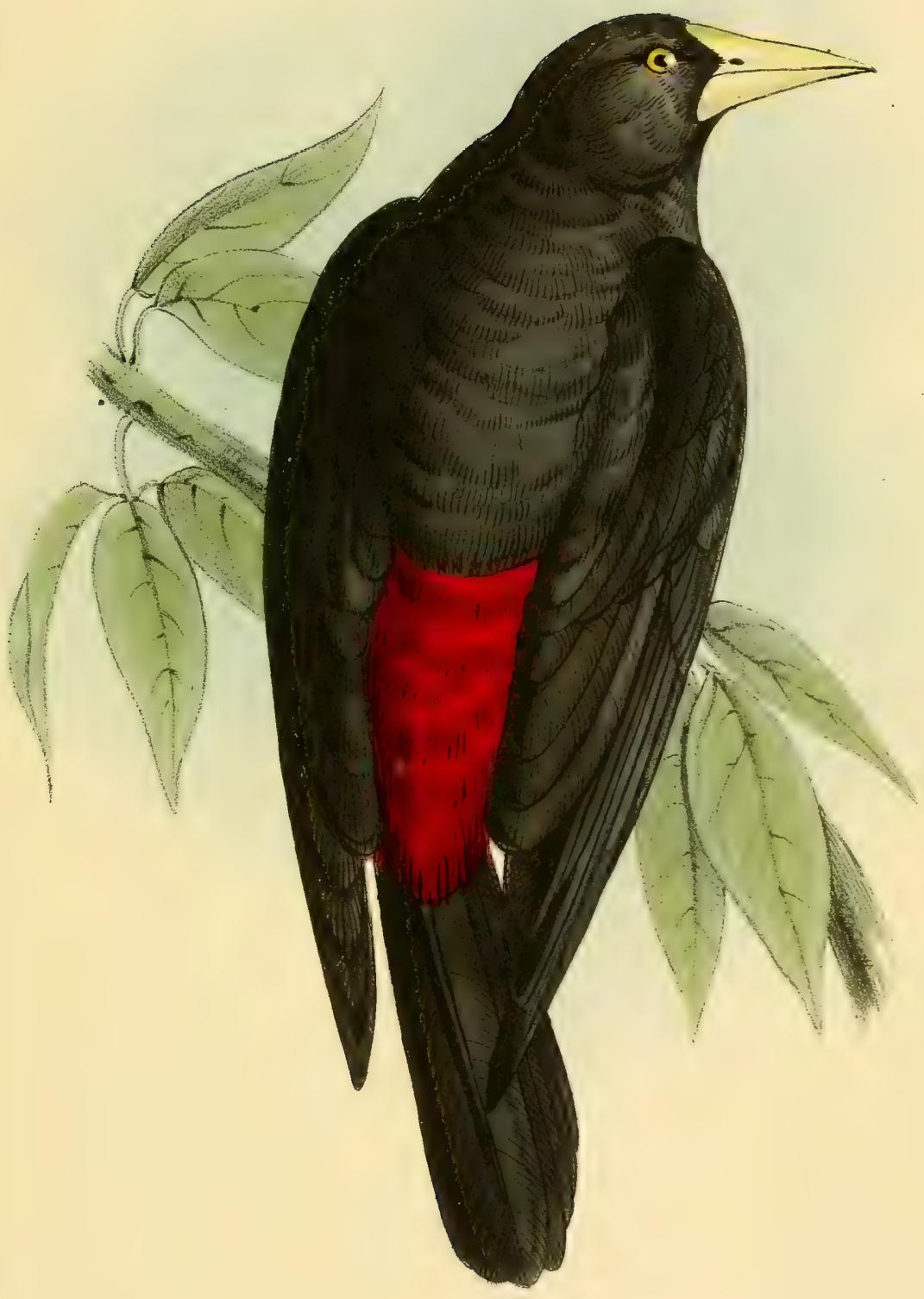

Greater Grimson mump'a Casszcan.

c. Affinis 





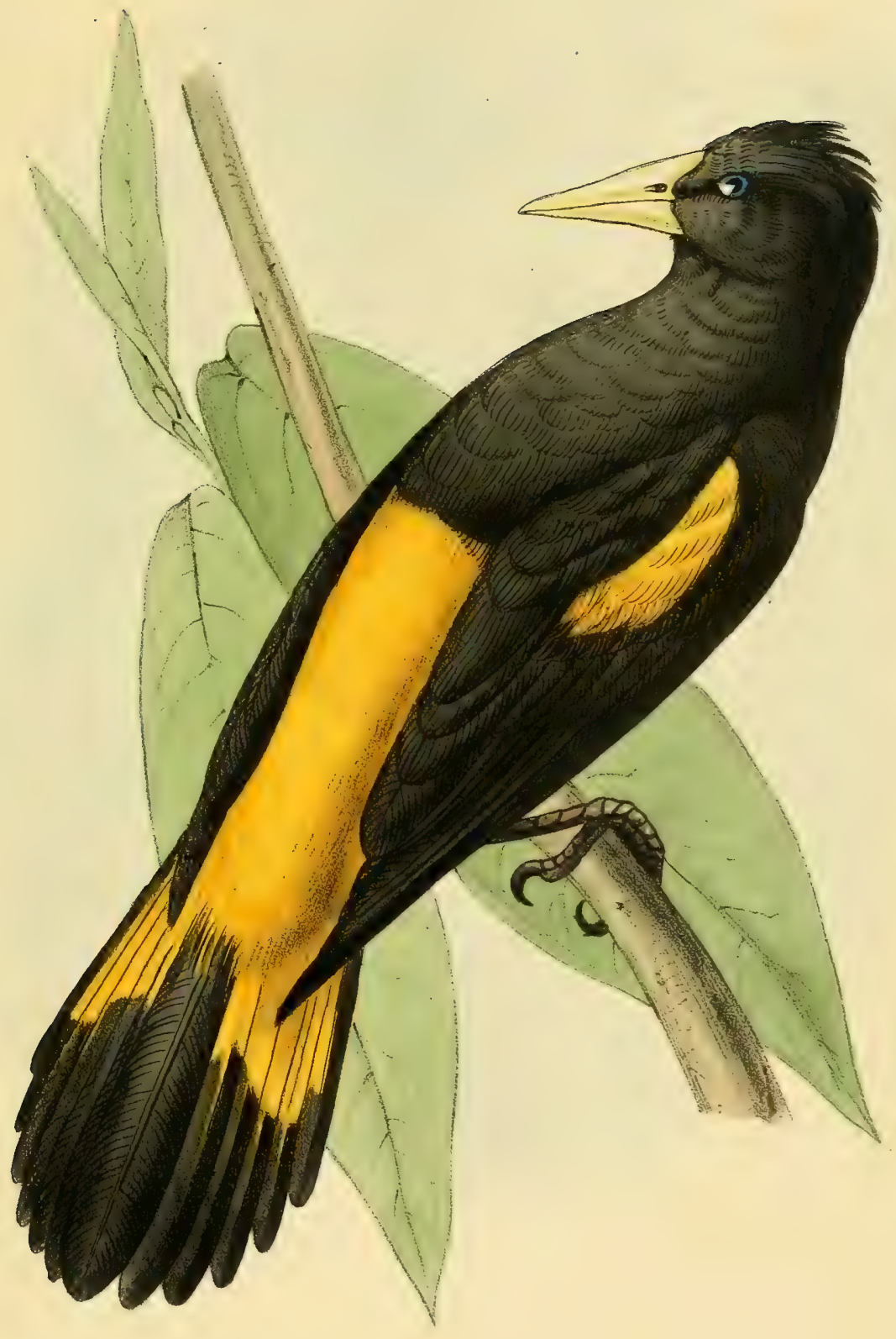

Yellow Backea Gassicum

C. Icteronotus 





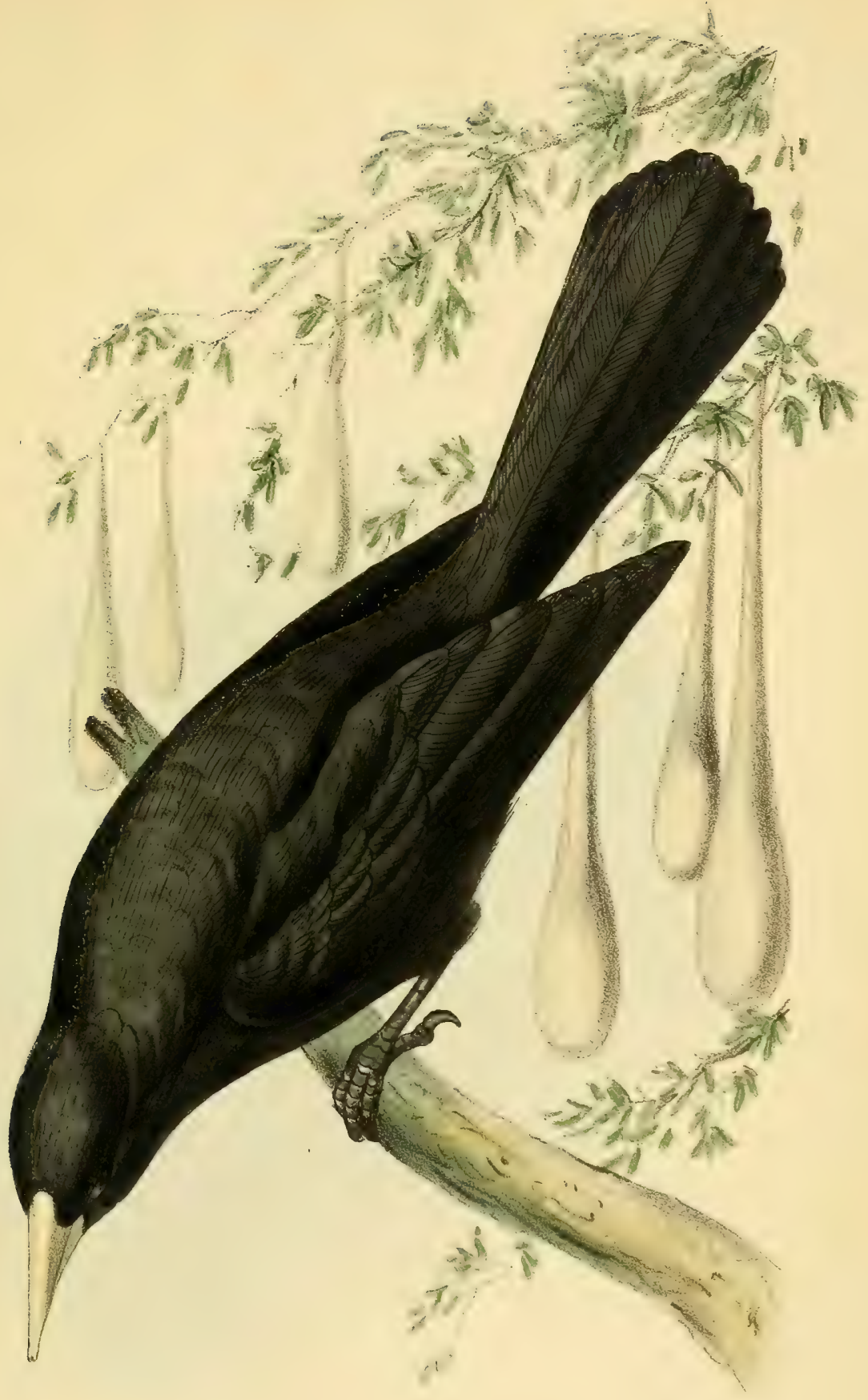







$$
<
$$







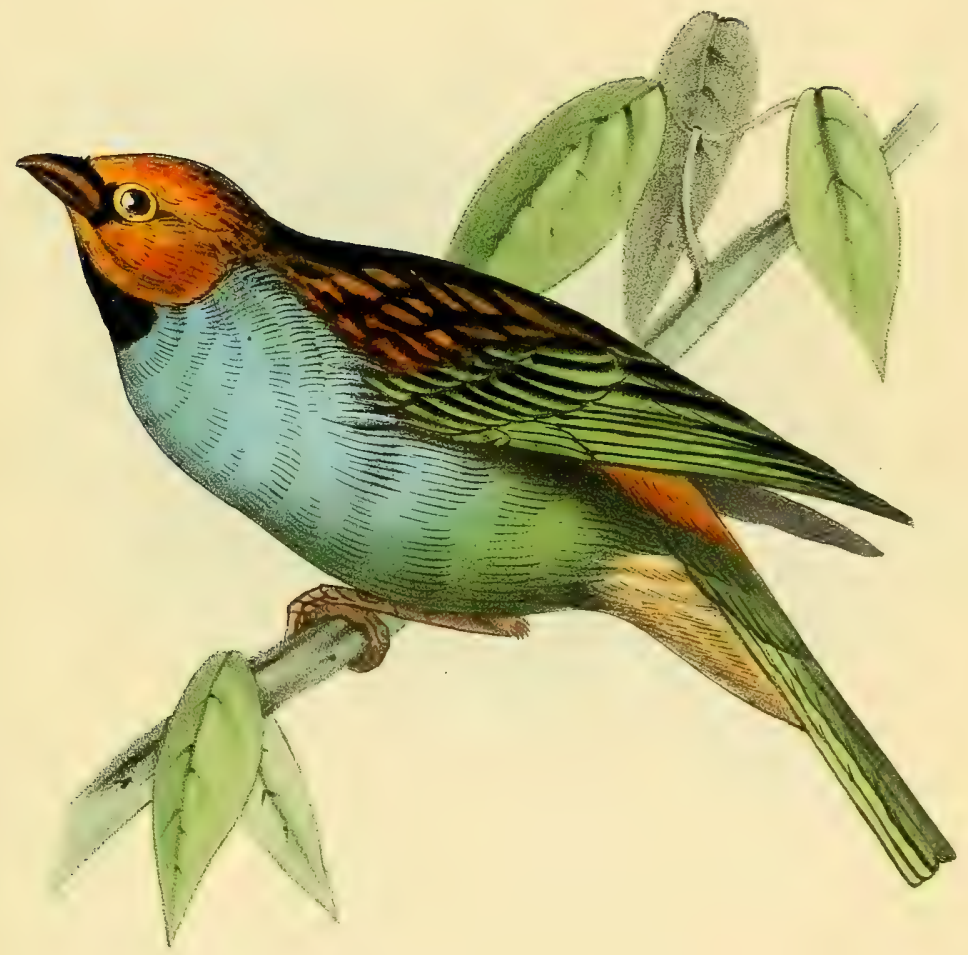

A. Citronella. 





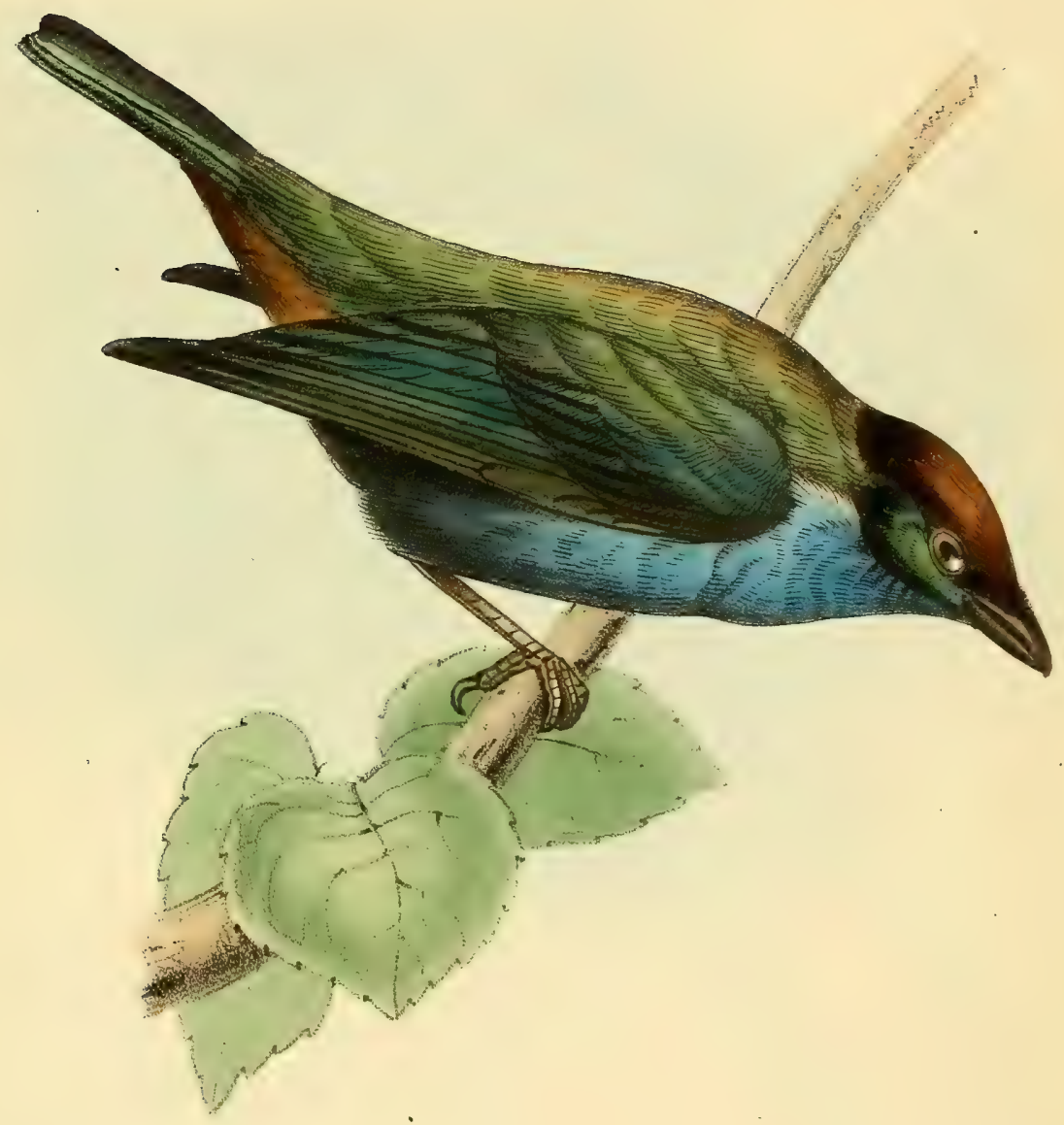

Chesnut cap'a Tanager

A. Cruculata 





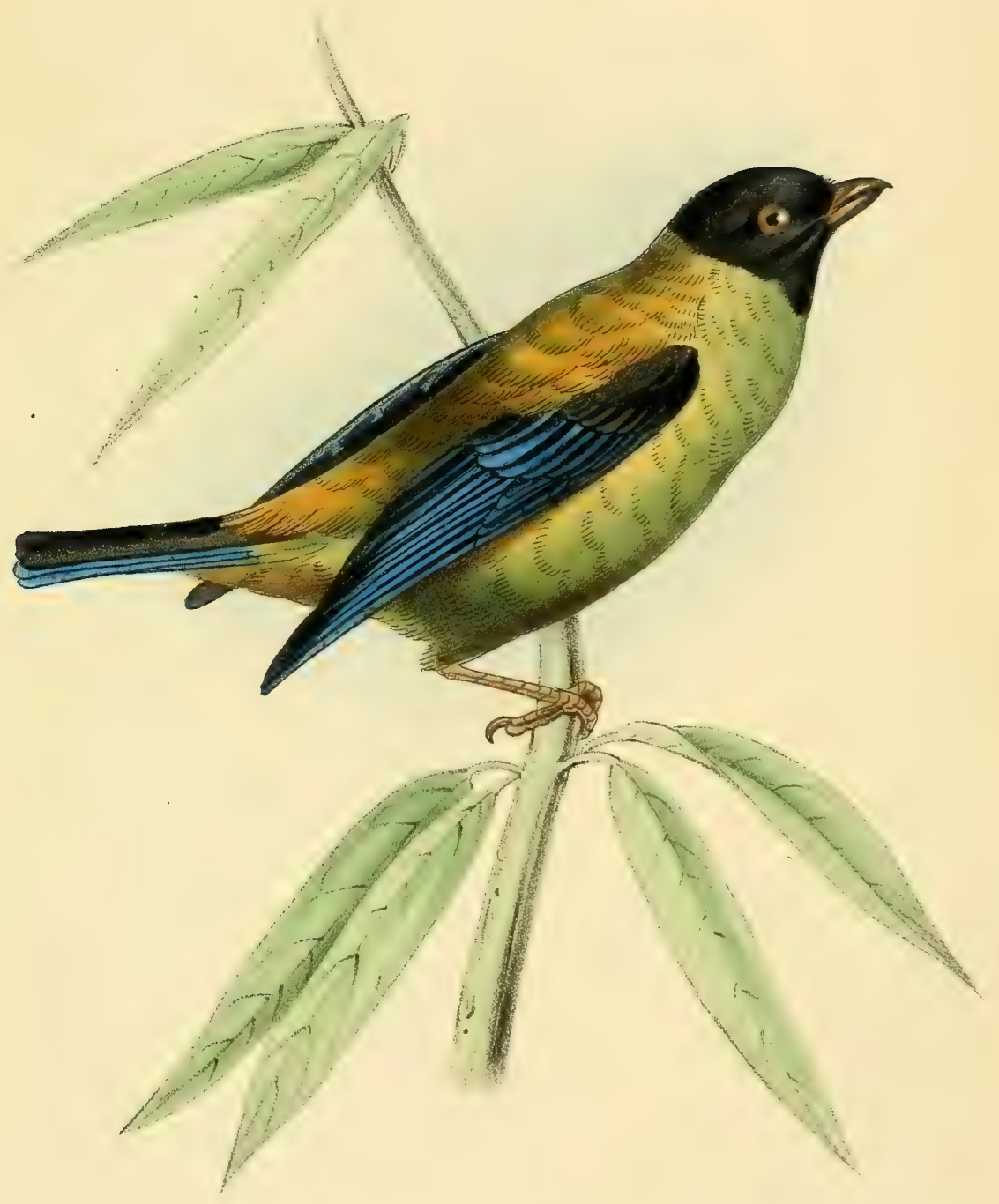

Blue winged Tanager.

A. eyanoptera. 





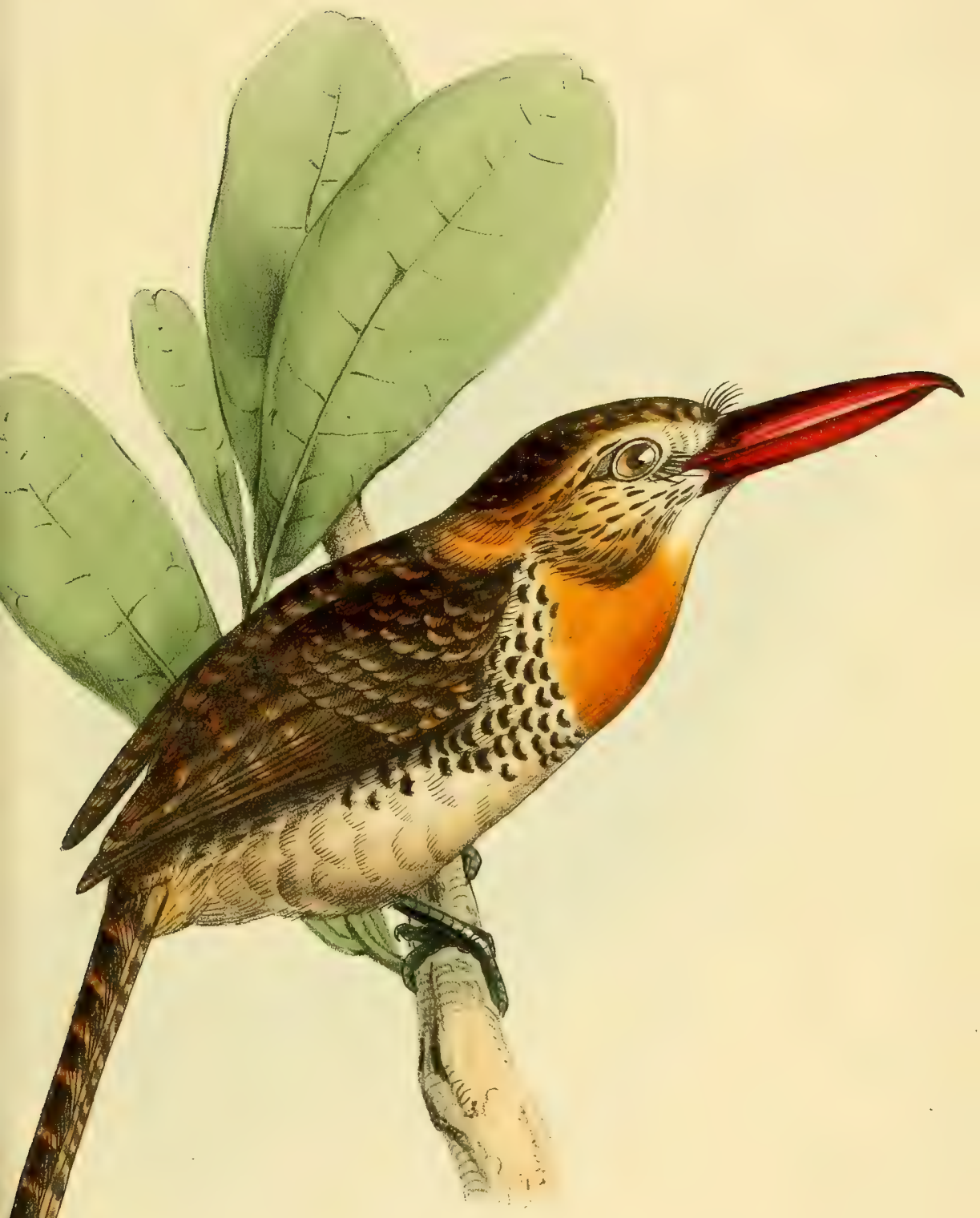

Iong bitl'd Puff-bird

I. Sommolenta 








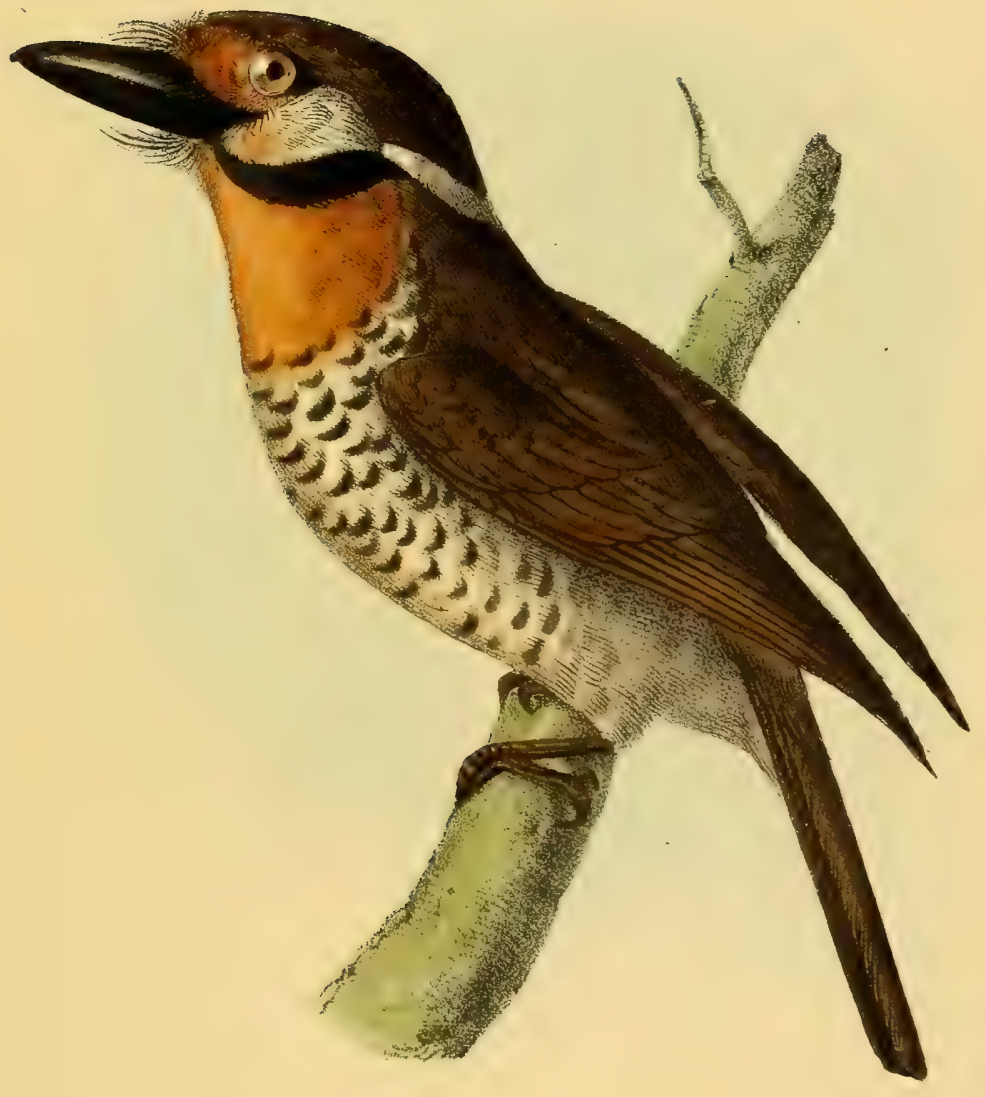

Spotted Puff-bird.

T.maculata. 





$$
R
$$







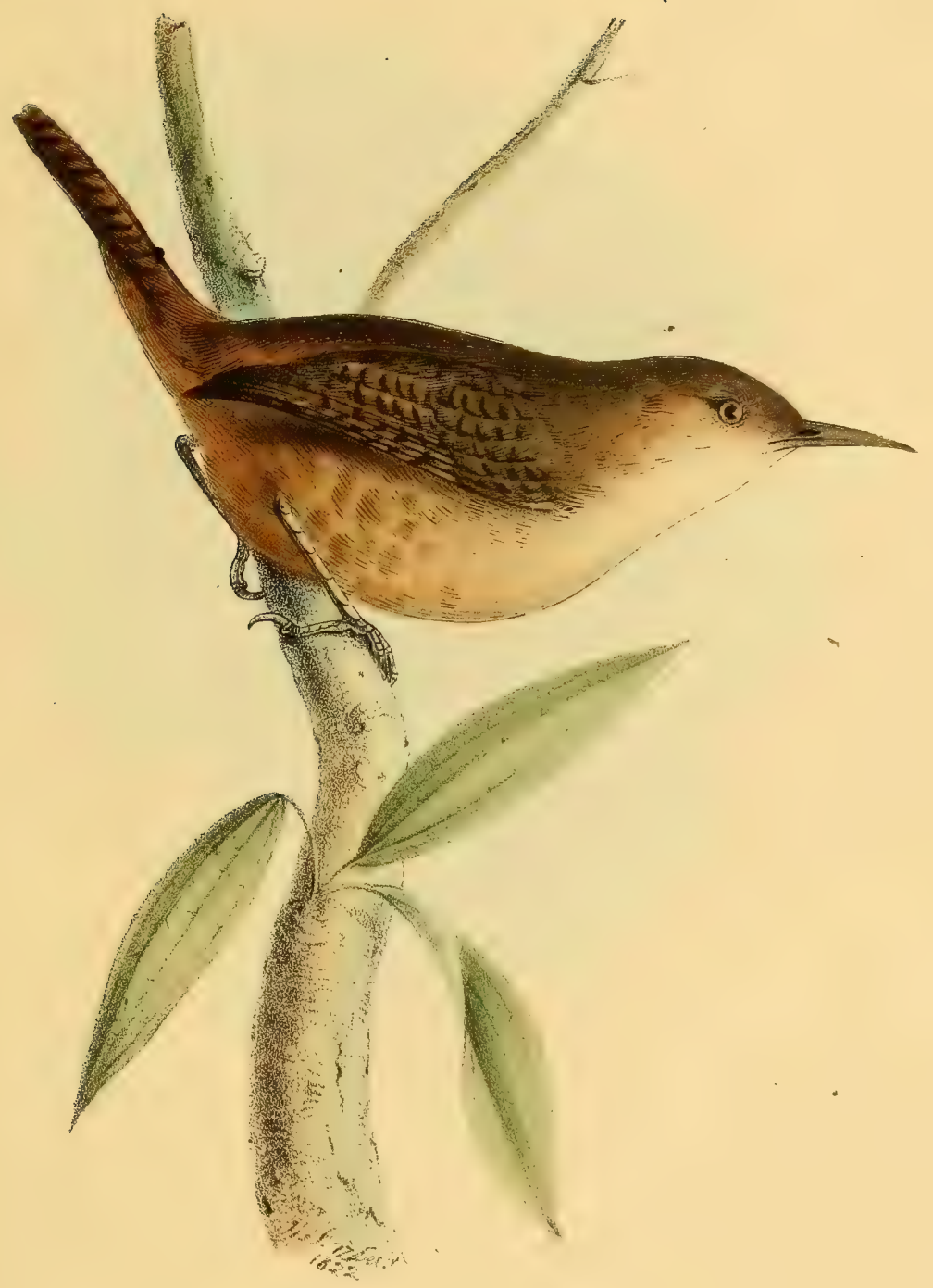

Tropical Wren.

(T.. Equinoctiatis.) 





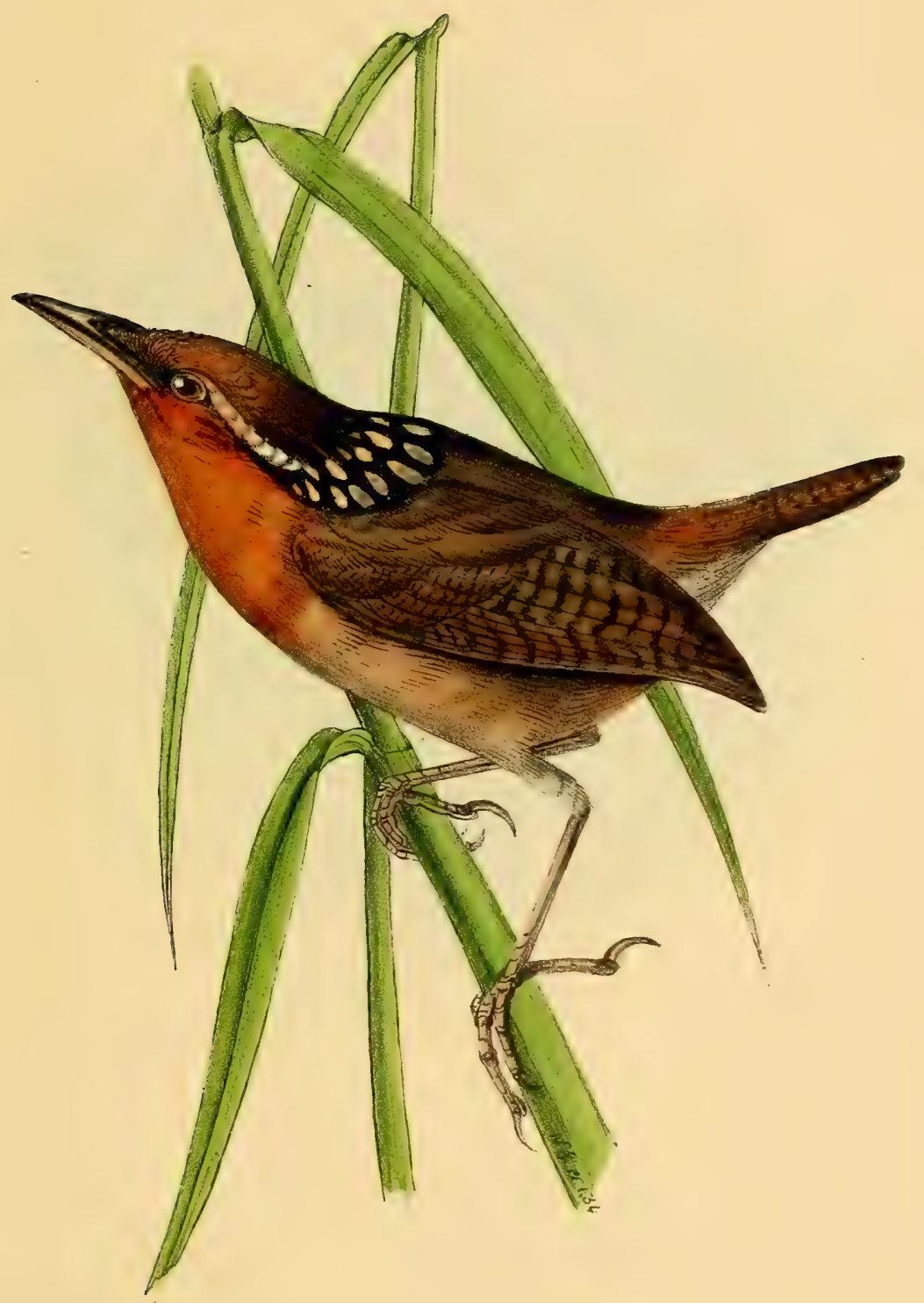

Rea breasted Wren.

I. carinakus. 





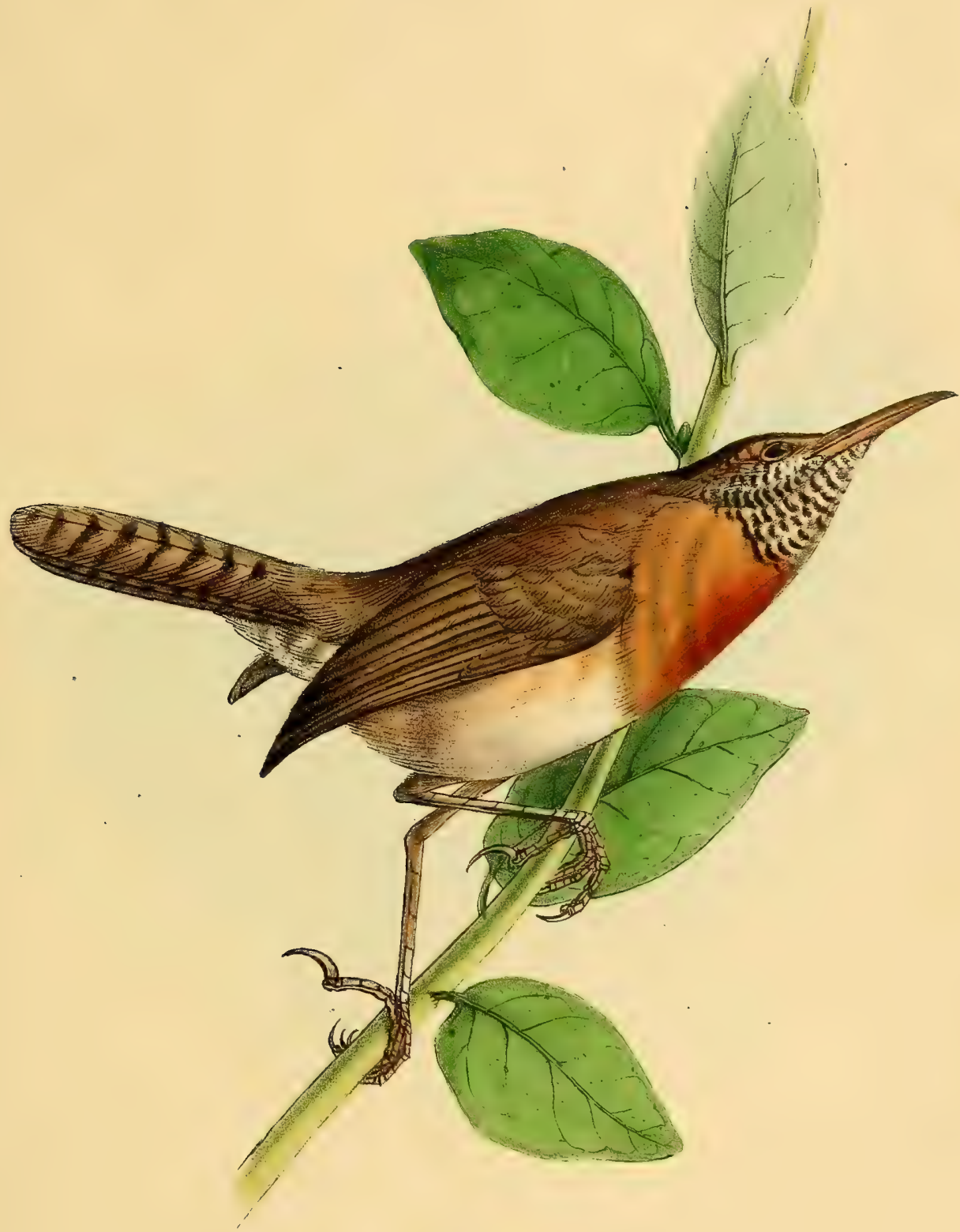

Bar-throated Wren

T. rutilans. 





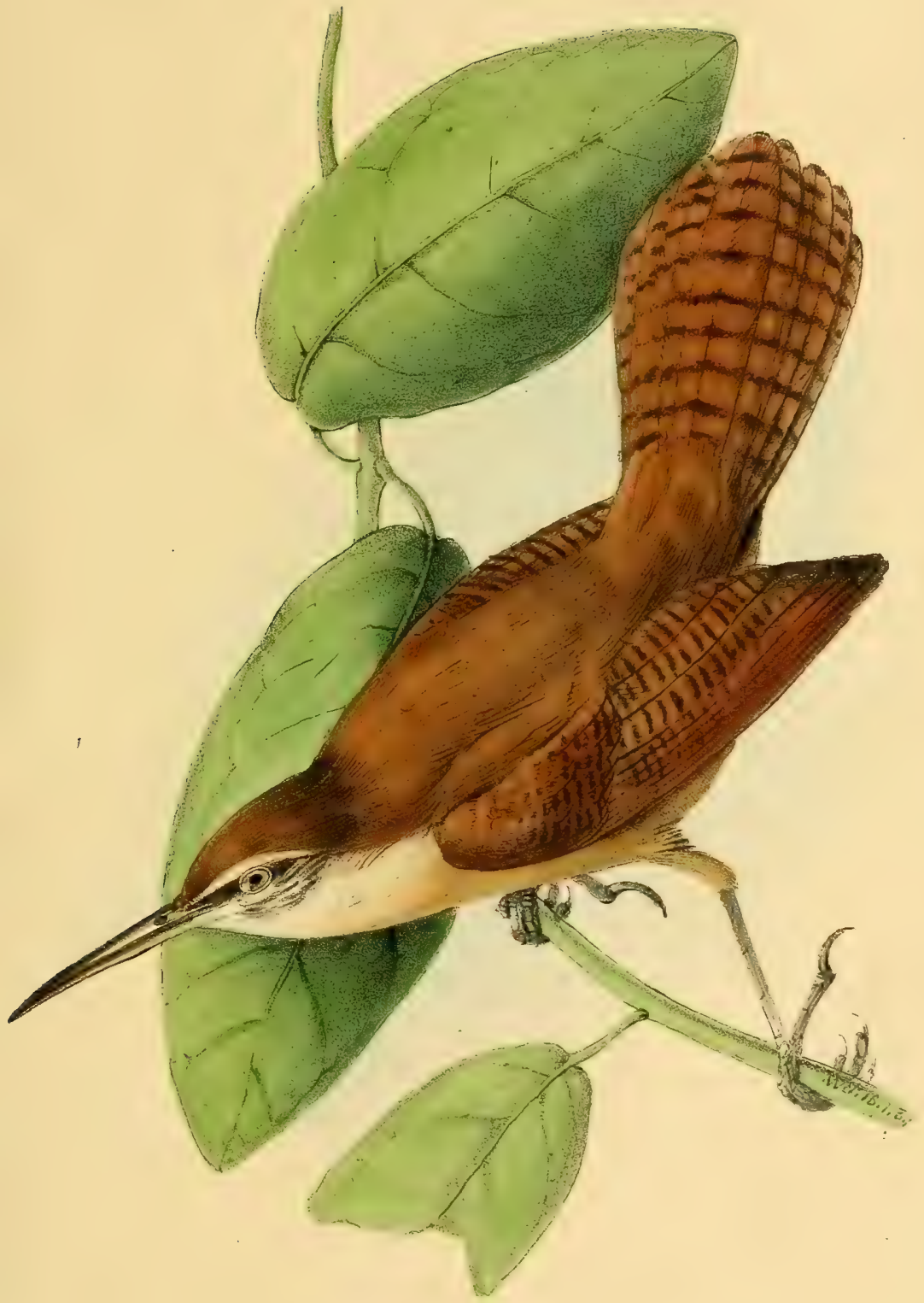

Long tedes. Wren

'THRYOTHORUS striolatus. 





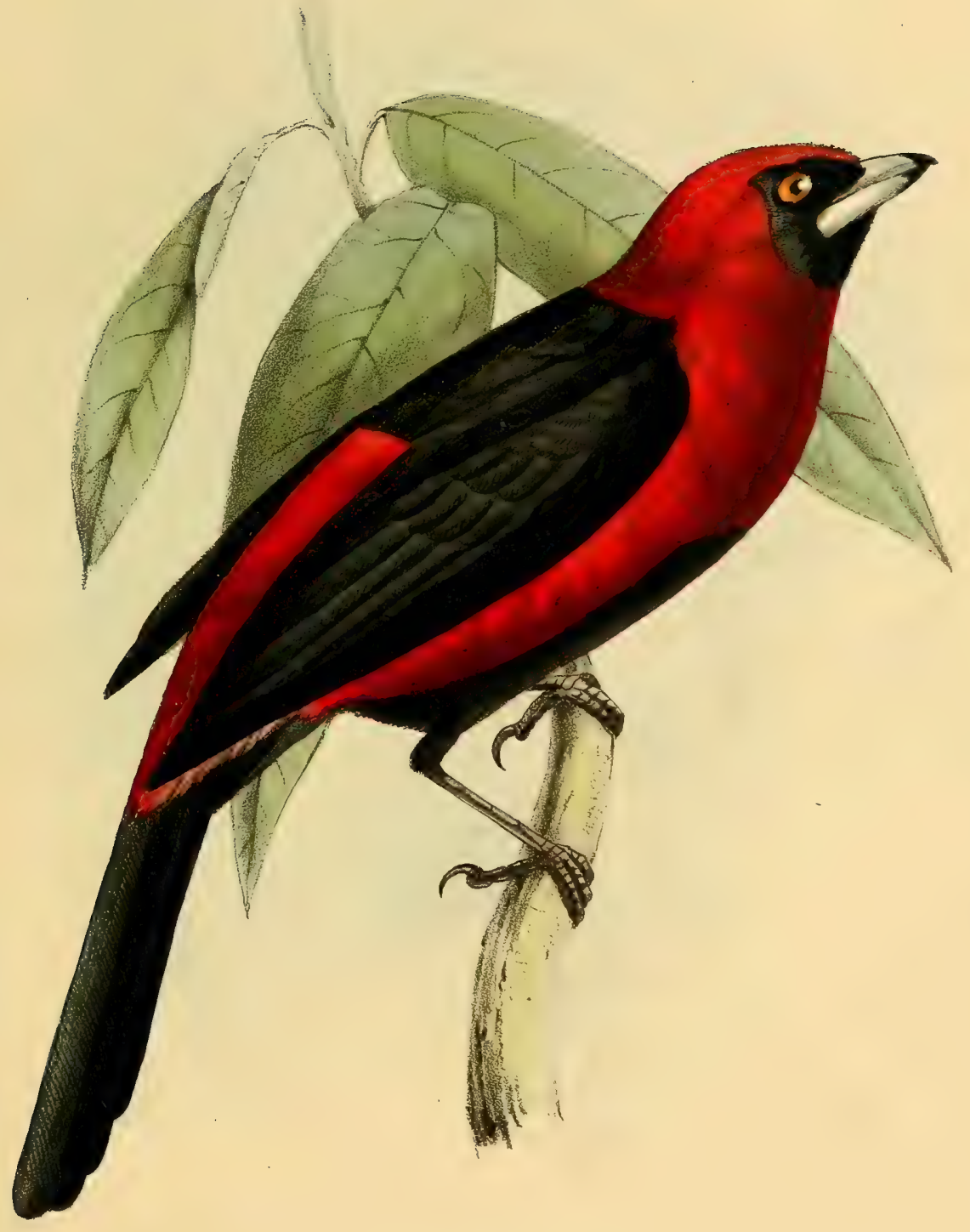

Black-masked Tanager.

R. Nigro-gularis. 





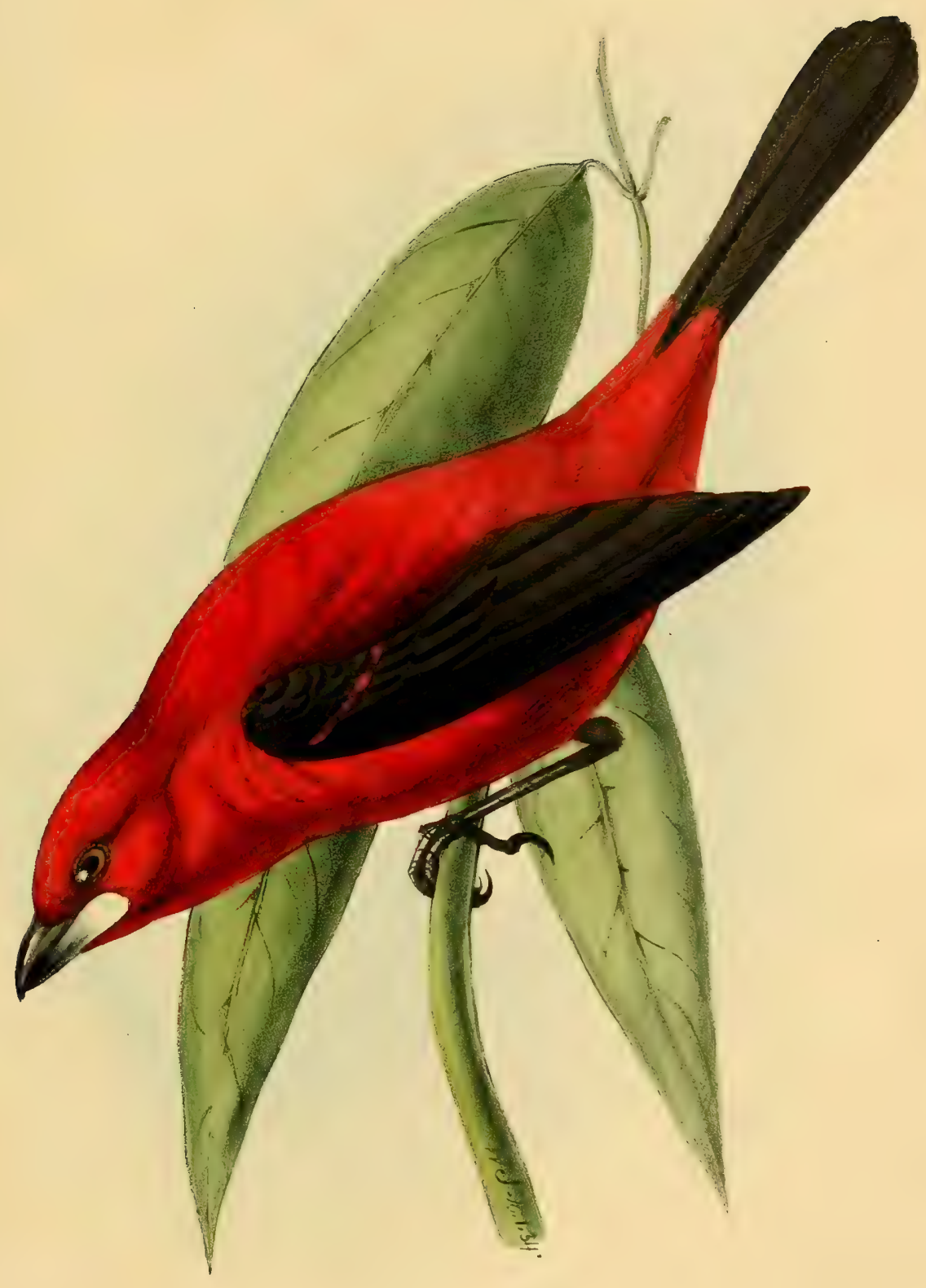

Crimson Tanager.

R. coccireus 





$$
p
$$







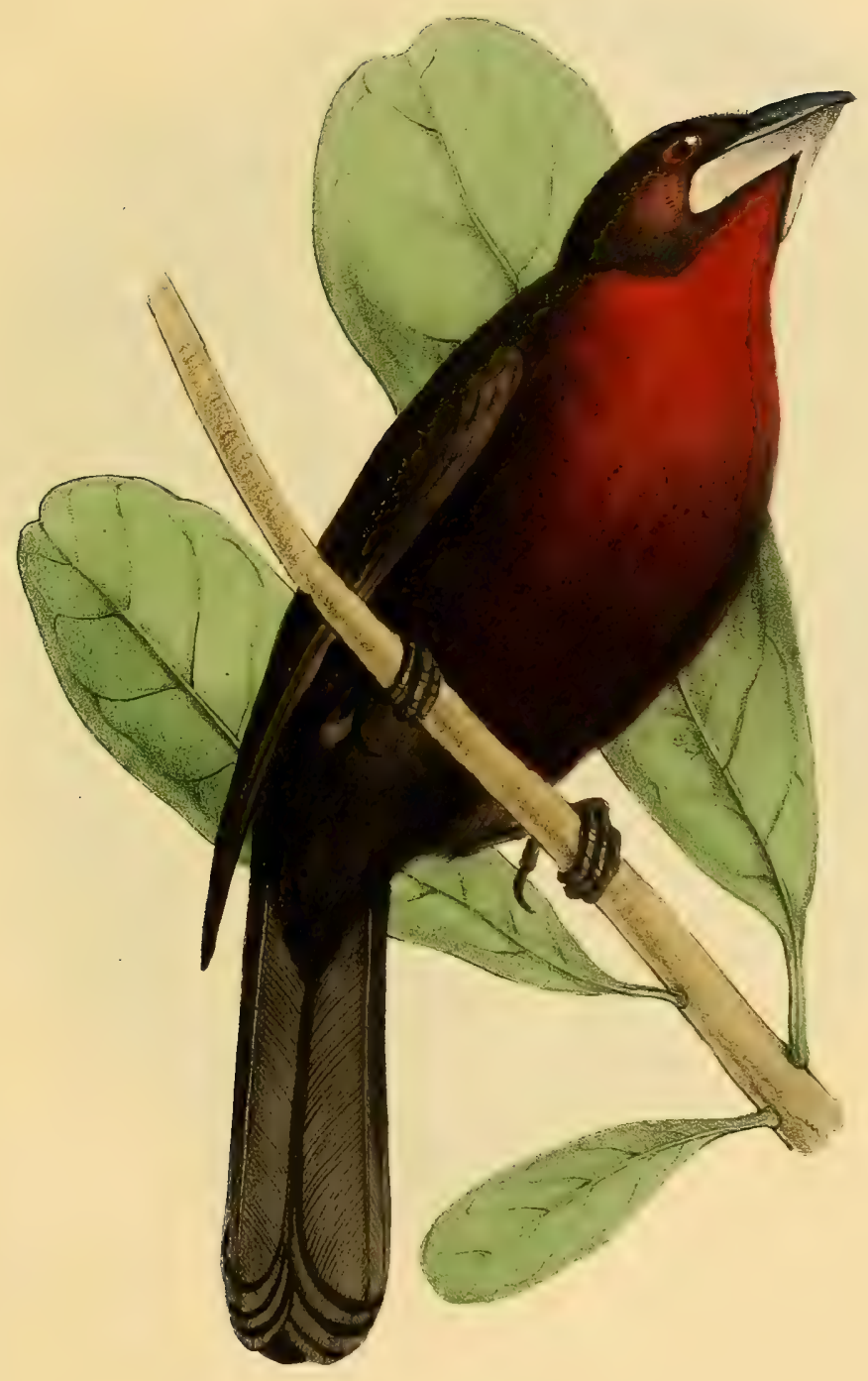

Marone Tanager.

R. atro-coccineus 





$$
\frac{12}{2}
$$







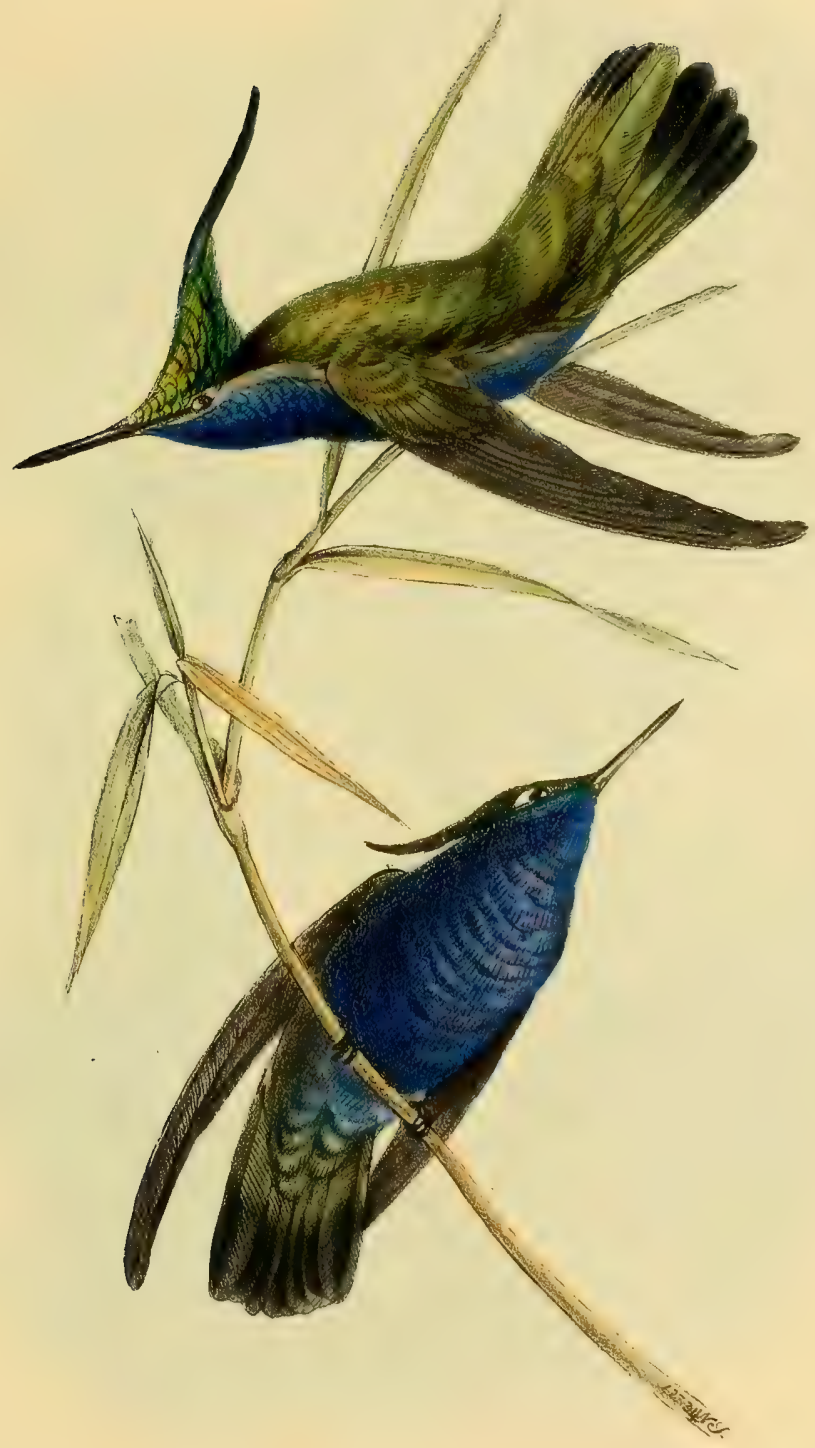

Delatande's H. Bird.

T. Delalandii. 





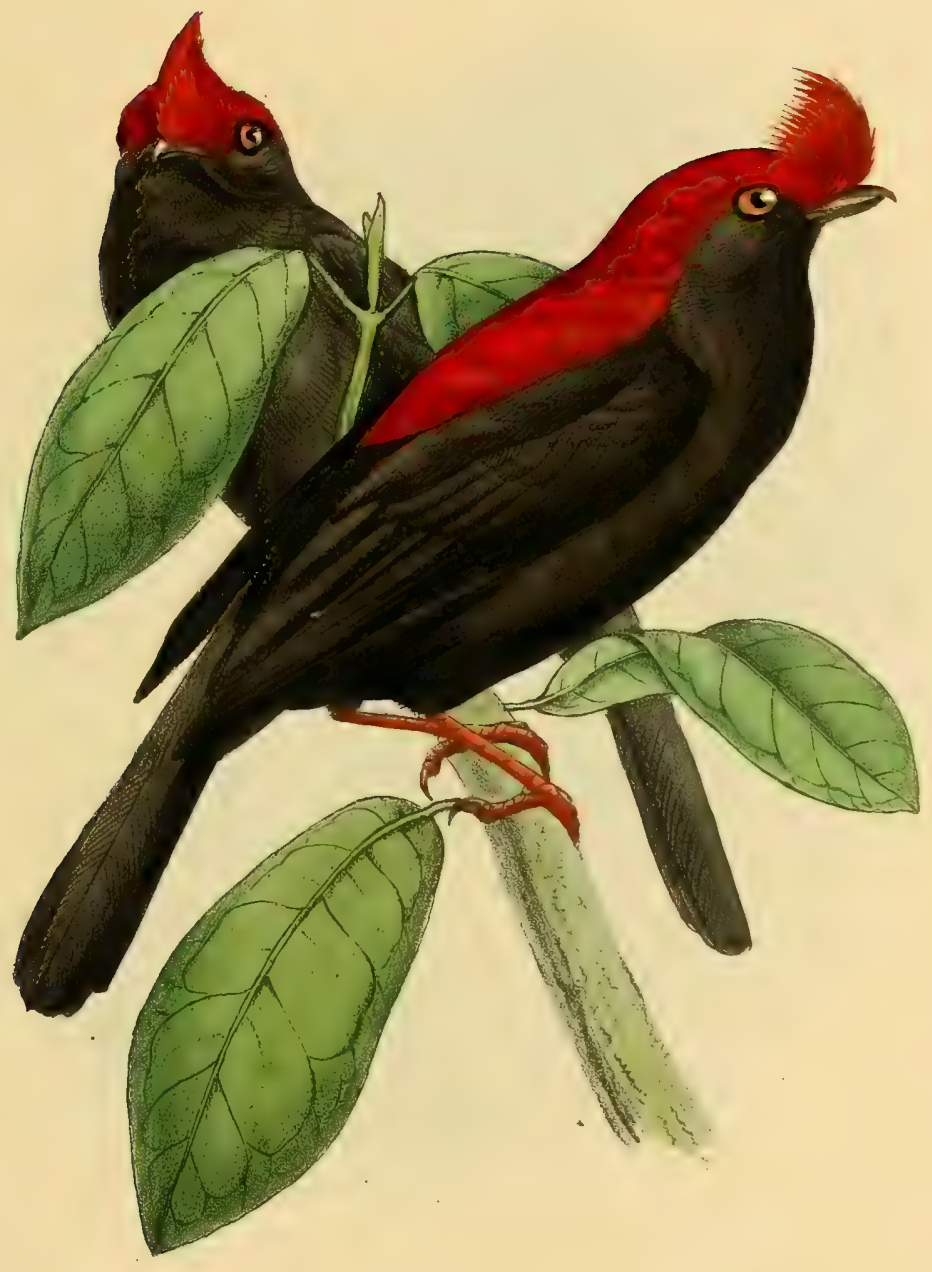

Helmet Manatin.

P. galeata 





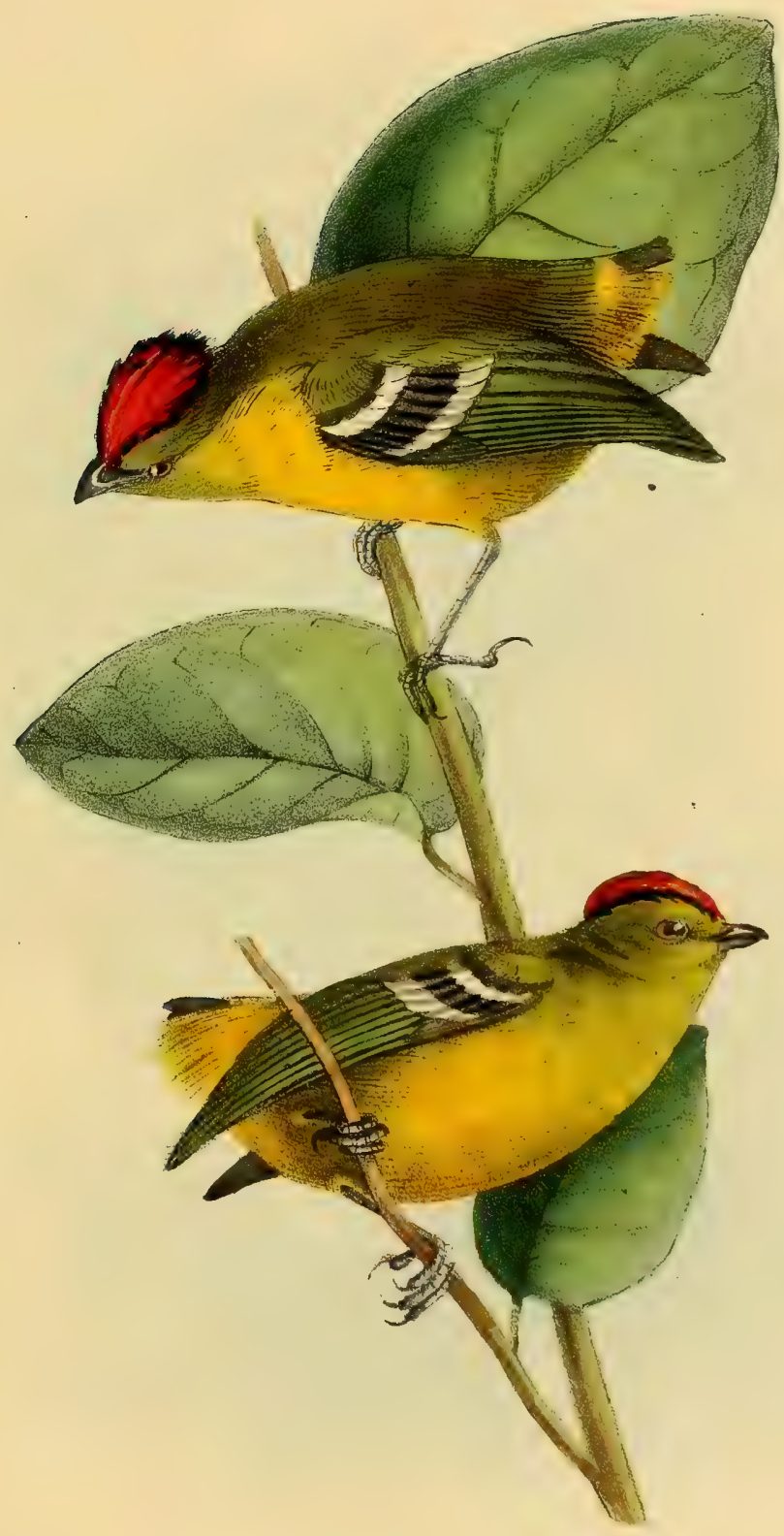

Short zarted Marzakin.

CALYPTURA cristata. 





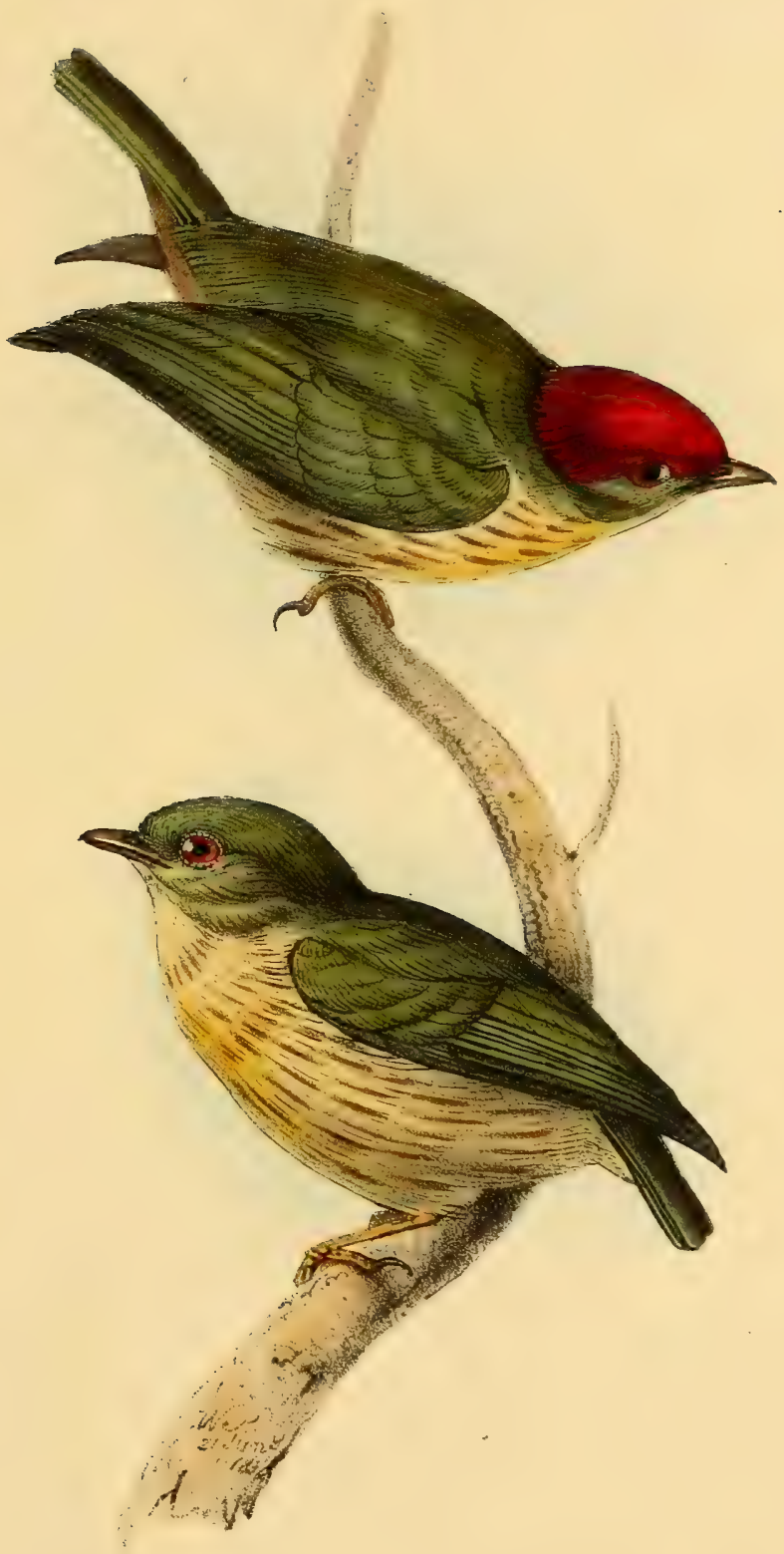

Striped Manakin. 





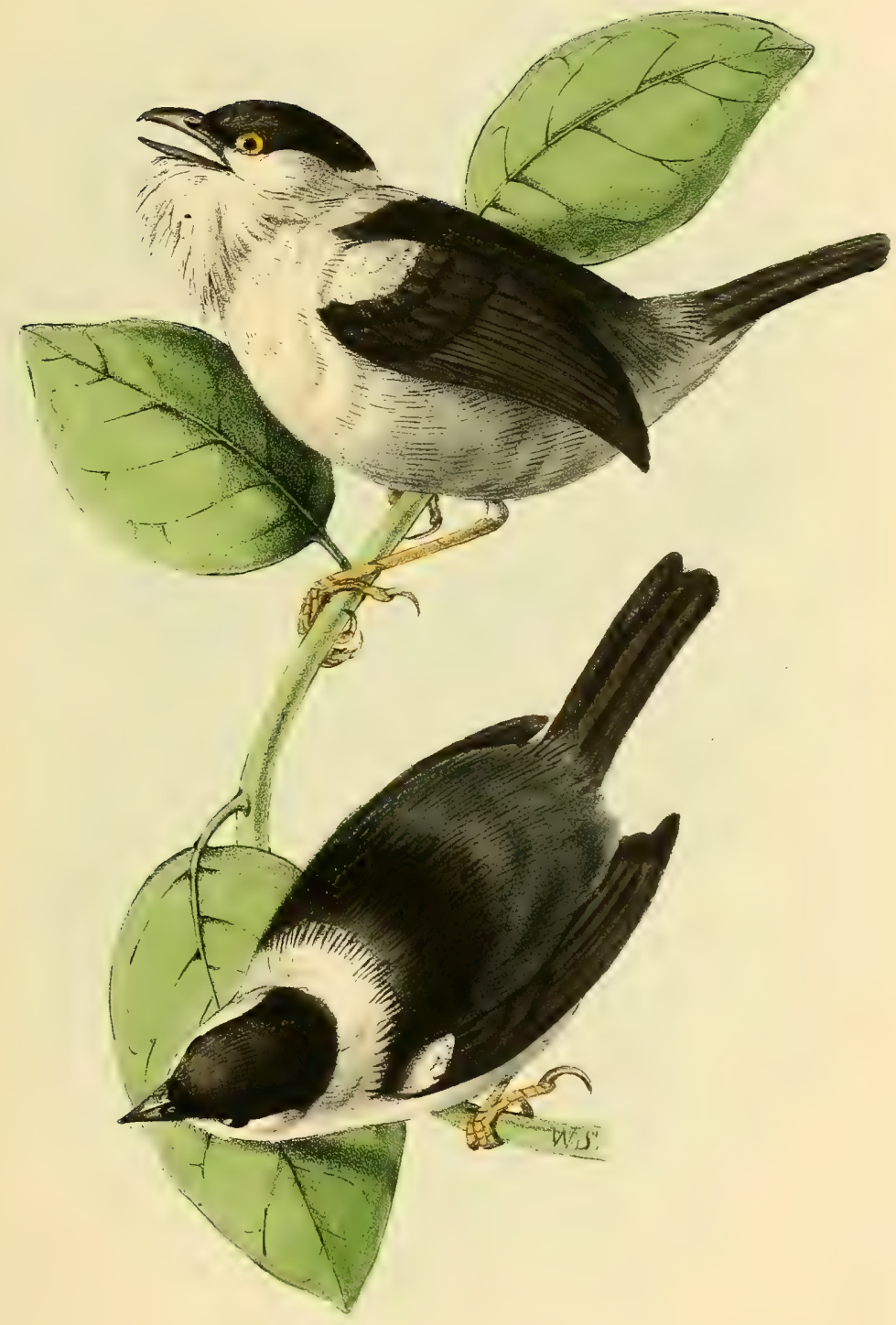







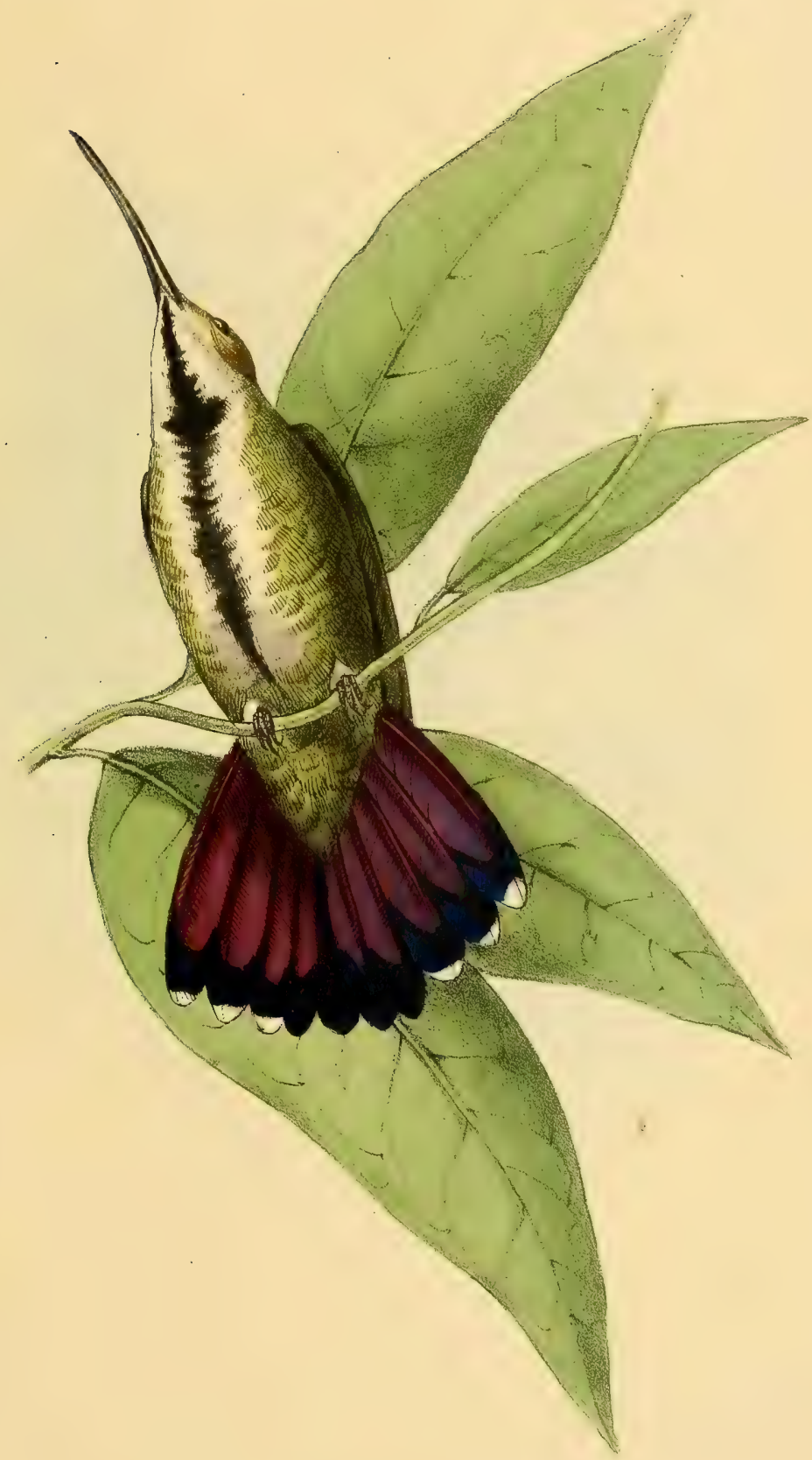







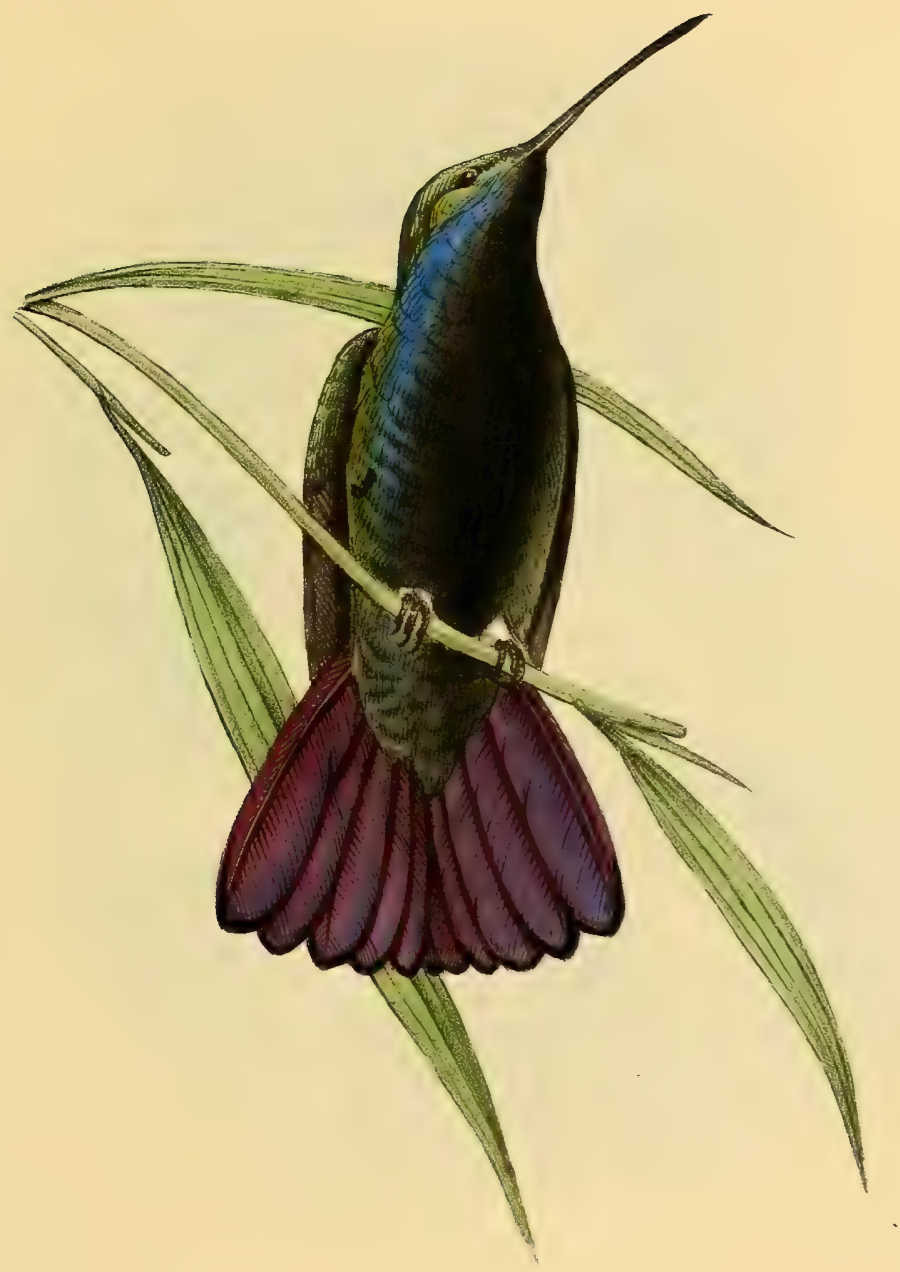







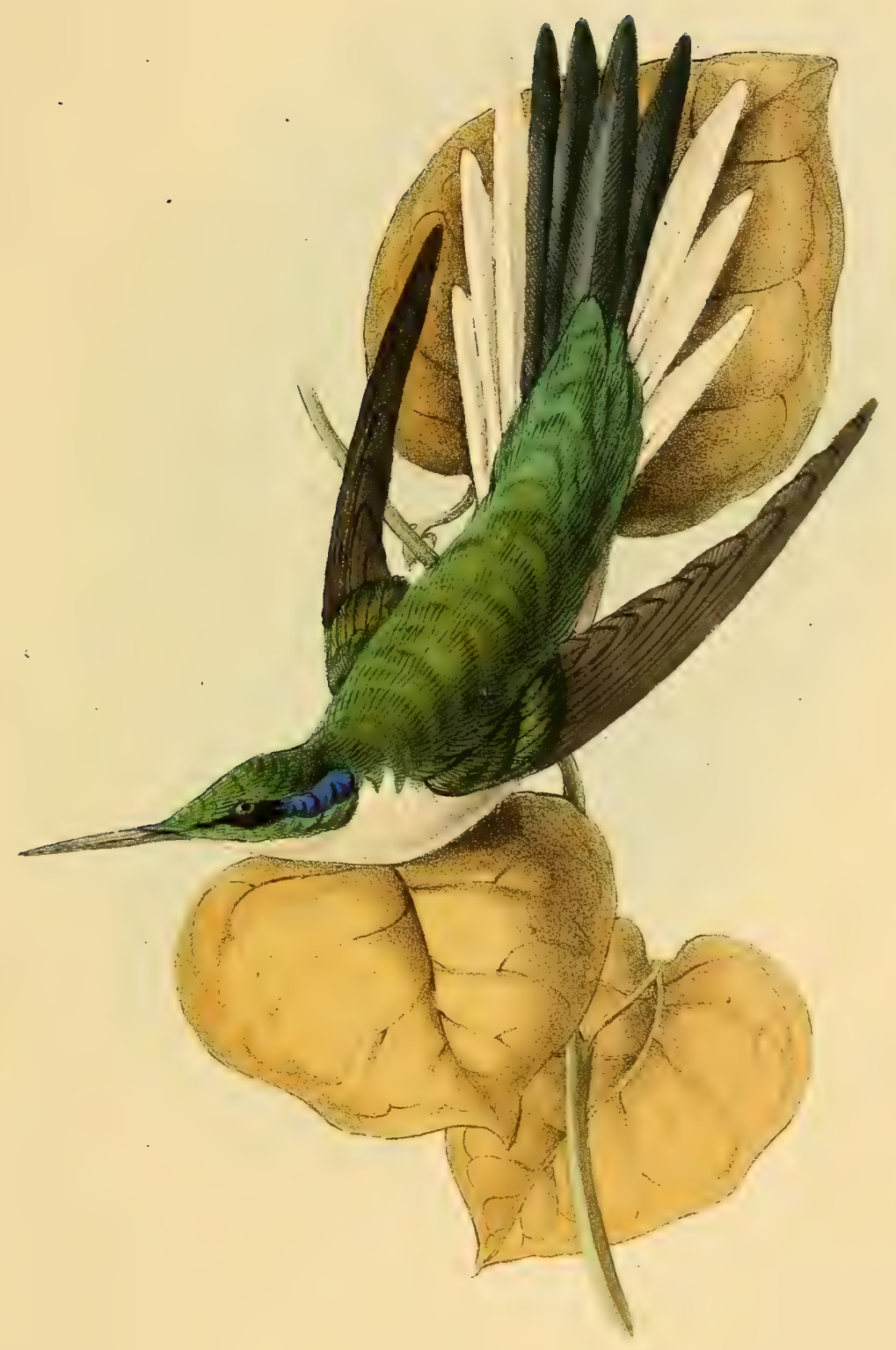







$$
\frac{1}{k}
$$







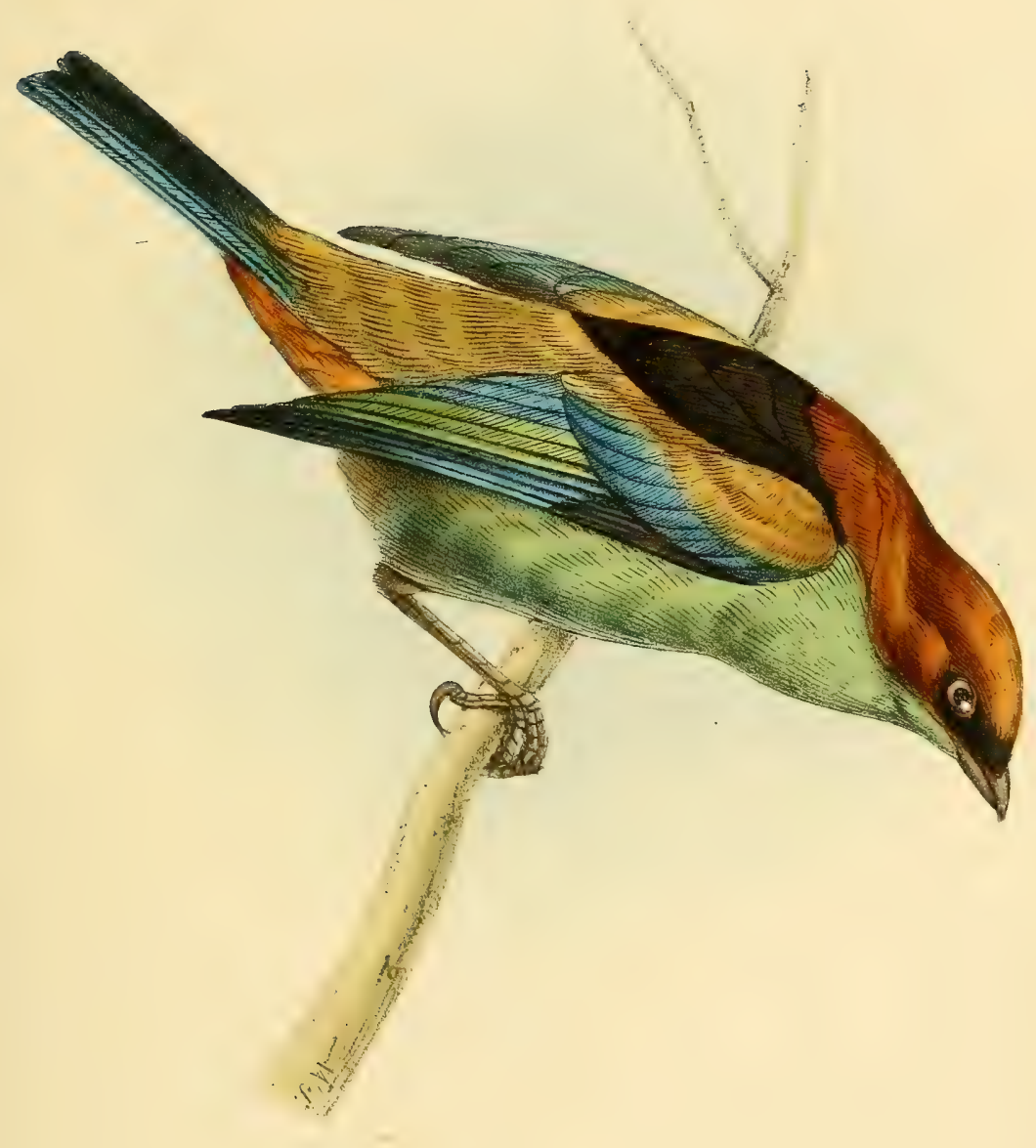

Black backed Tanager.

A.melanotus. $S_{w}$ 





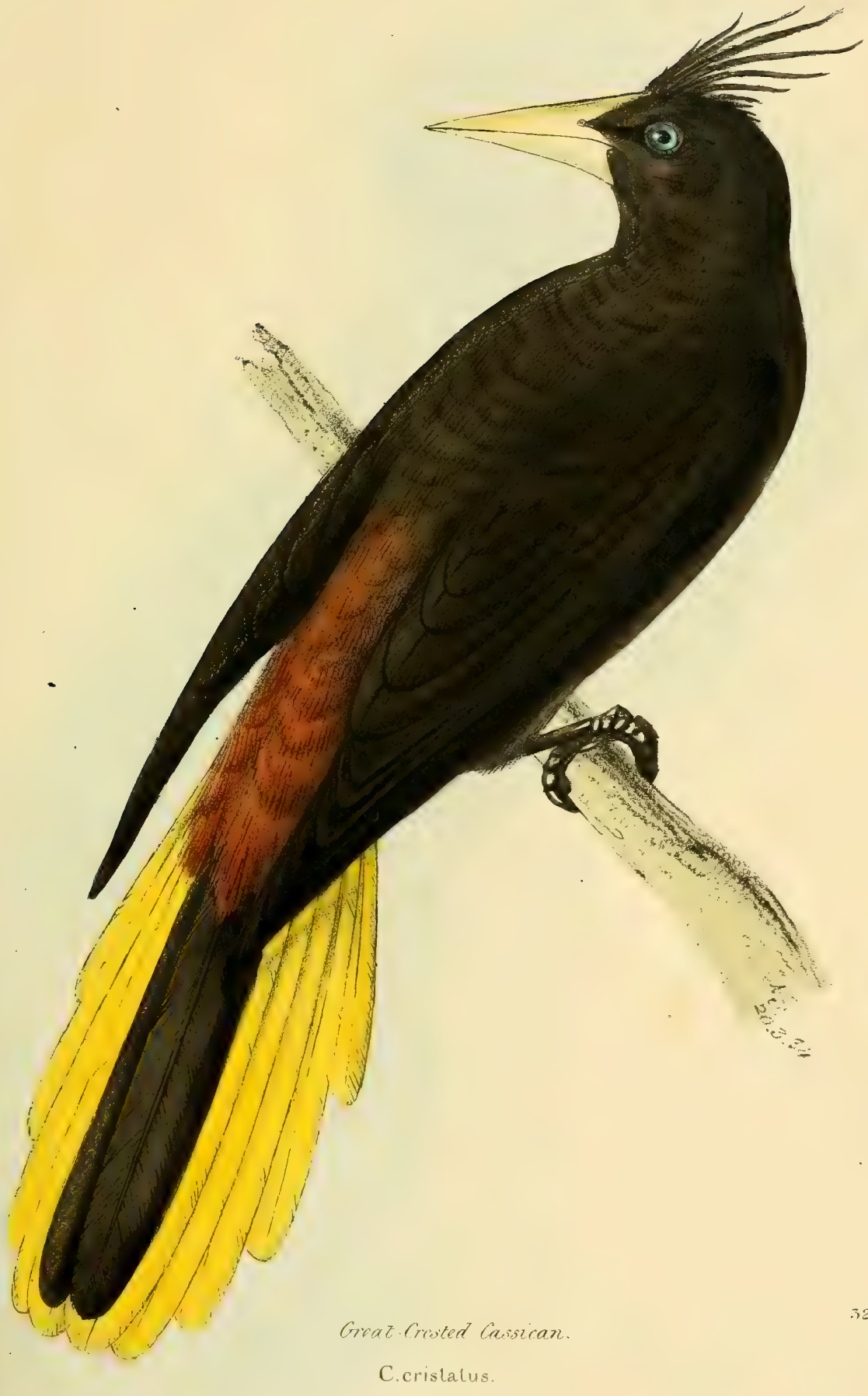







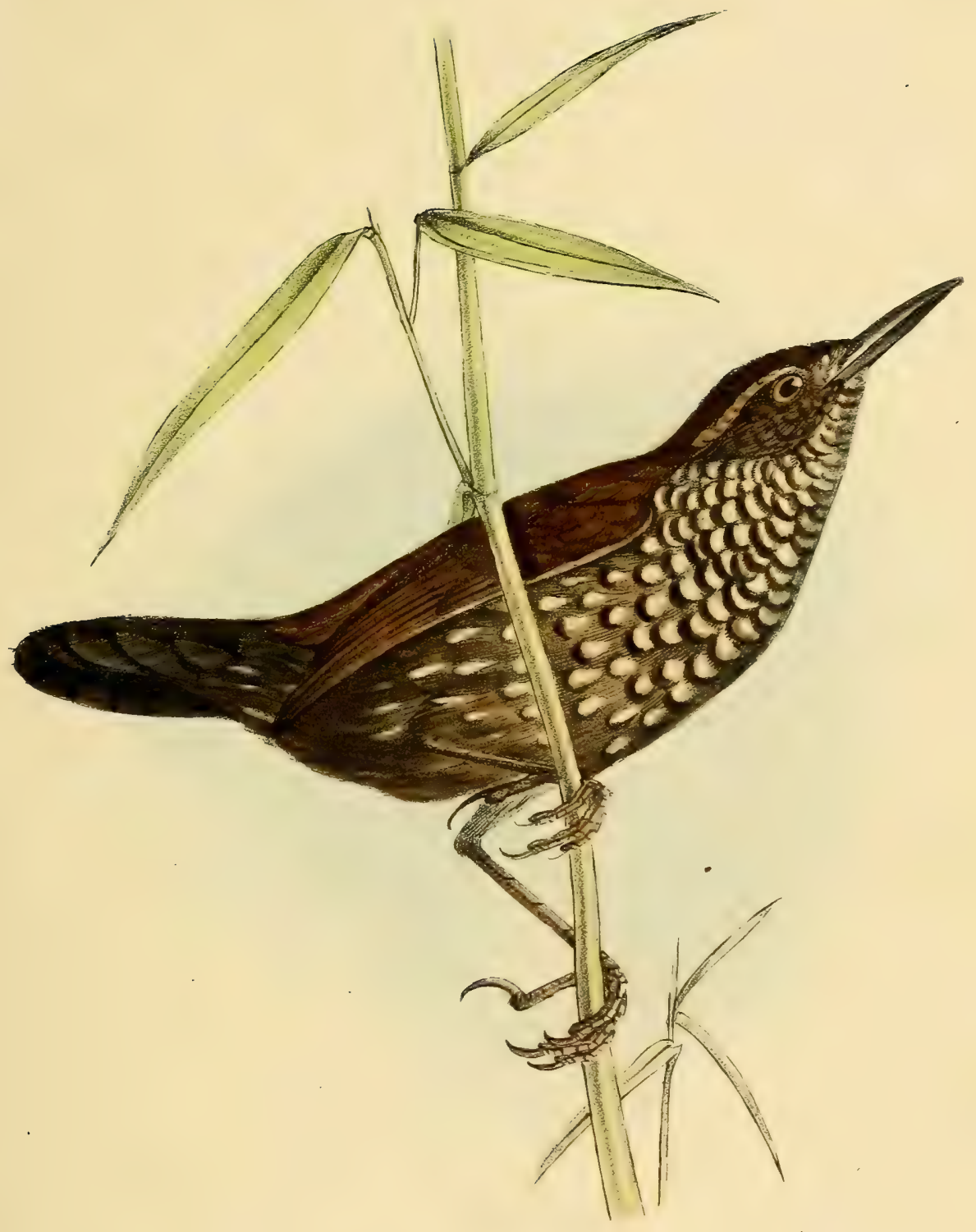

33.

Sharn zailed Wren.

LOCHMIAS squamulata. Sw. 





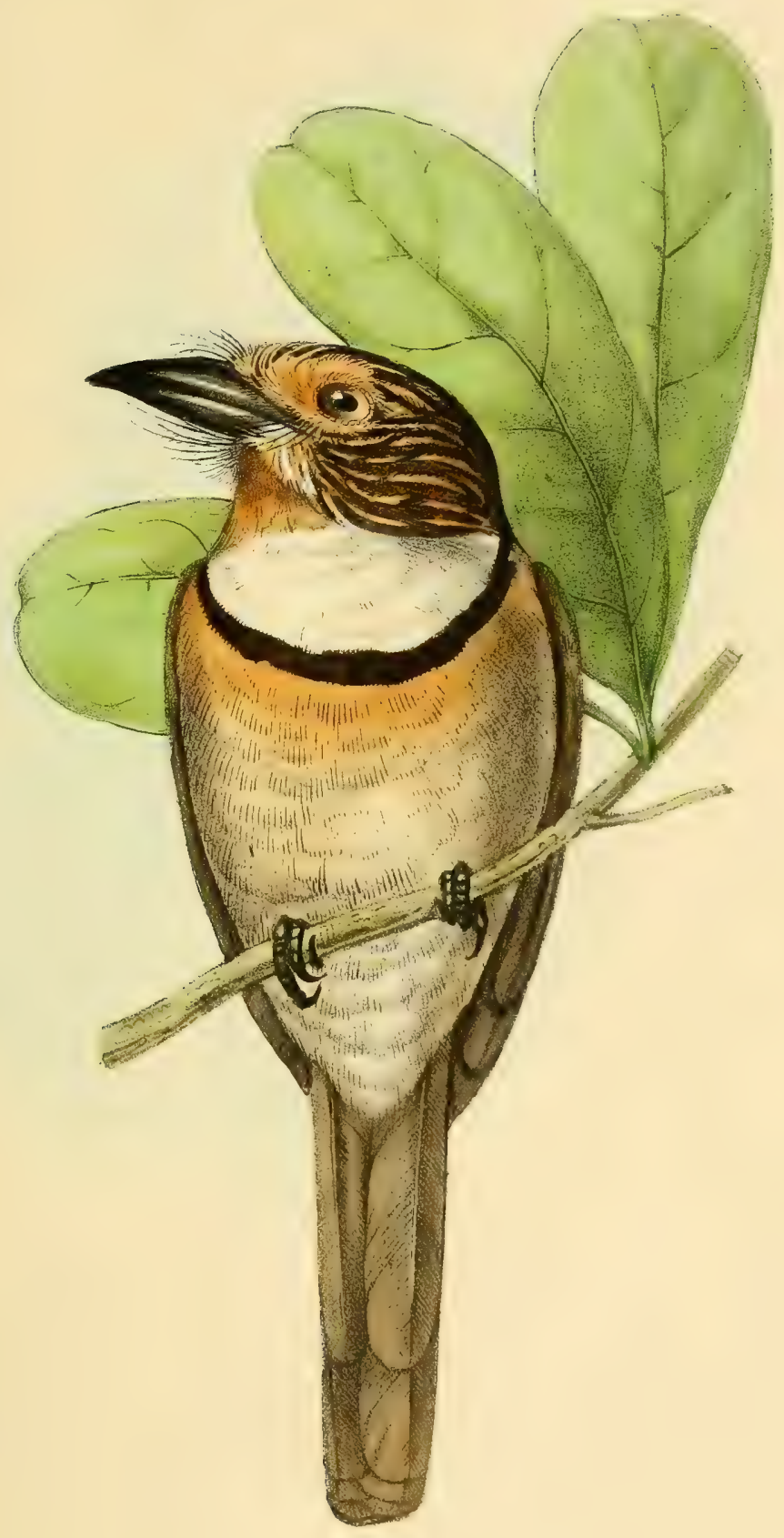







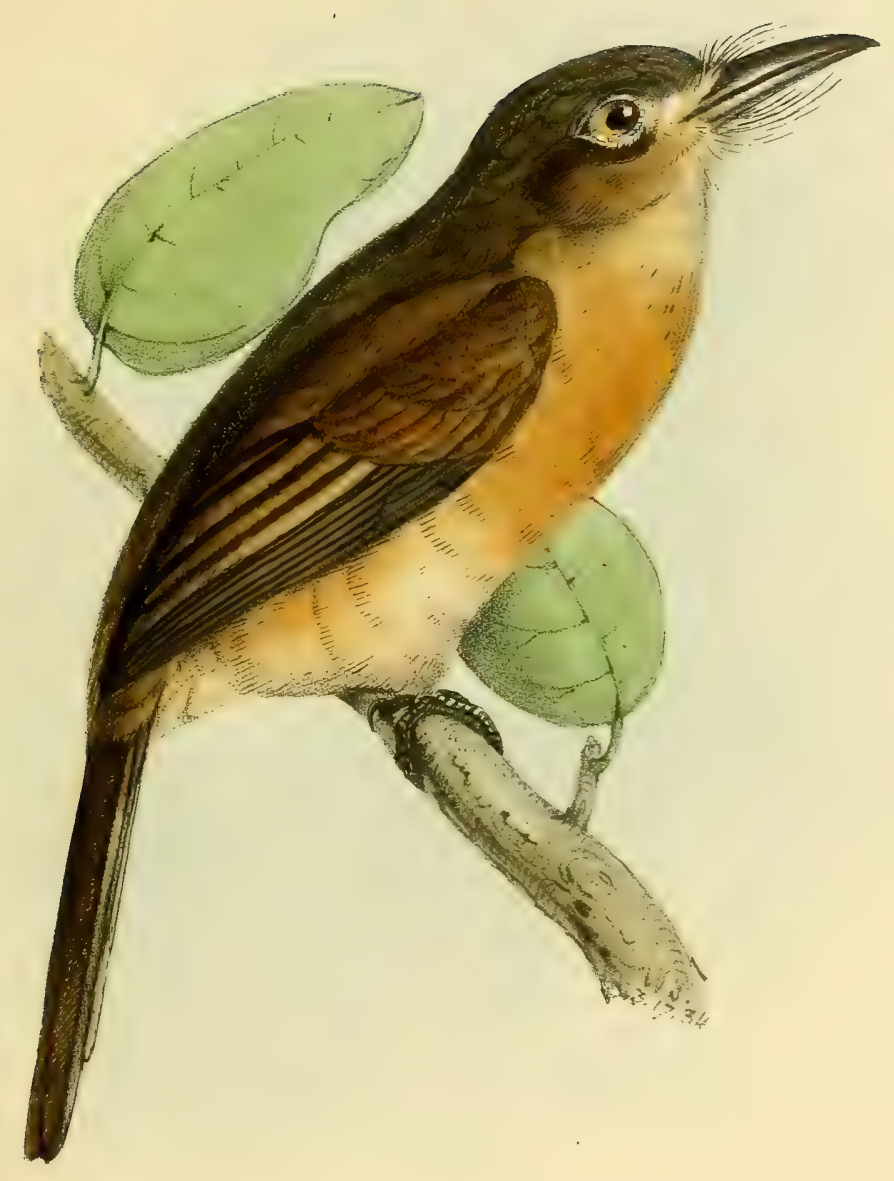

Tied-breasted Puff Bird.

I. rubicula. 





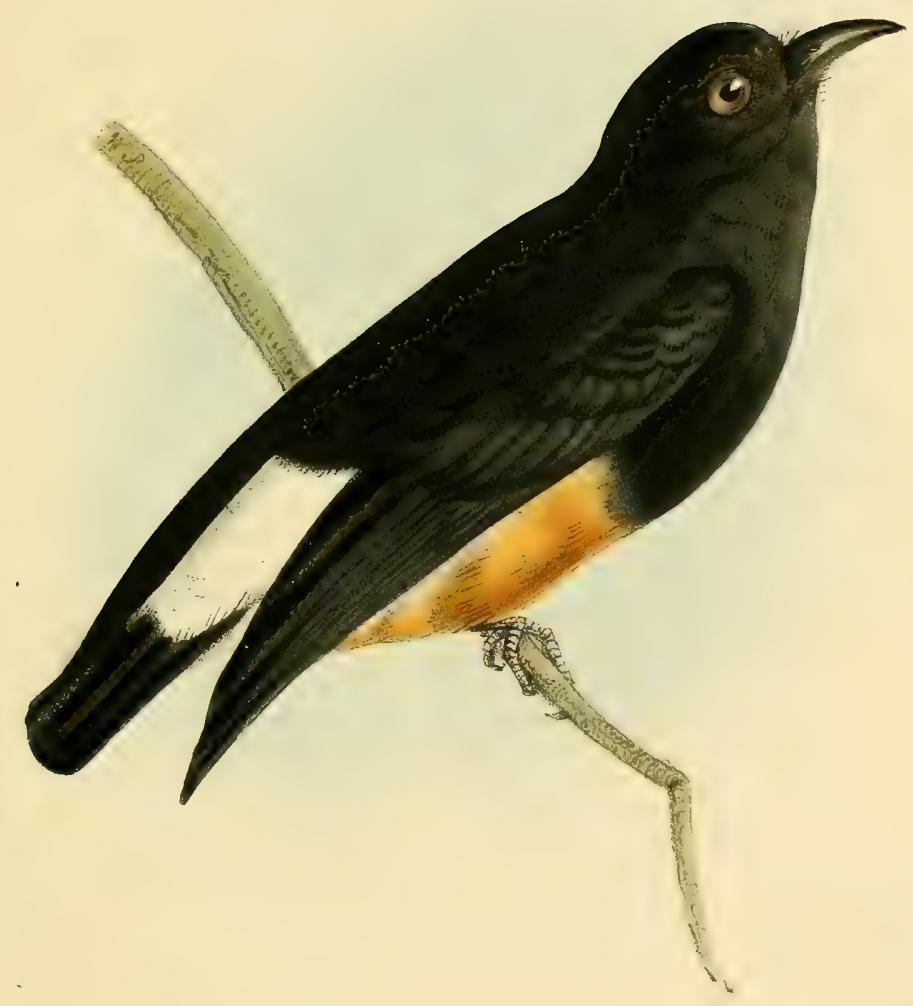

Swn7t mw Priff-Bird

I. tenebrosa. 



$$
\text { . }
$$








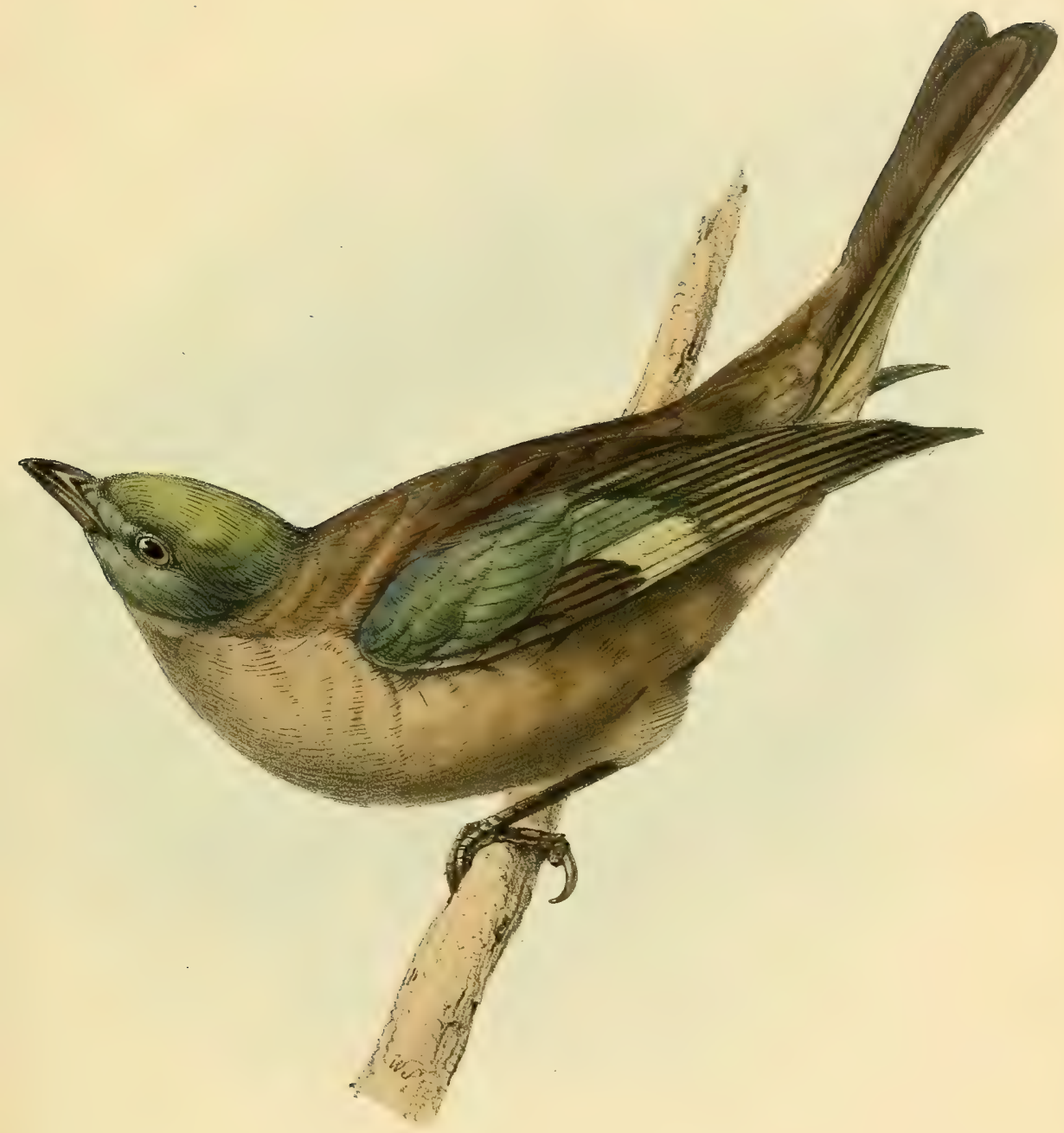

Olive-grey Tanager

I Olivascens. Irich. 





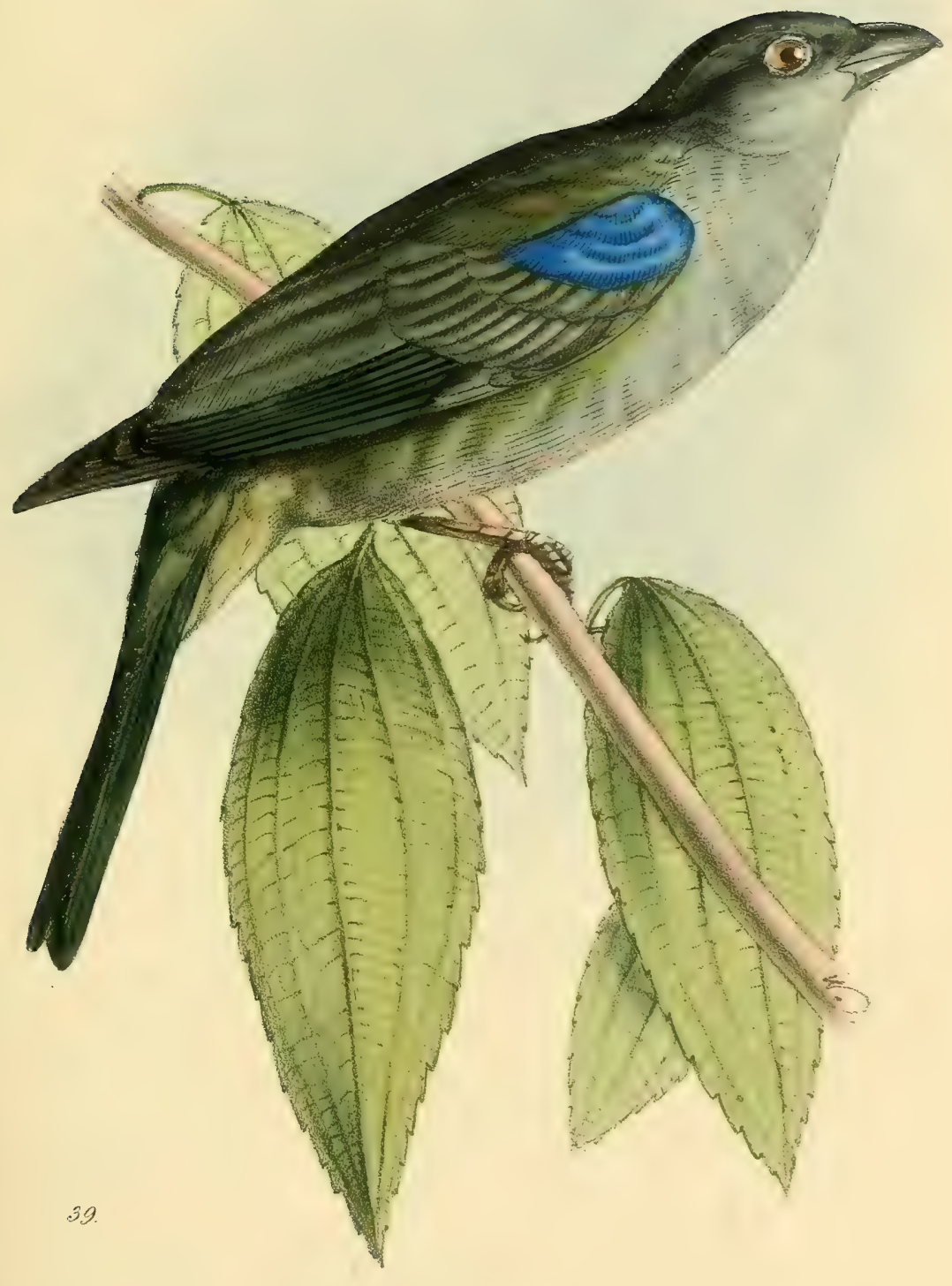

Bishop Tamegi.

T. Eplscopus 





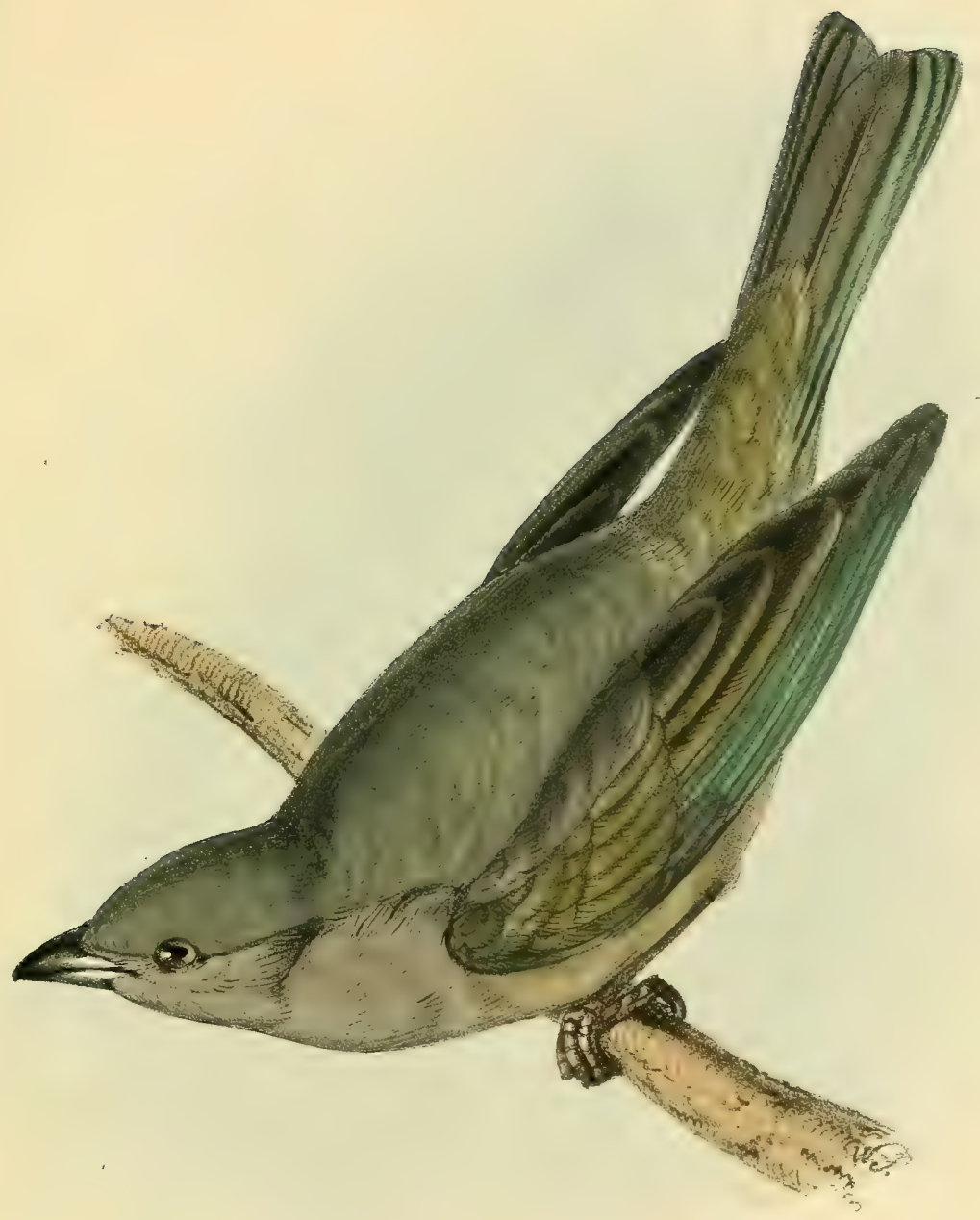

I. mornata siw 





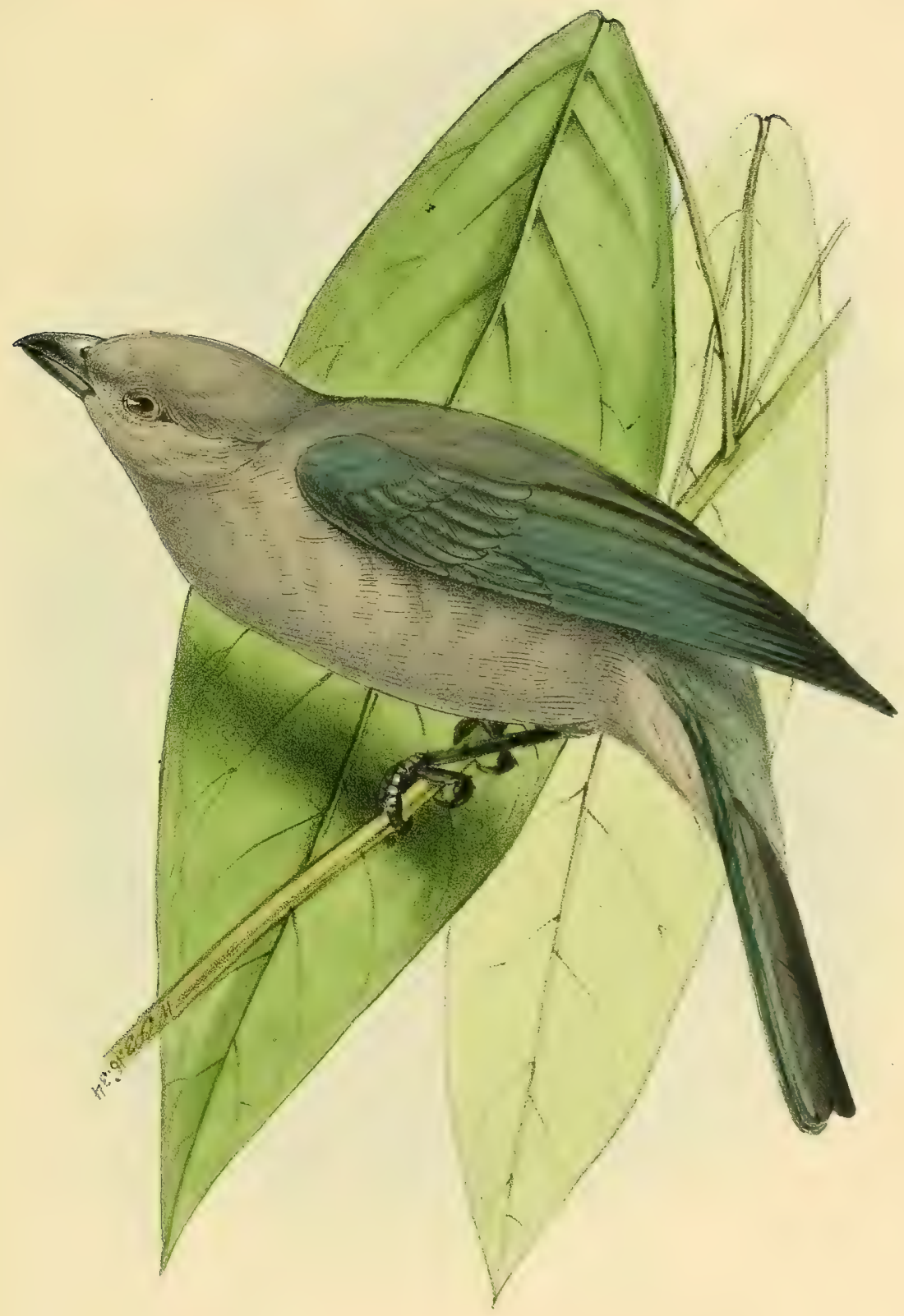

Bun-grex Tamager:

I. criestes Spria 





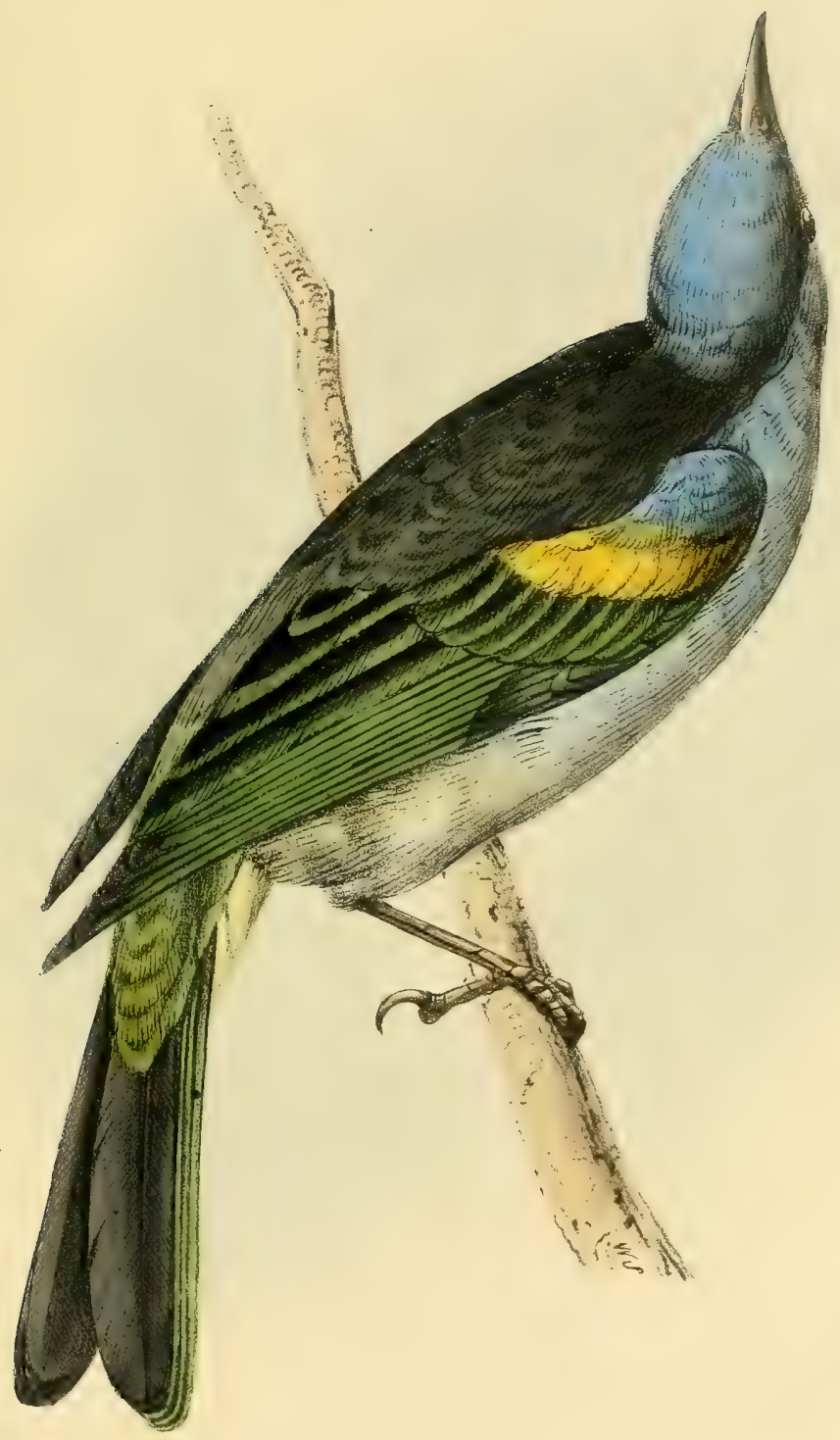







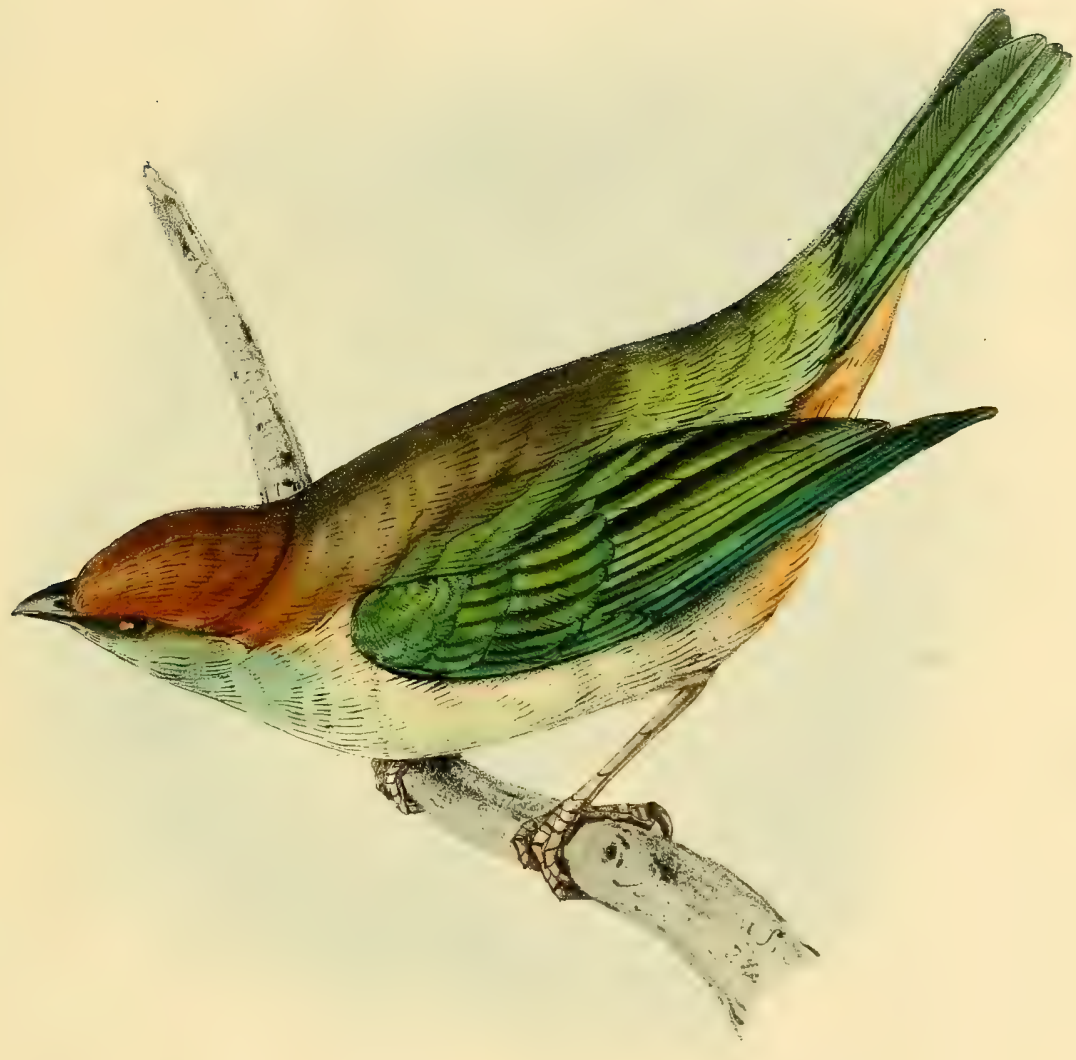







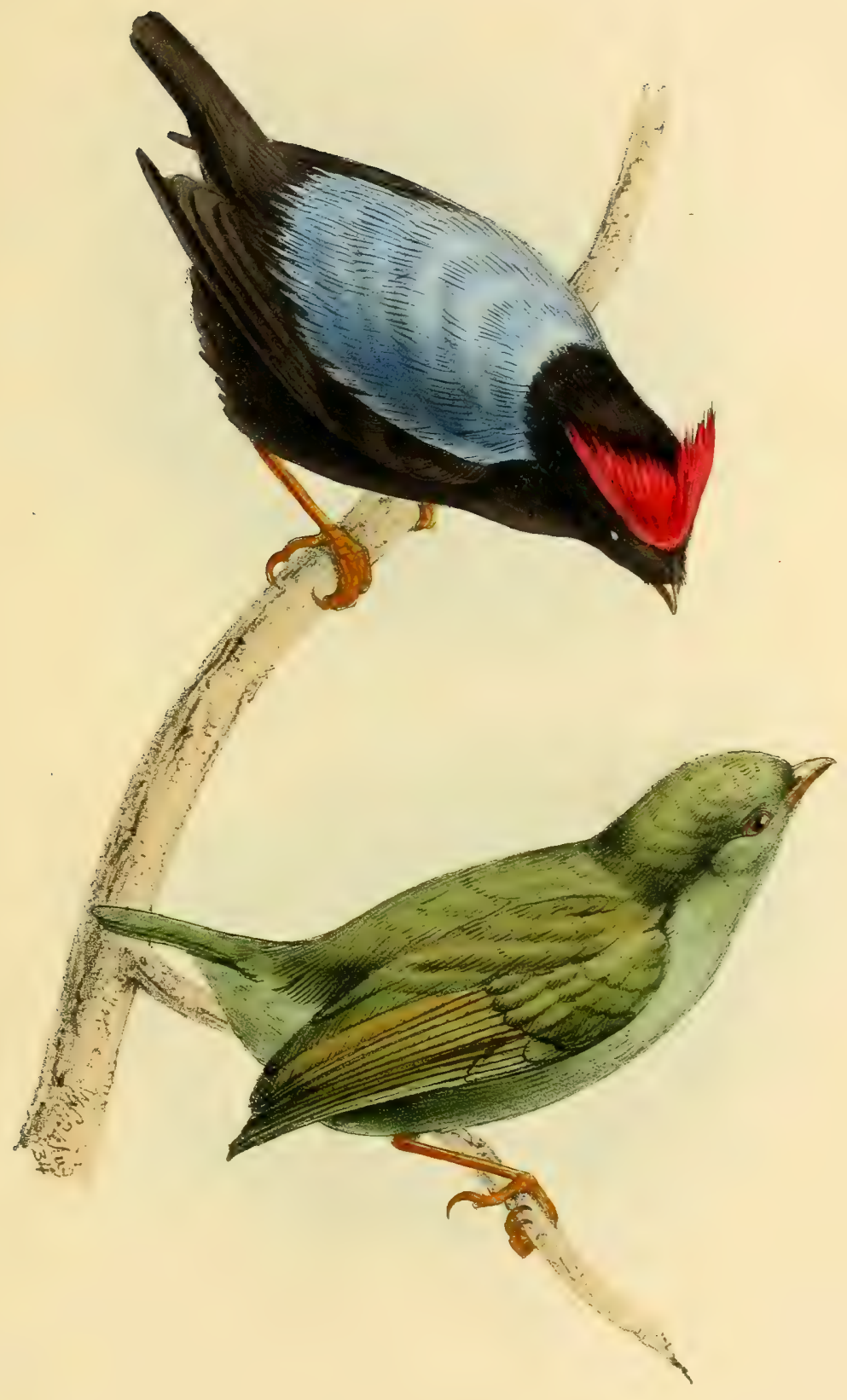

Btwe-backed Iranakin

Pipra pareola. I 





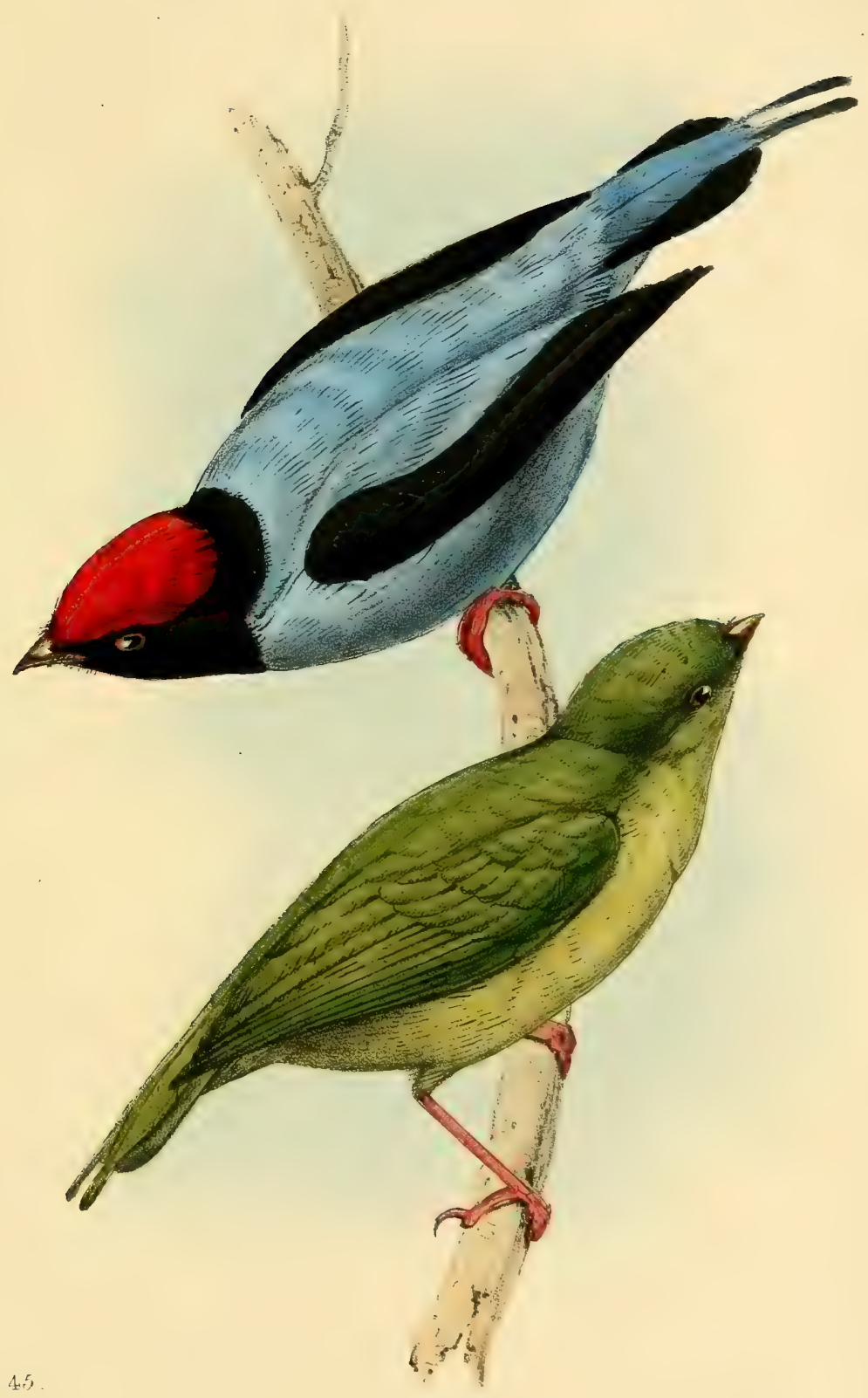

Long-taited Manakin.

P. caudata. Sh. 





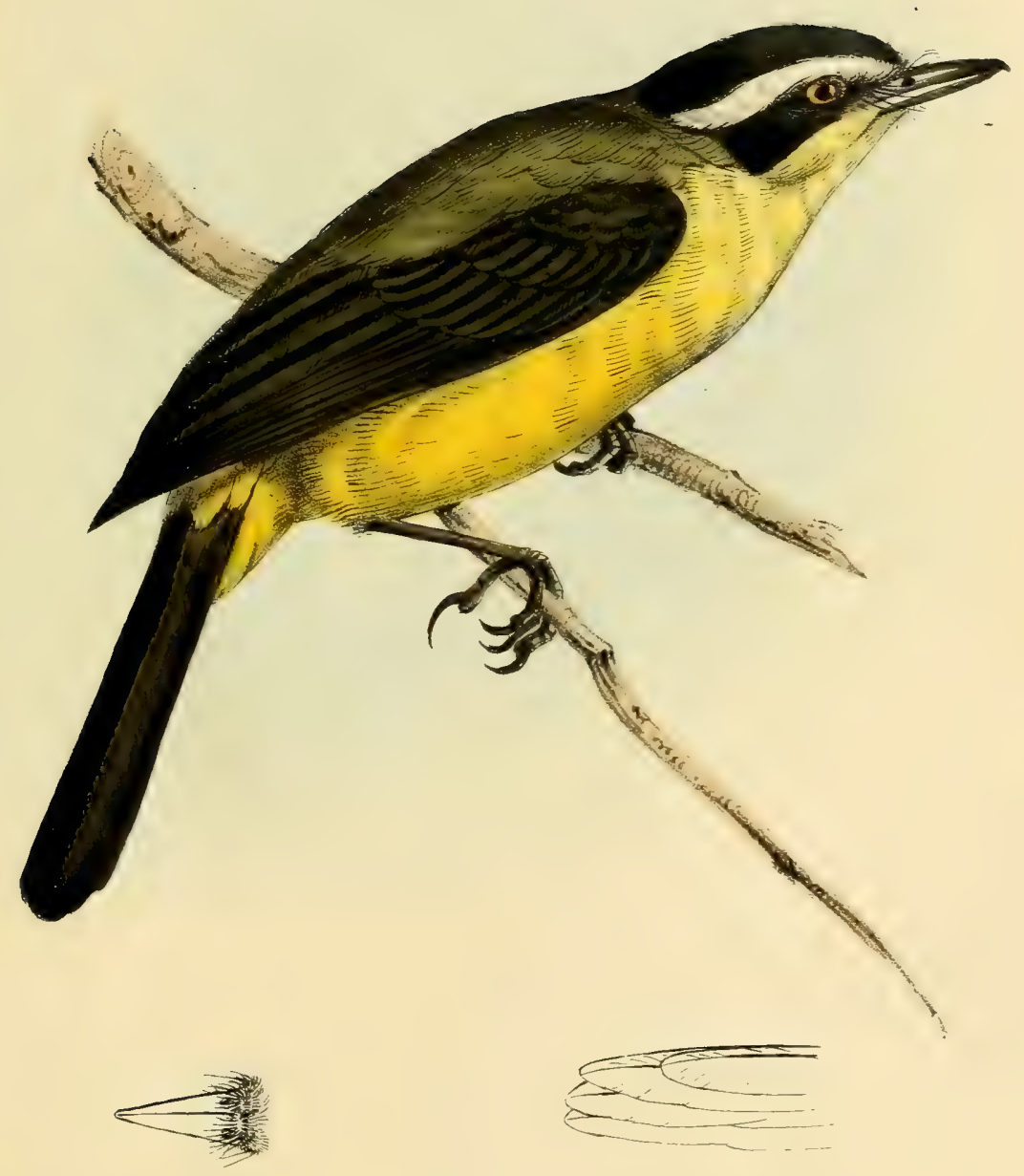

White eyebrow' Flycutcher. 





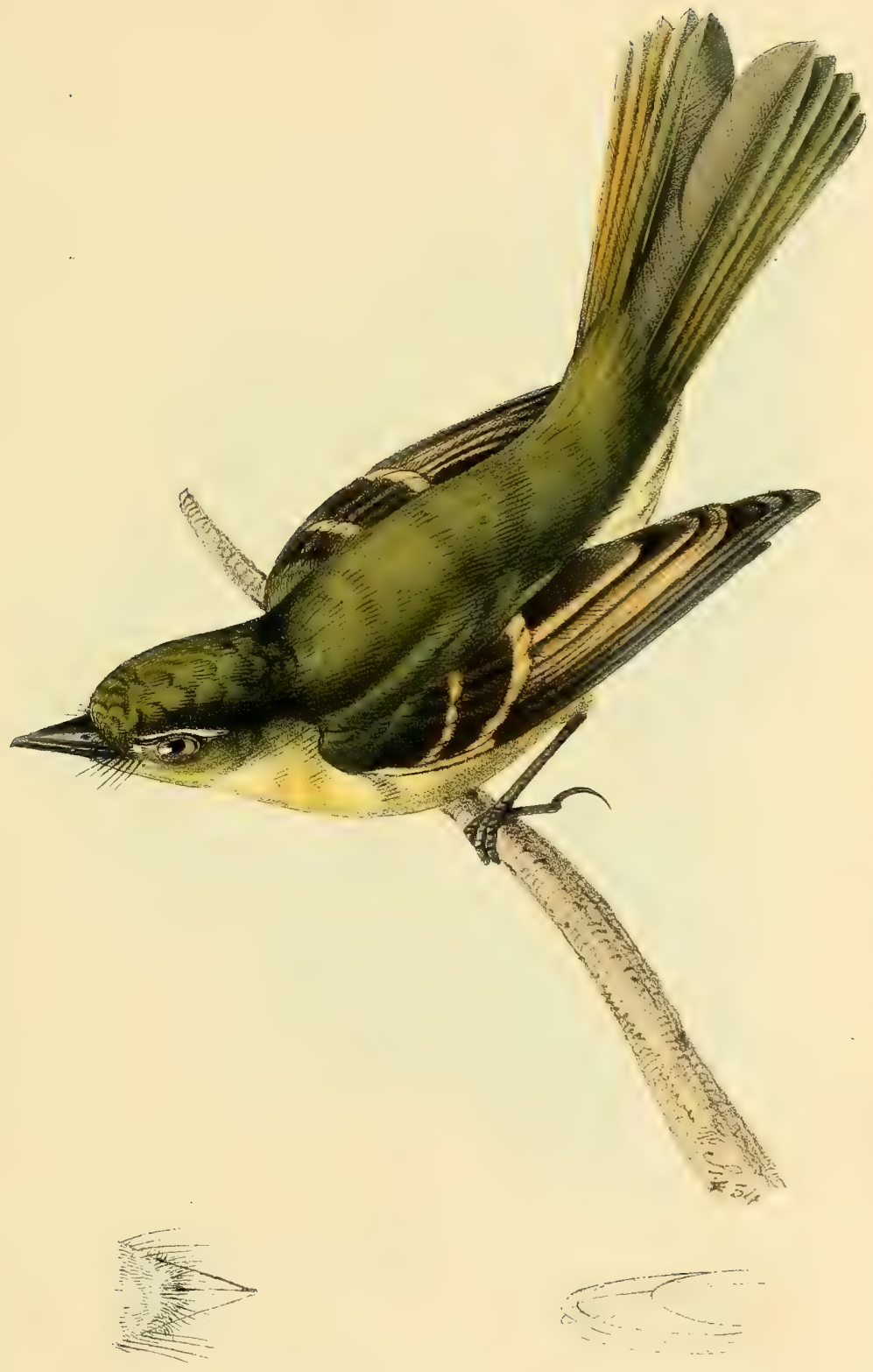

Great hended Hicatcher.

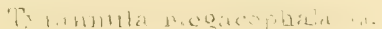







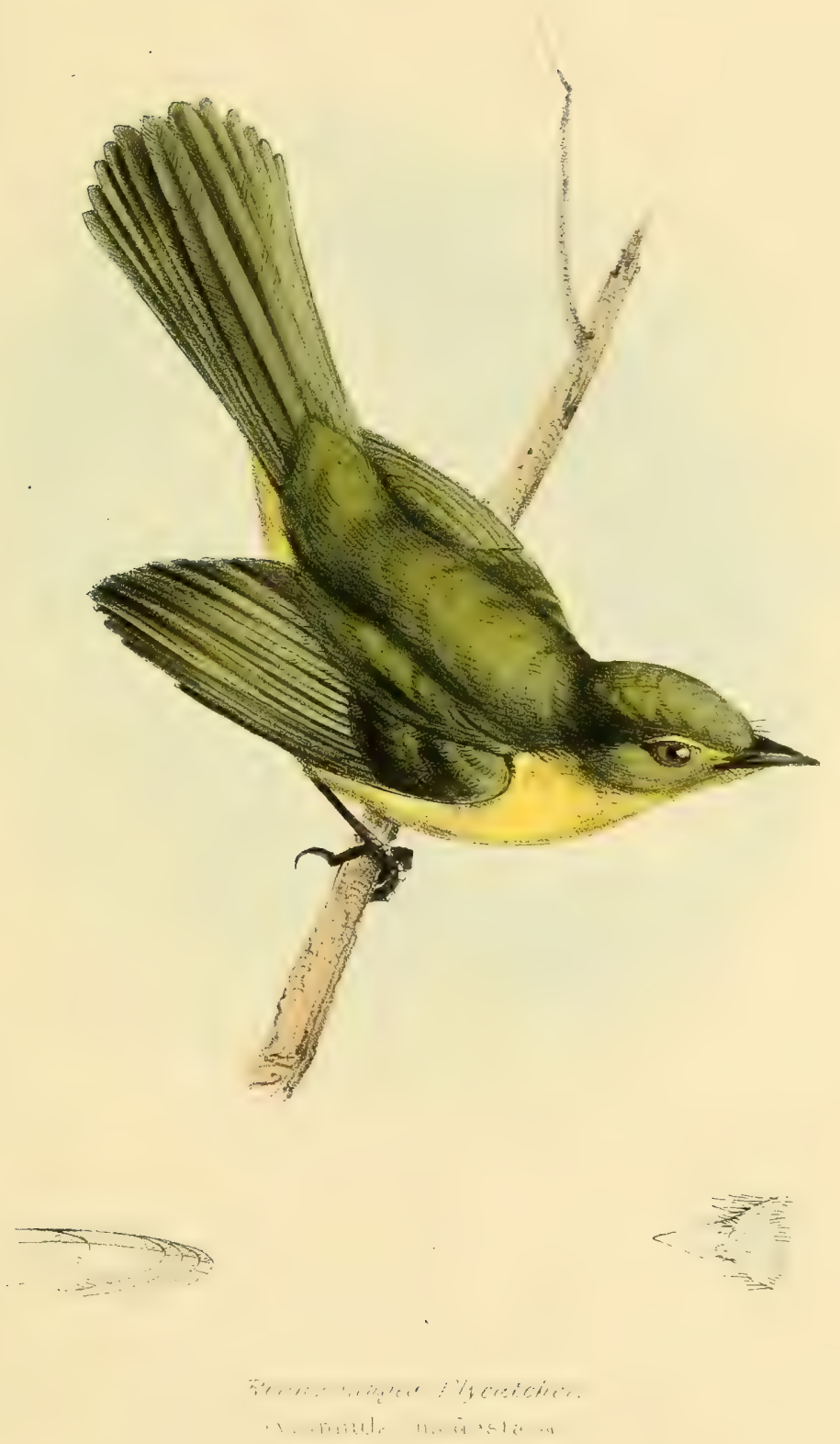







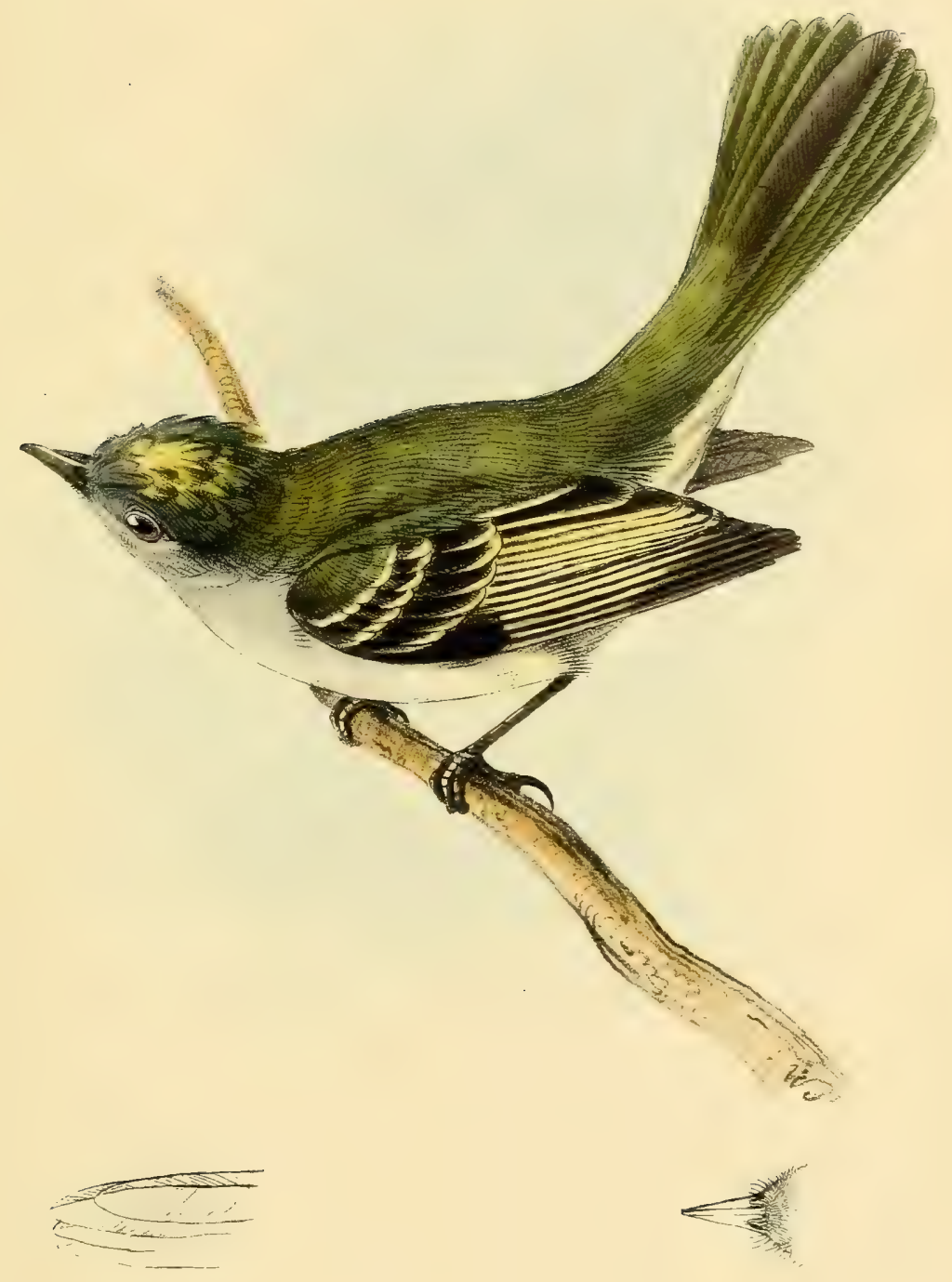

Straw-crested Flycatcher:

Trramula cauiceps sw

49. 





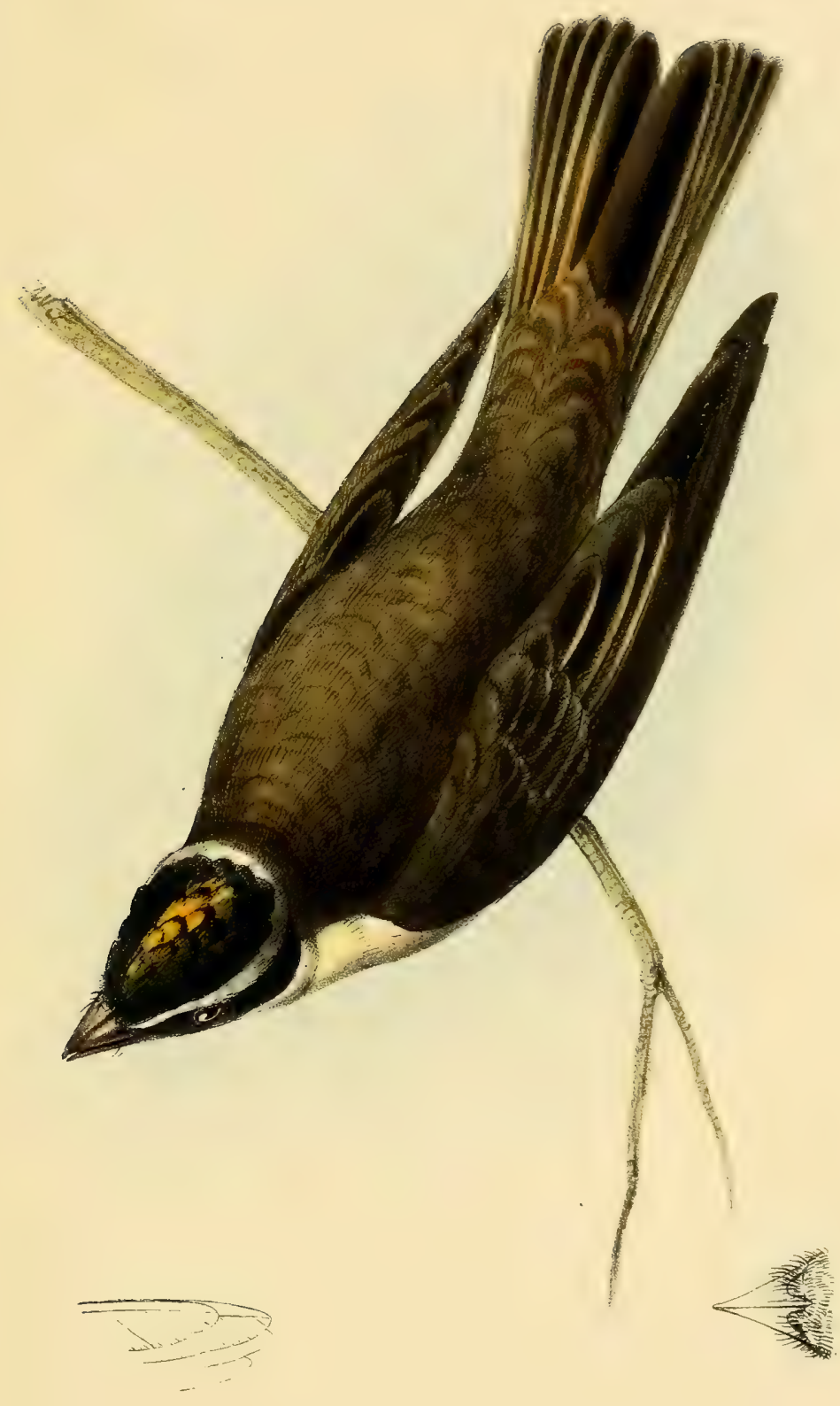

Iittle Tyrant-flycatcher

Tyrannus circurancinctus $S_{n}$ 





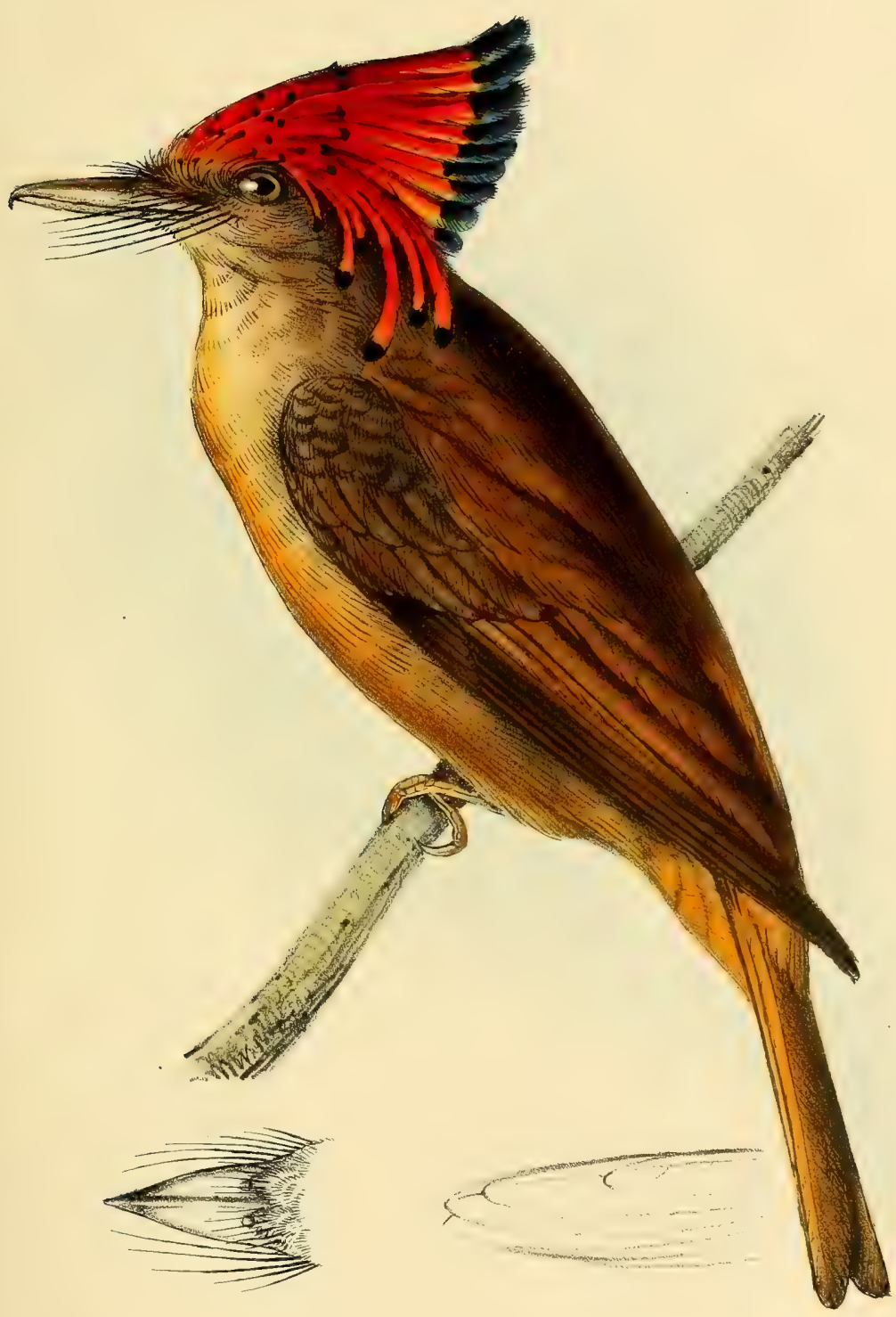

51.

Royal Iody.

NLE GALOPHUS Regius. Sw

Naz. Size. 




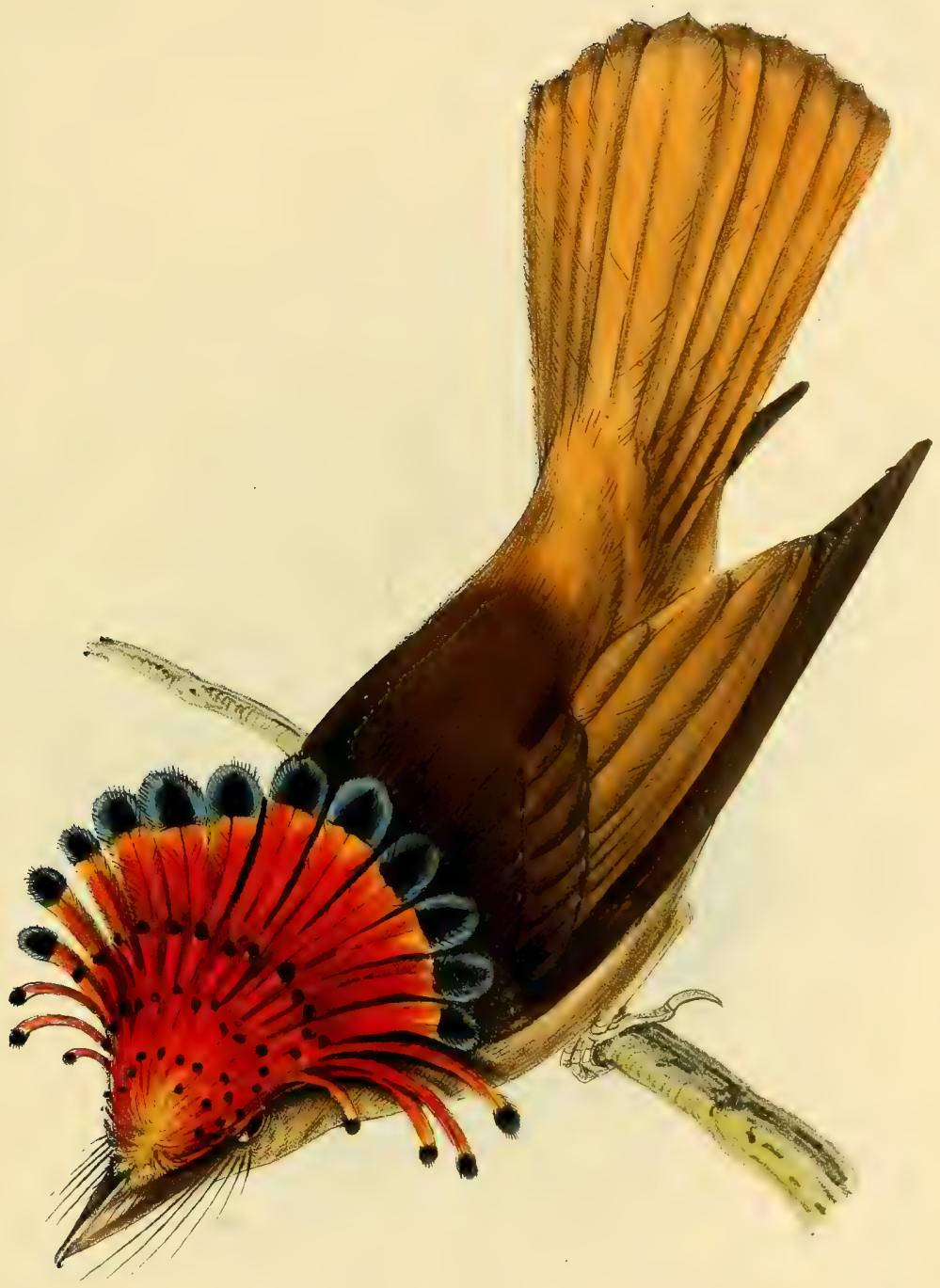

Royaz Tody. .

MEGATOPHUS Regit.S. I $W$. 




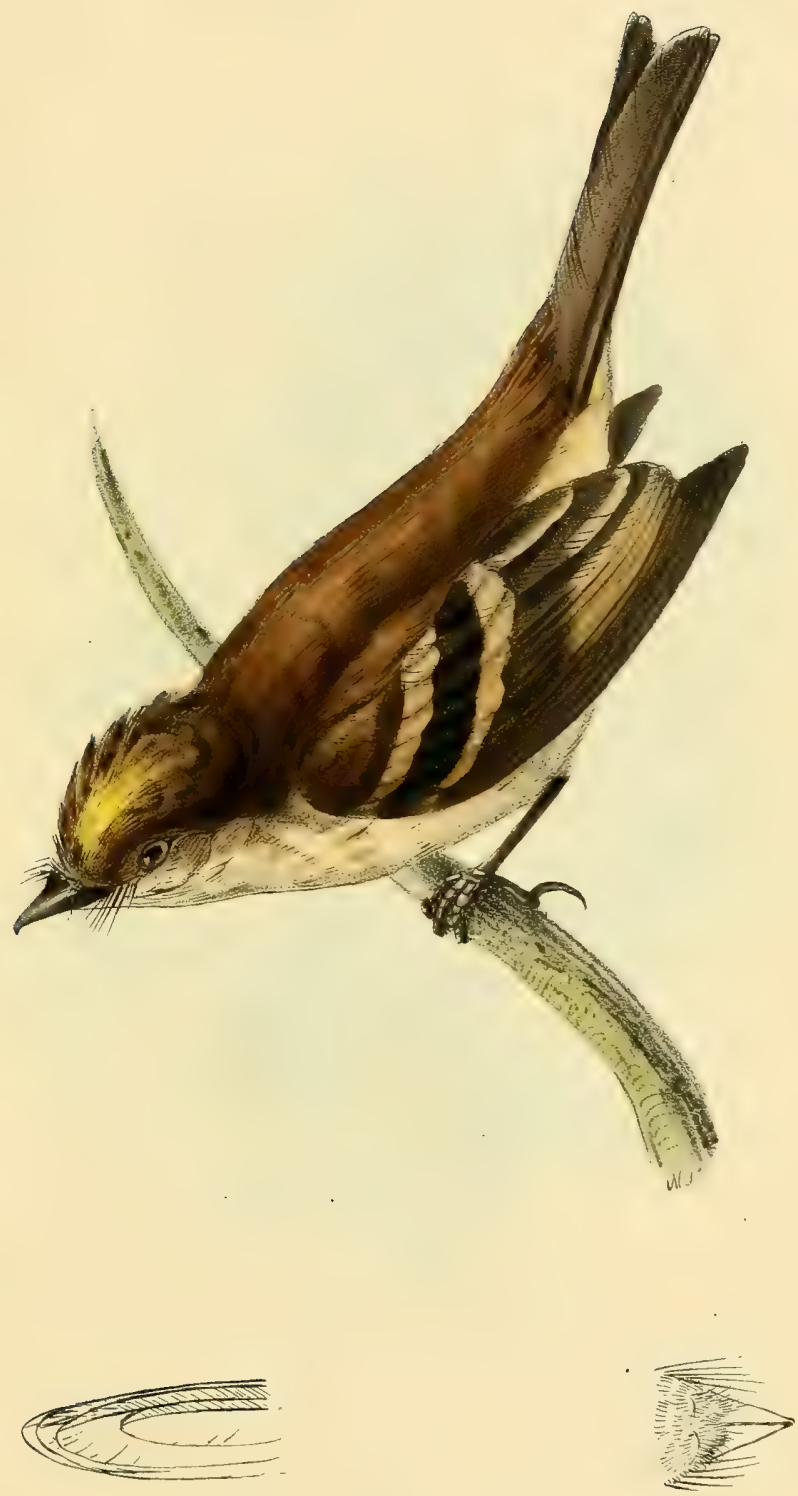




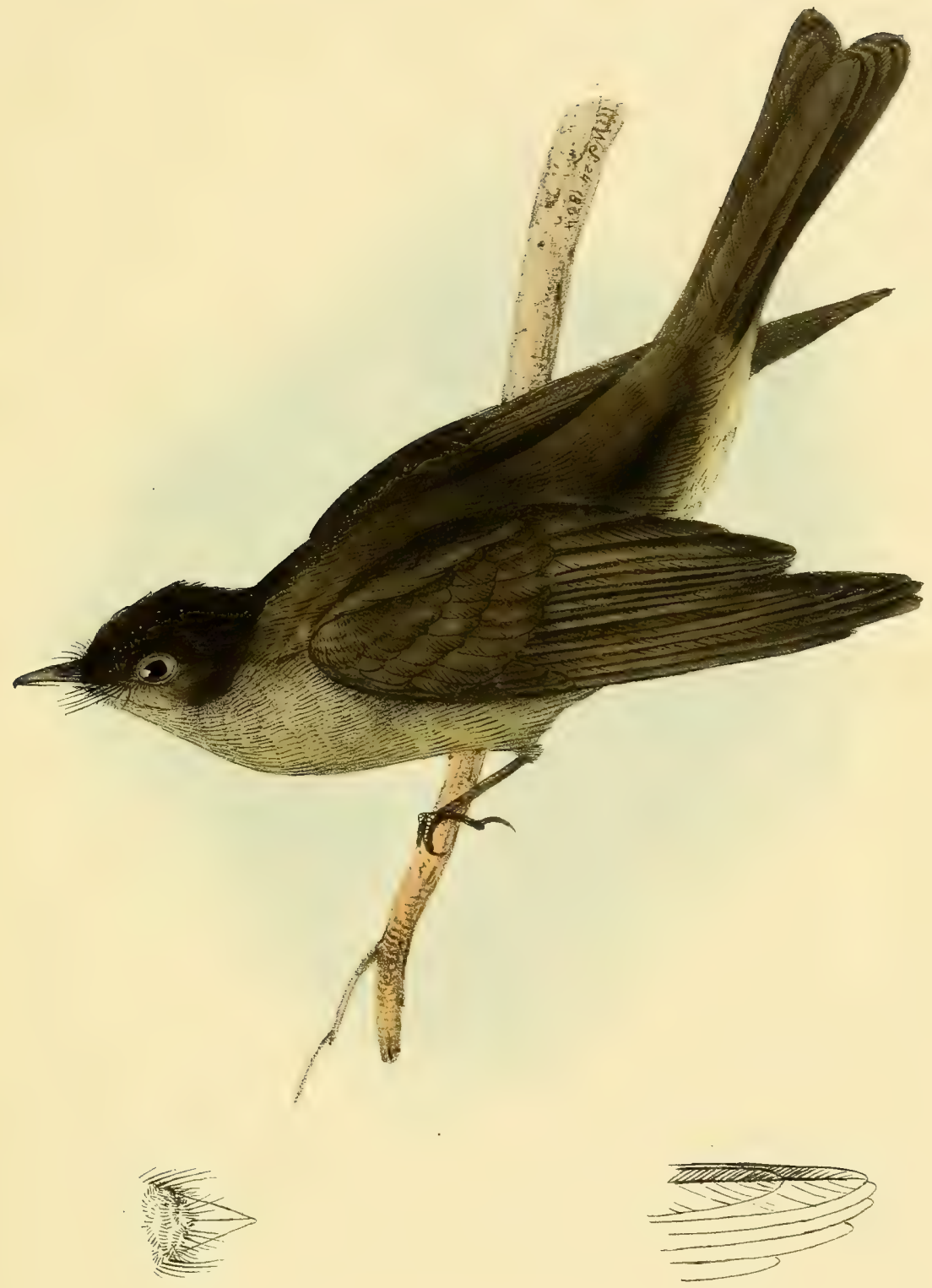

Short-footed Flycatcher.

54.

Tyrannula curtipes. $S_{w}$. 





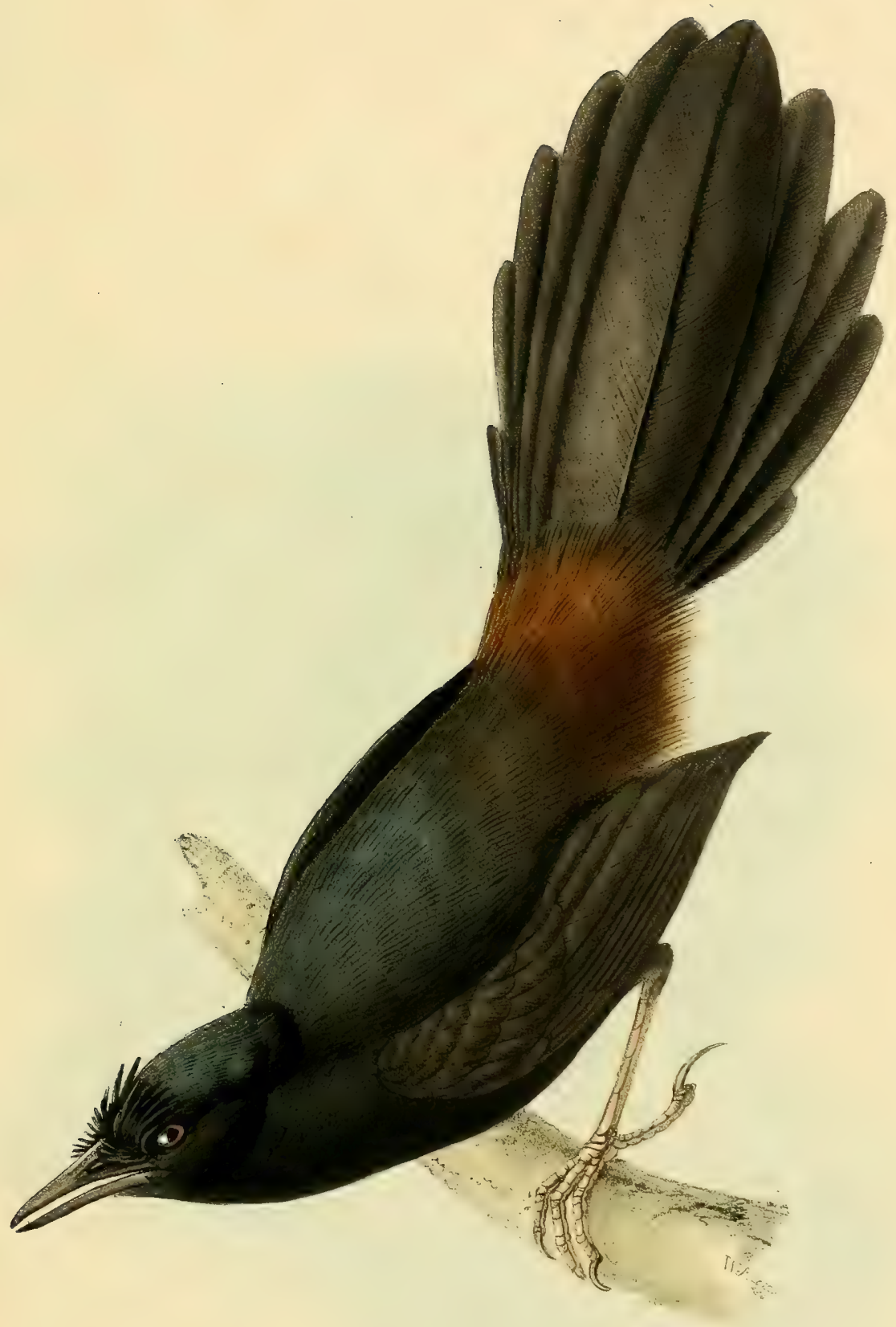







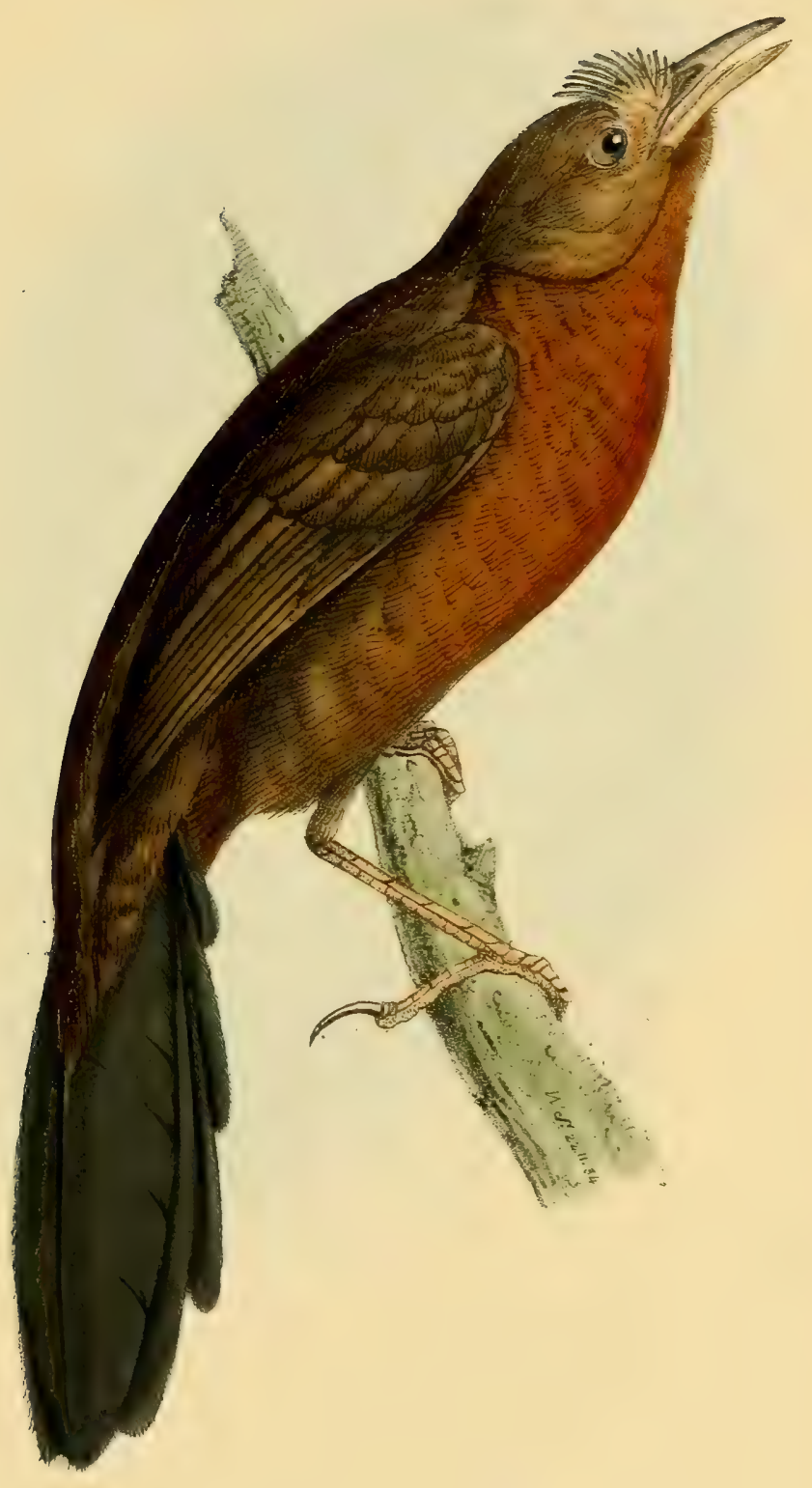

Kinob-fronied Wren frimaie 





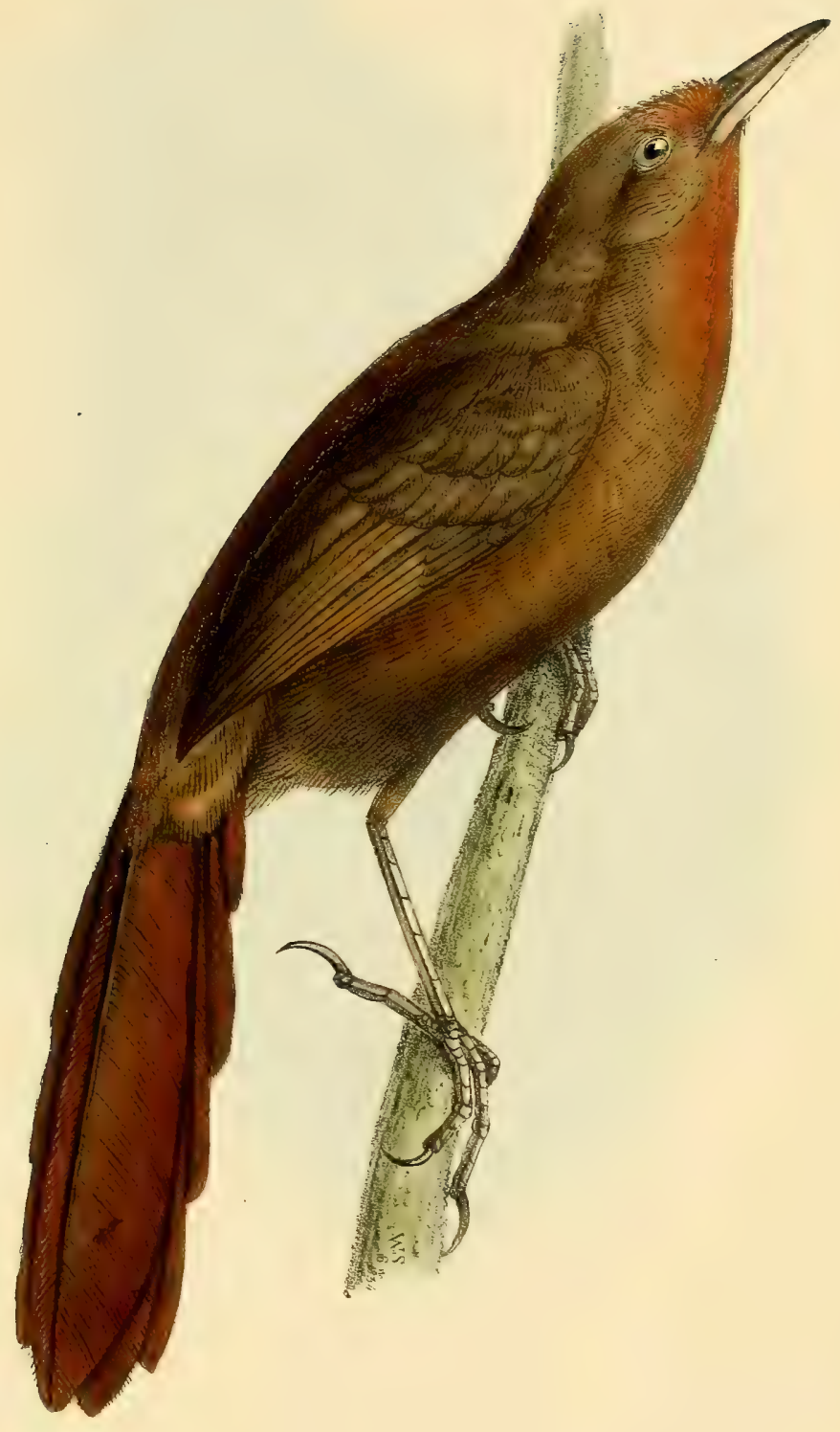

Fied-breas? Wrext

Platyurus "ffiruis $S_{\text {s }}$ 








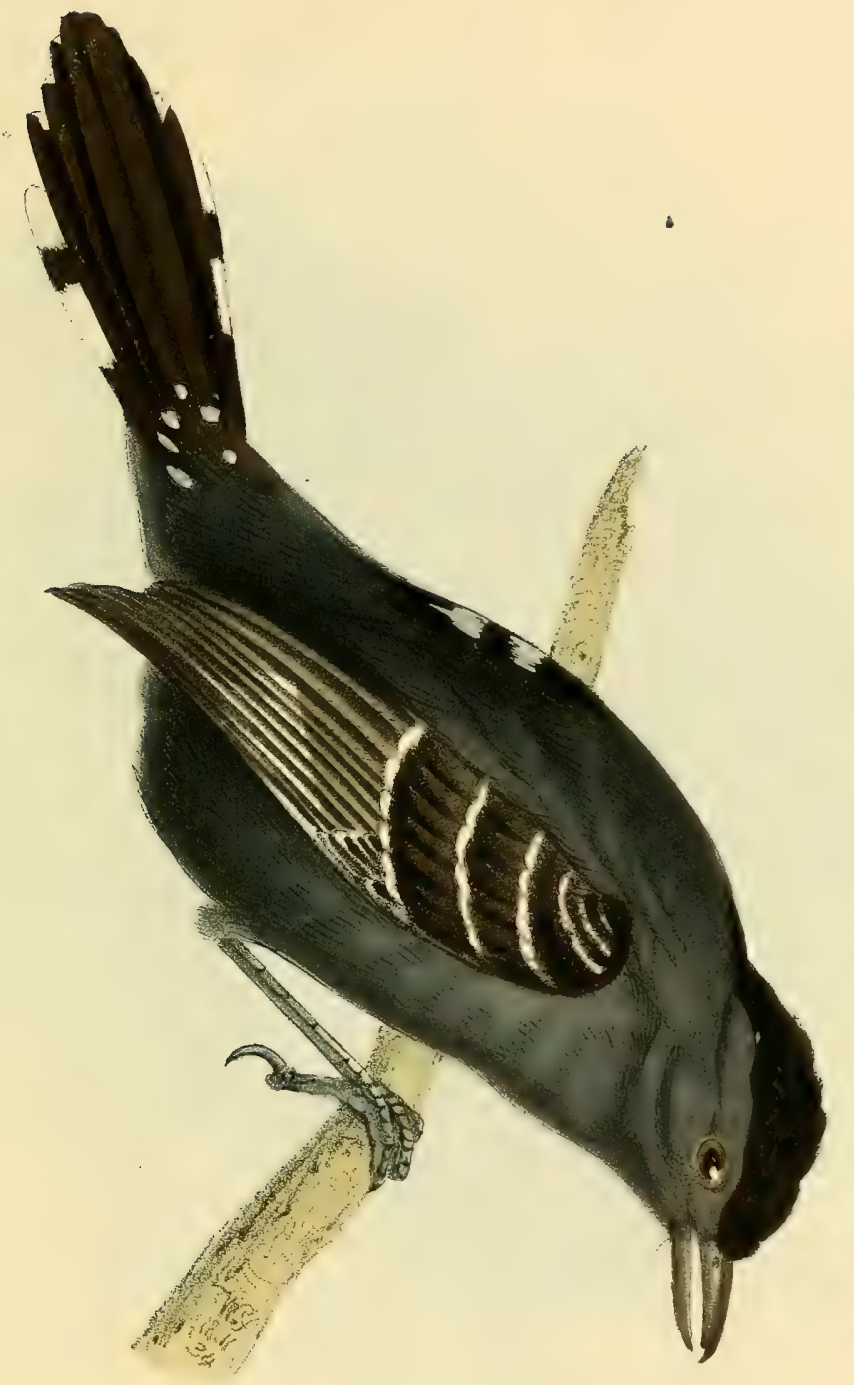







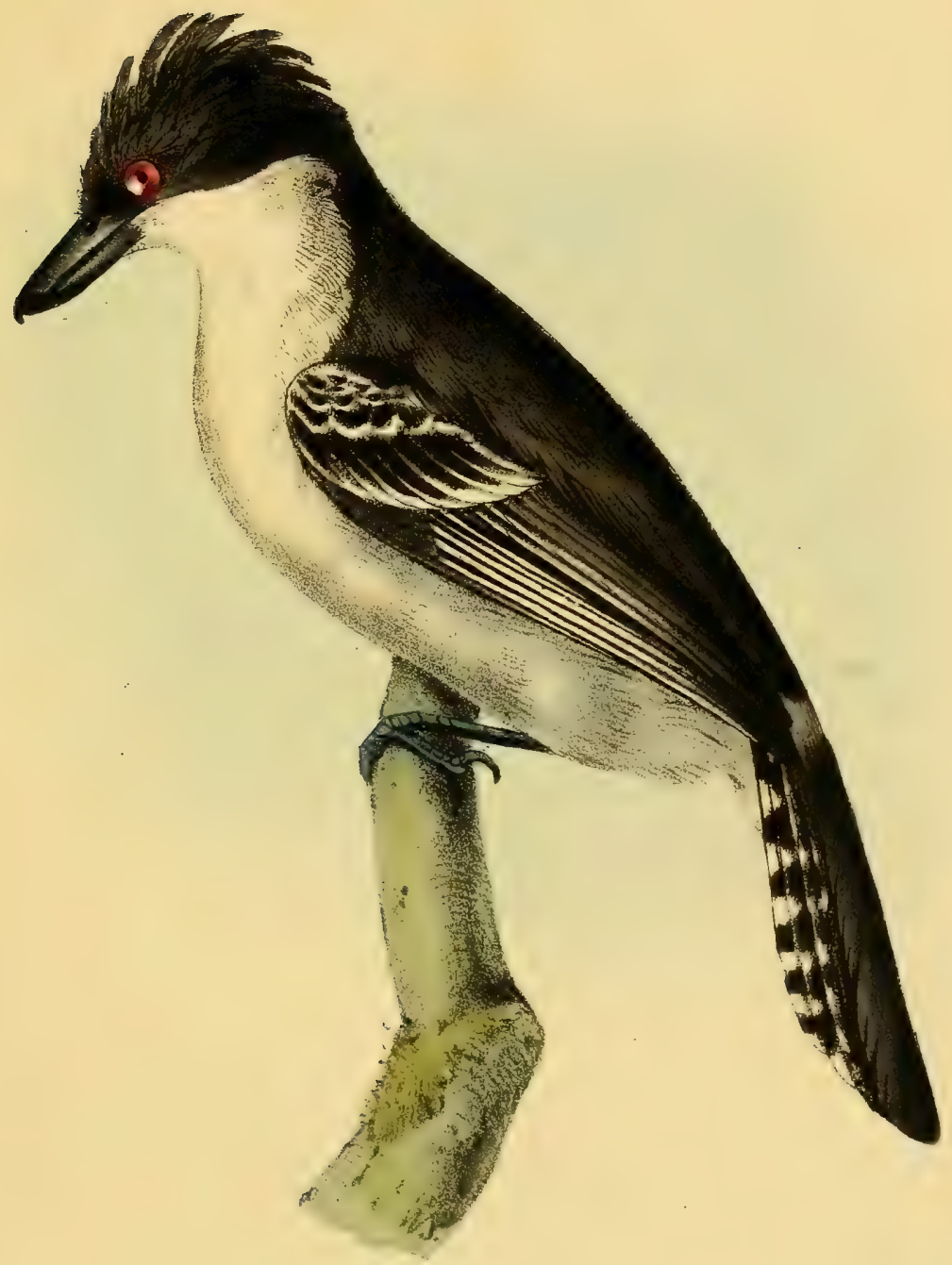

Red-eyed Shrite

Gii. 





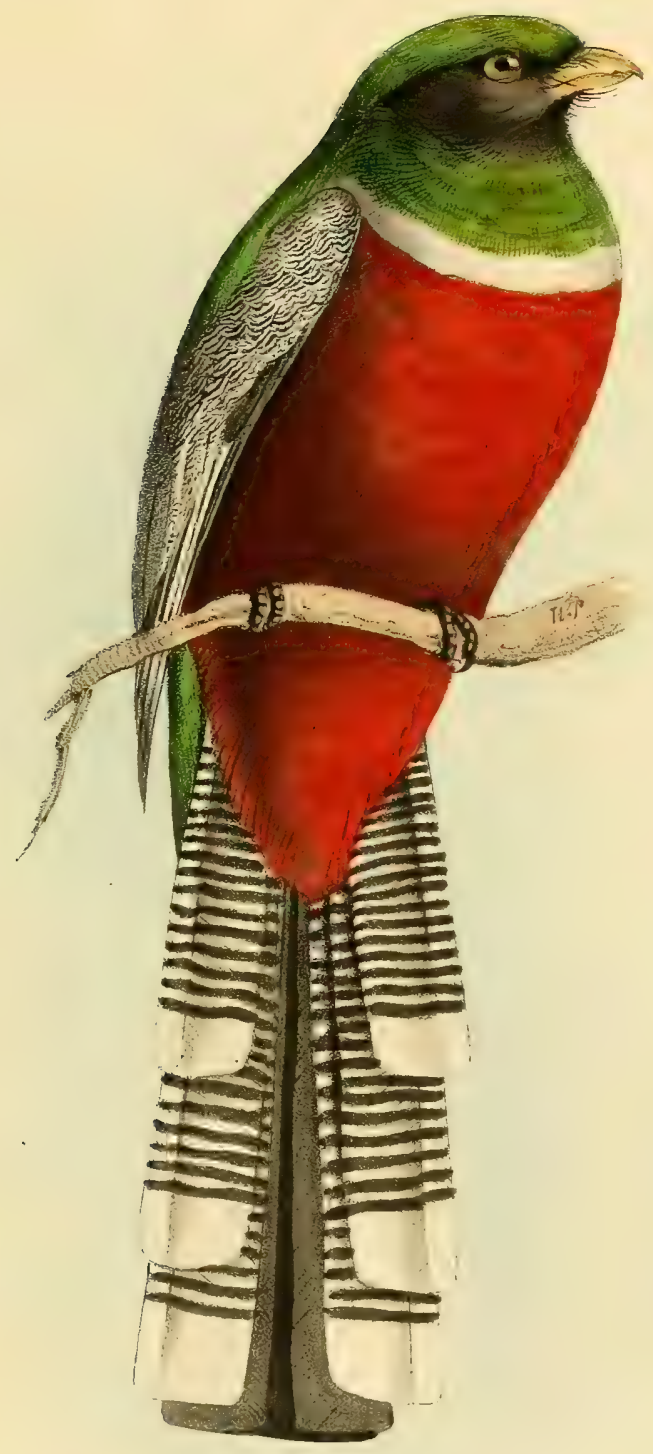

Trogon auratris. Sw 





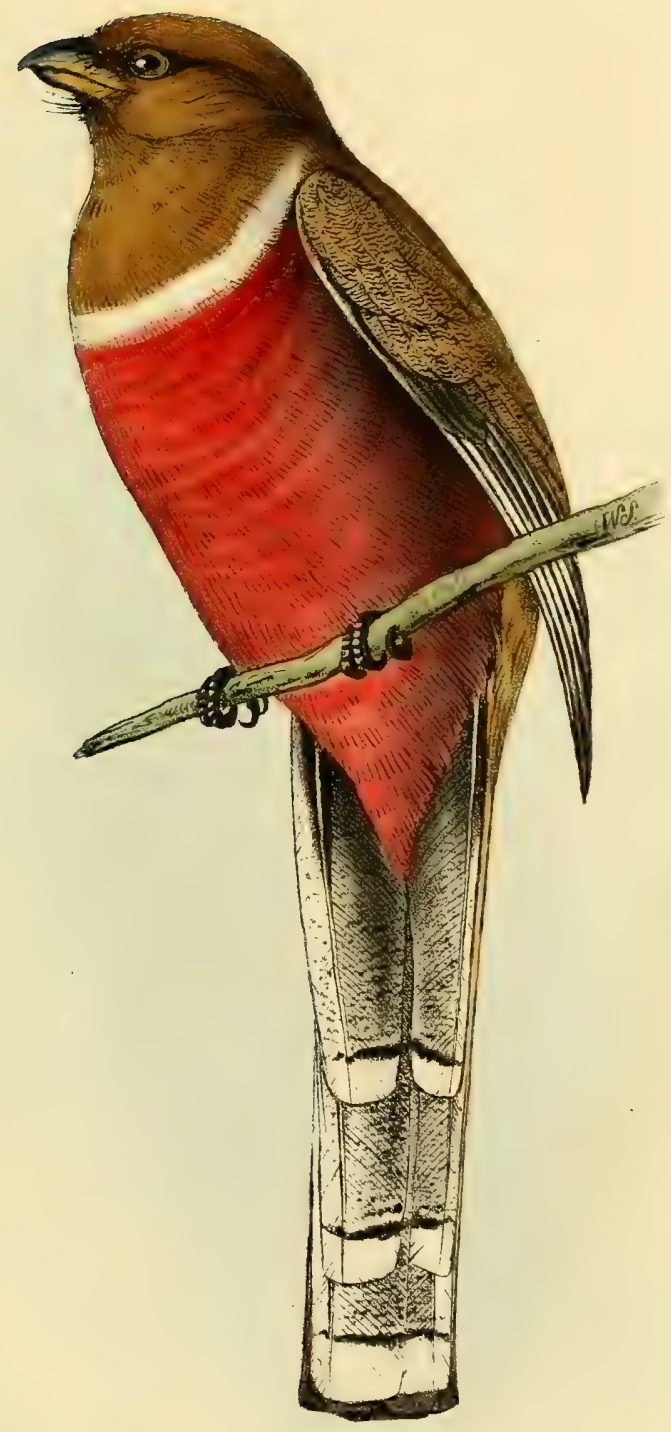

Green breasted Frogon

Trogor auratus, sw 





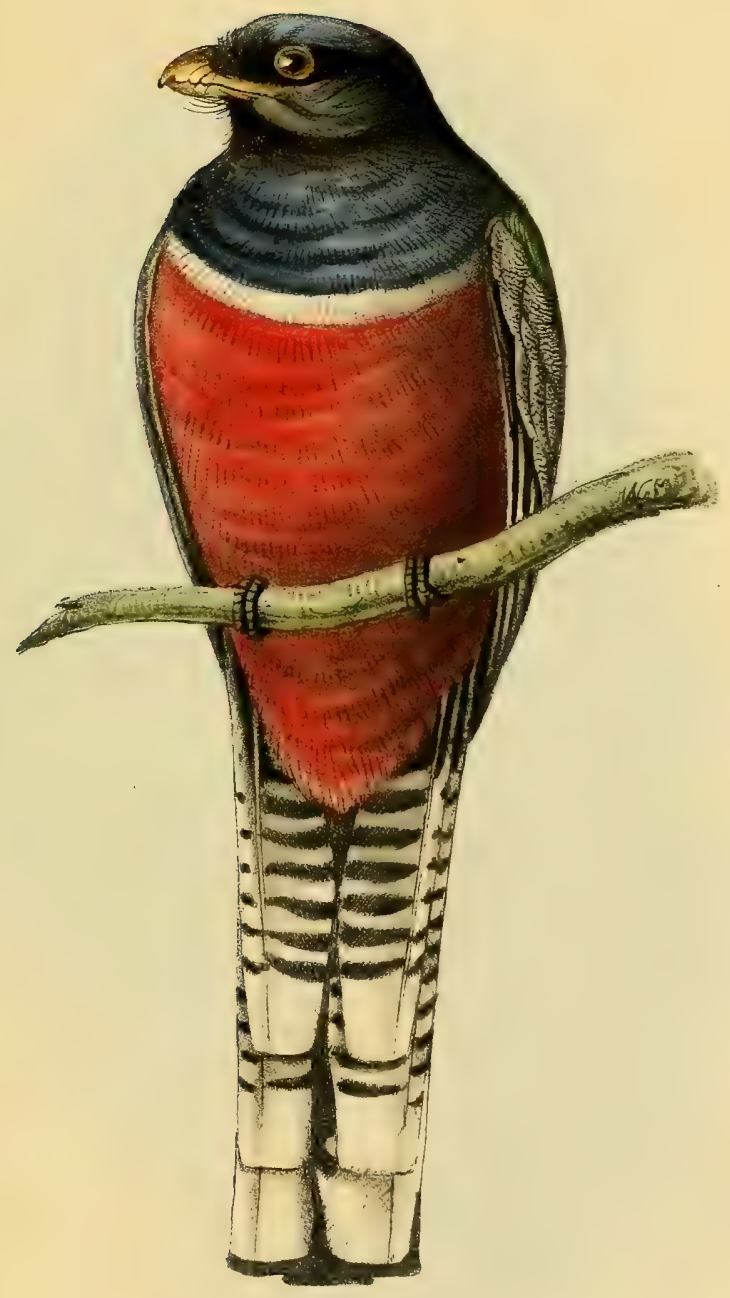

Pumpte-breasted Trogan maite

Trogon purpuratus. Sw. 





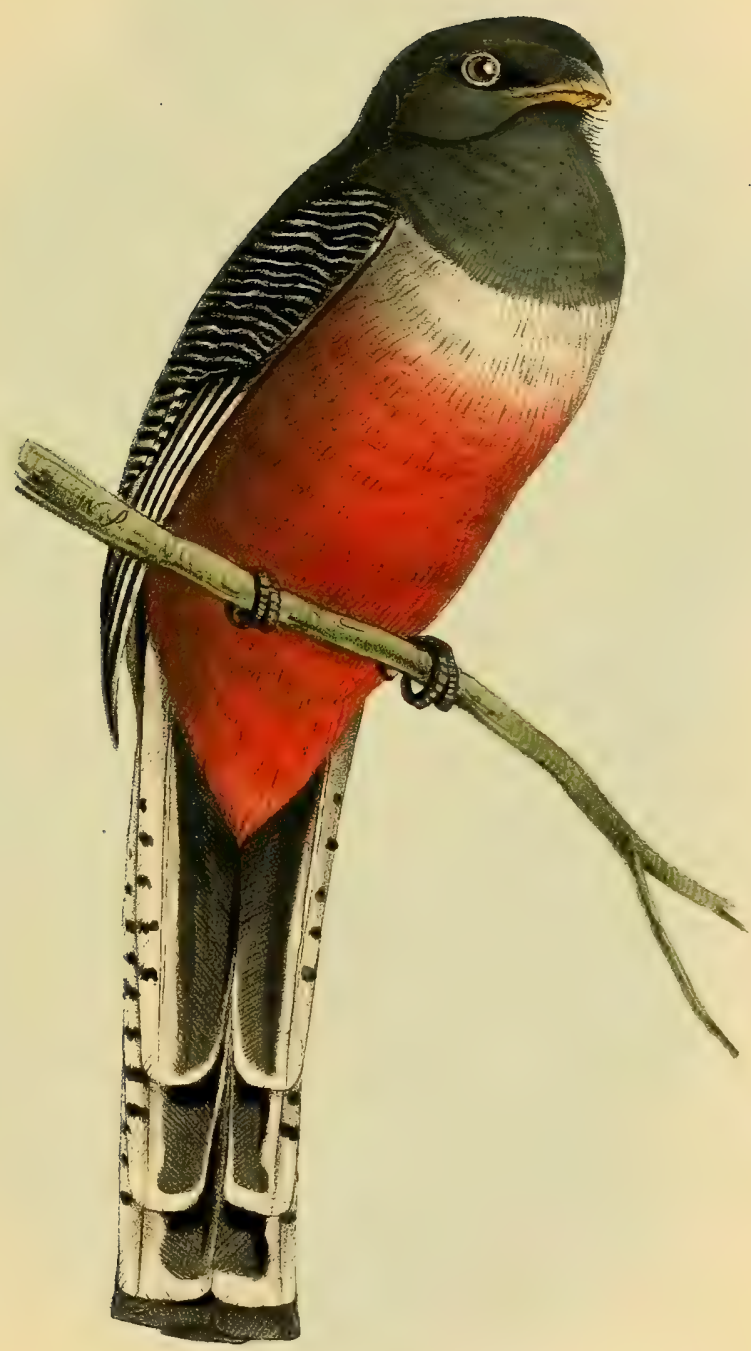







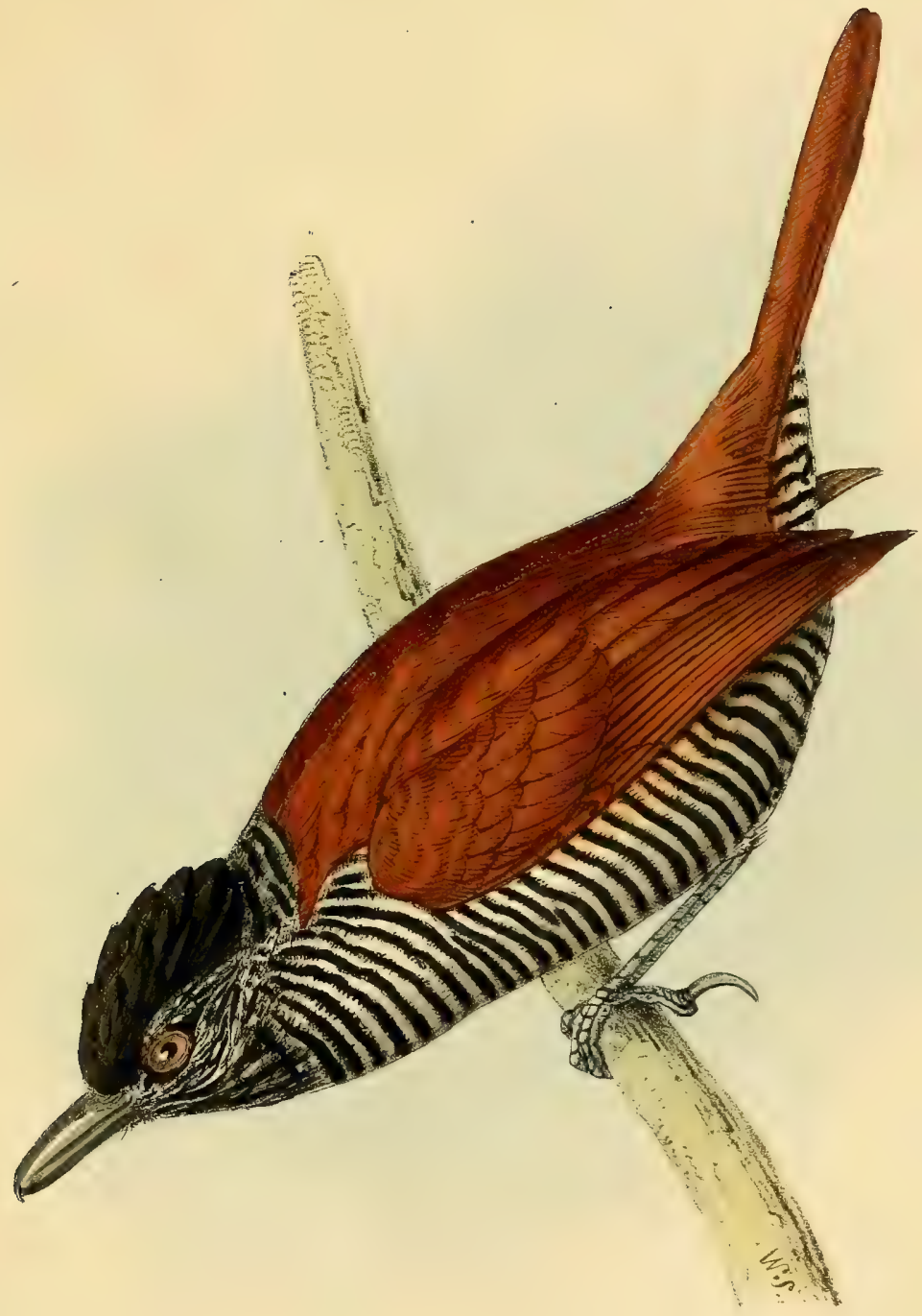

Red-backed Bush-shitike mite

'Thamnophitus sadrus. $s_{w}$. 





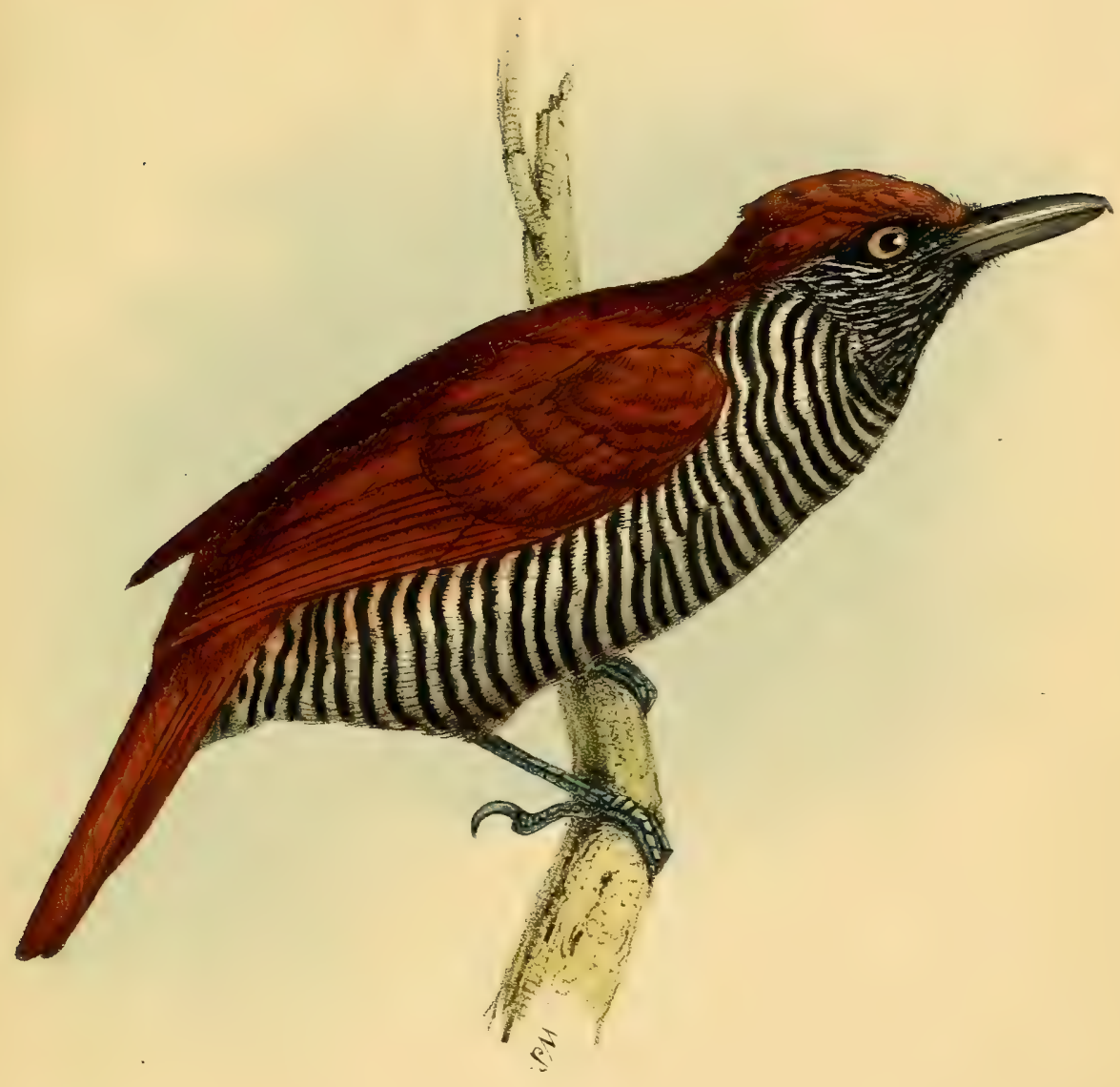

Red-backed Bush-shrike female.

T. badius. SAv. 





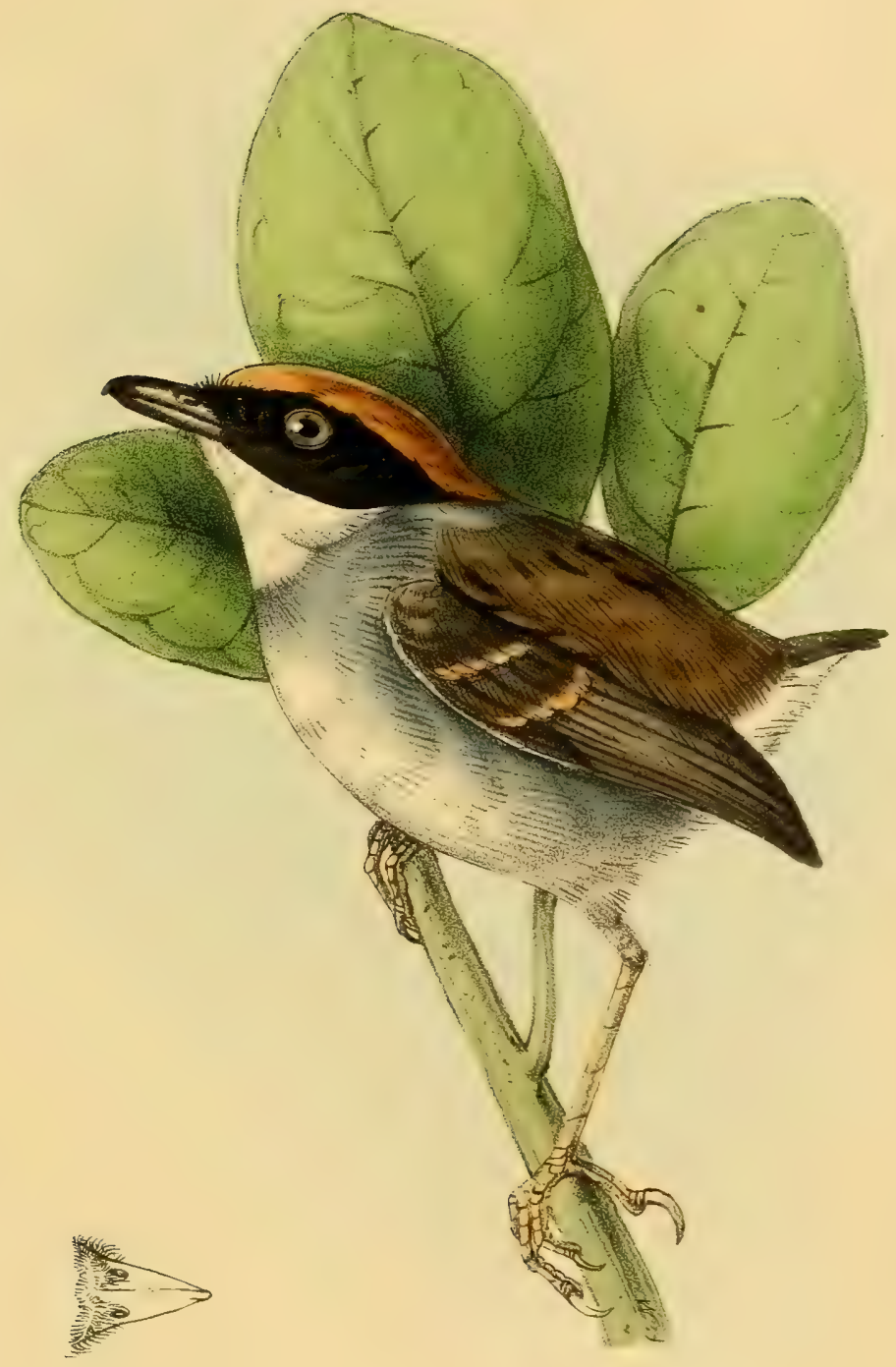

Rufous crowned Flatbitt mate. 





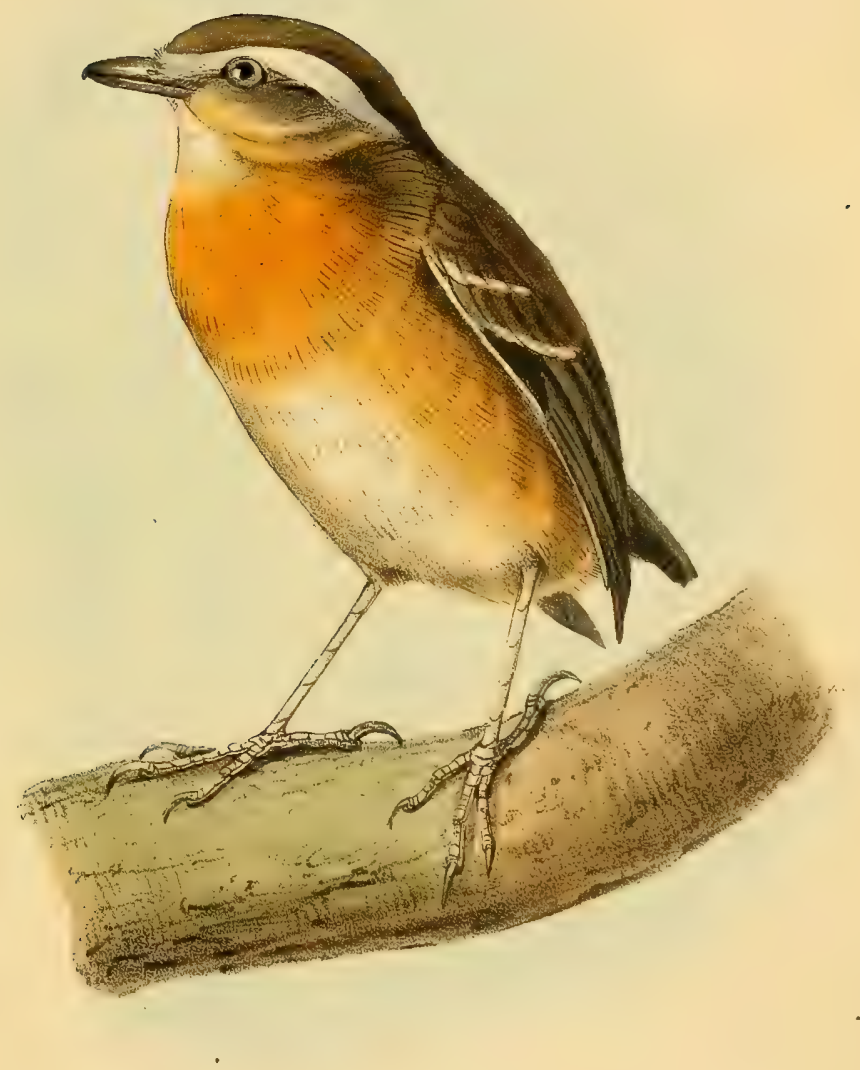

Rufous crowned Fiatbill fenate.

Con ruficeps. Sw. 





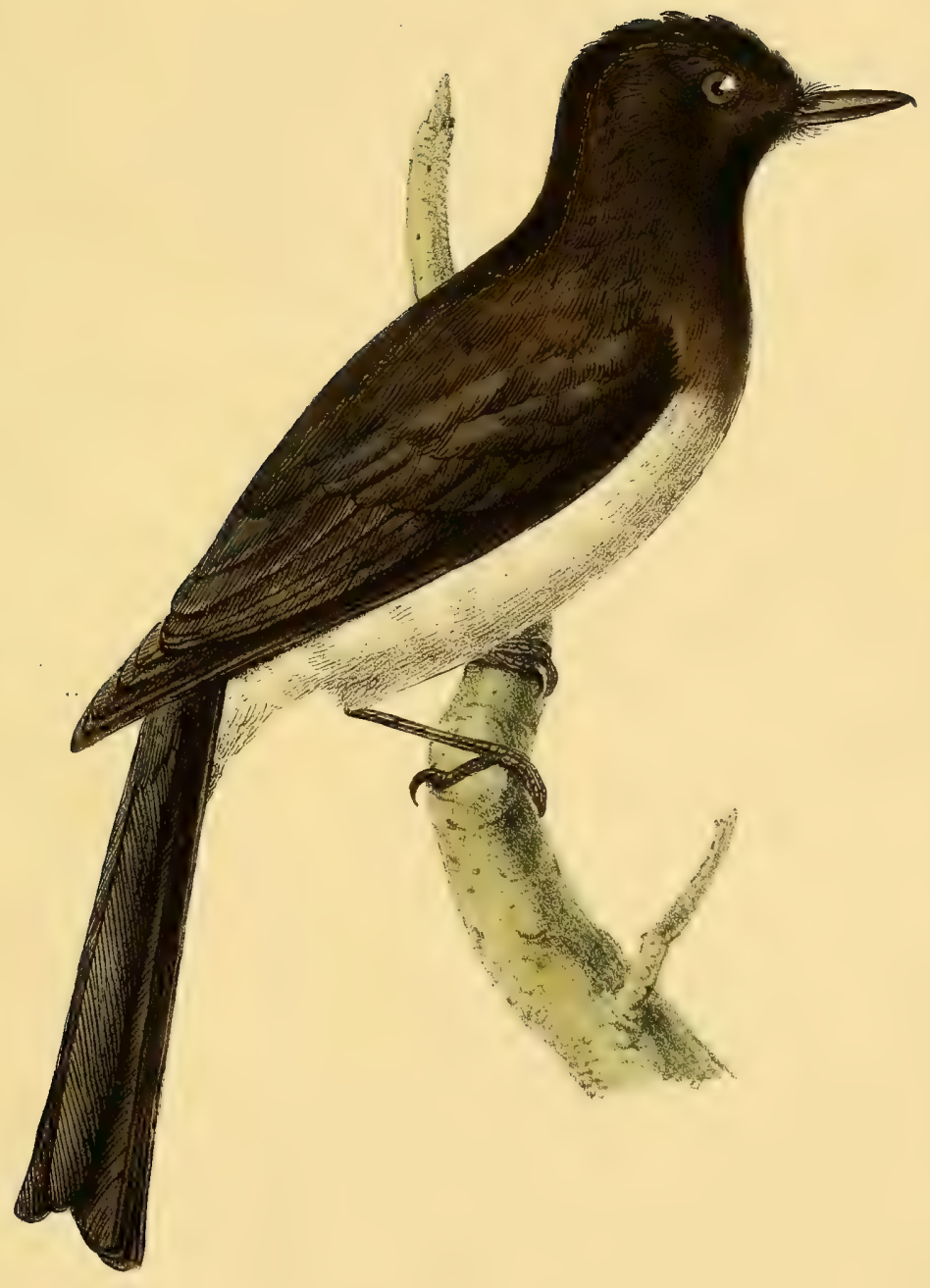

Sooty Flycatcher 





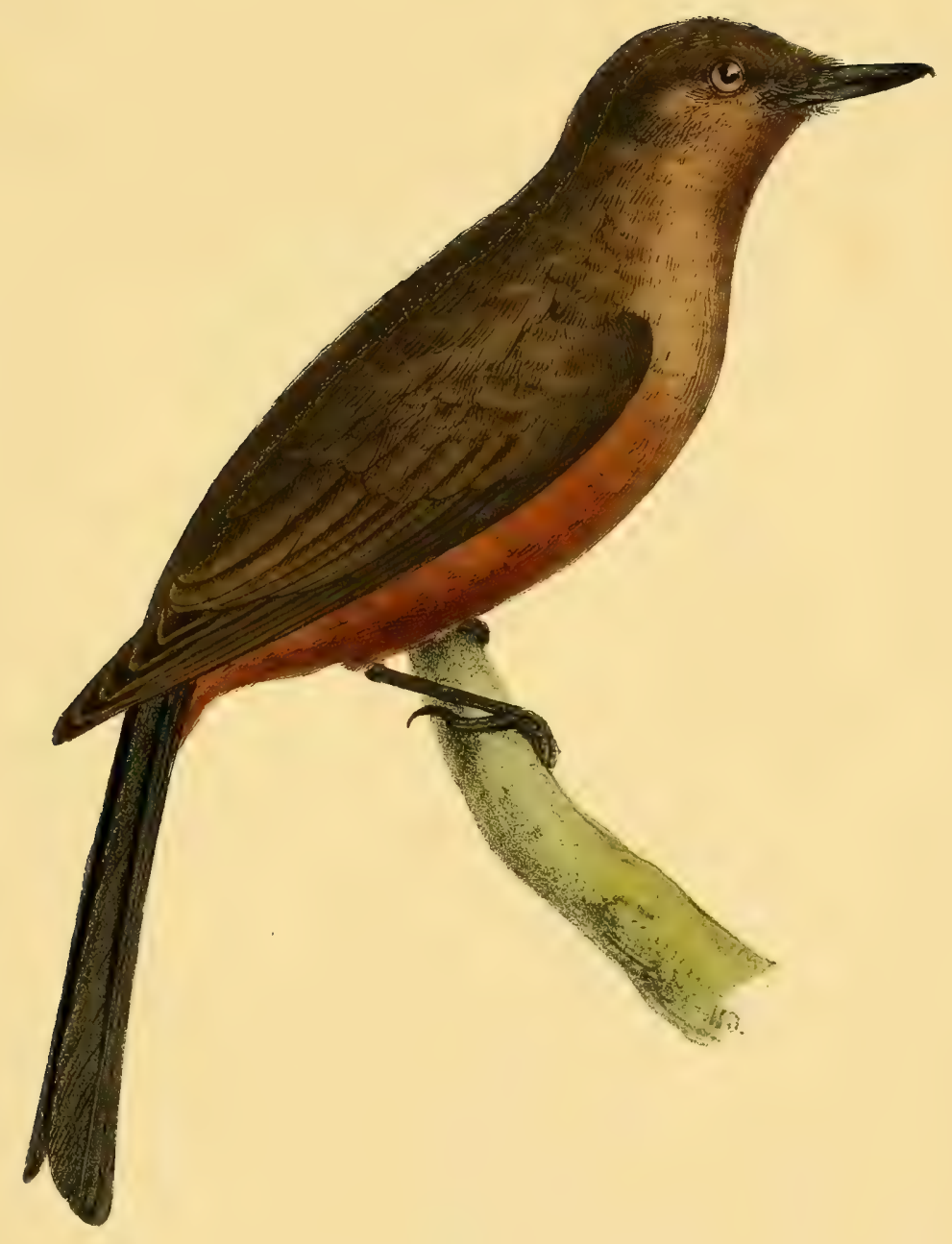

Black tailed Flycutcher. 





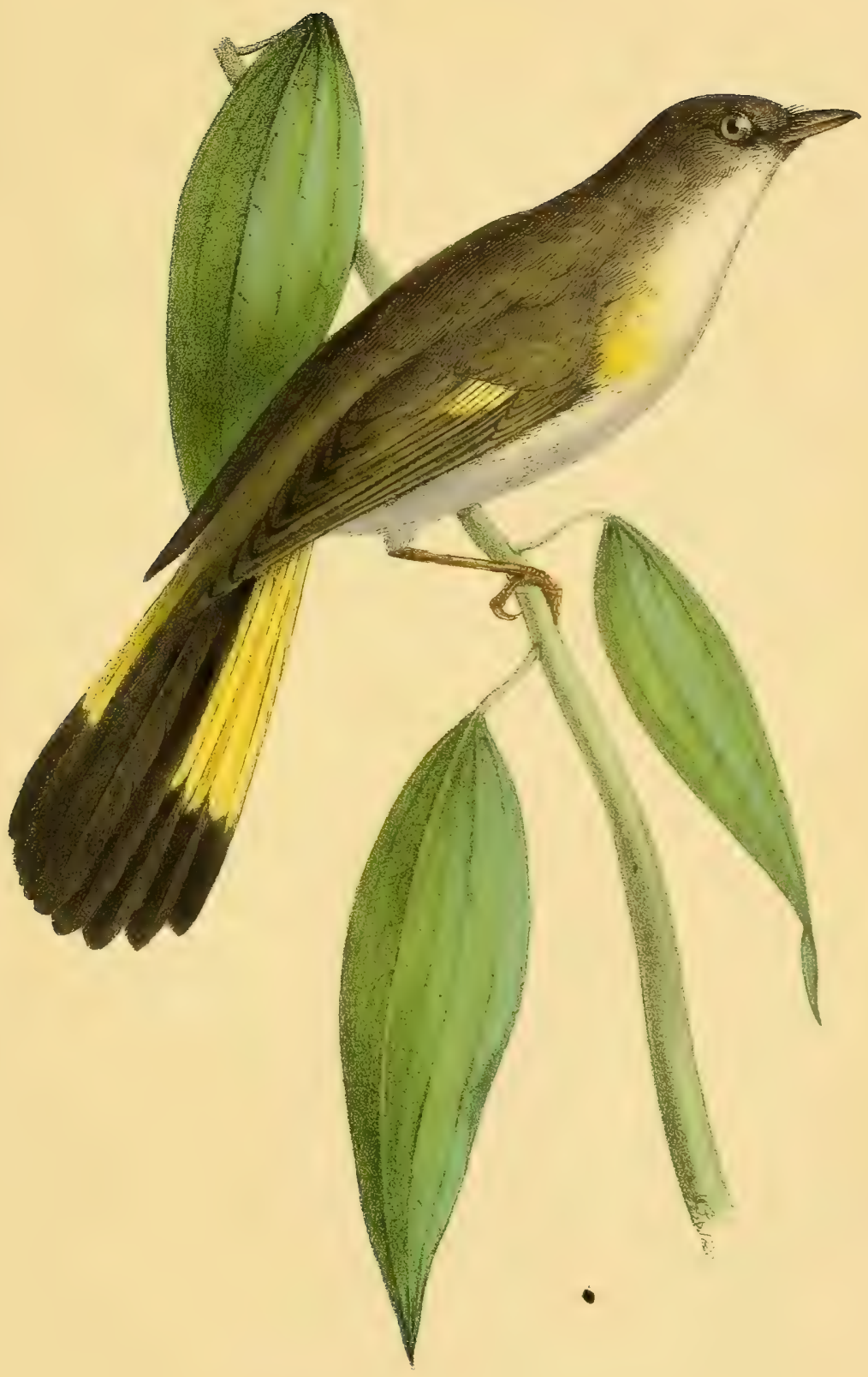

Iellow-tailed Flycatcher.

M. flavicanda. 





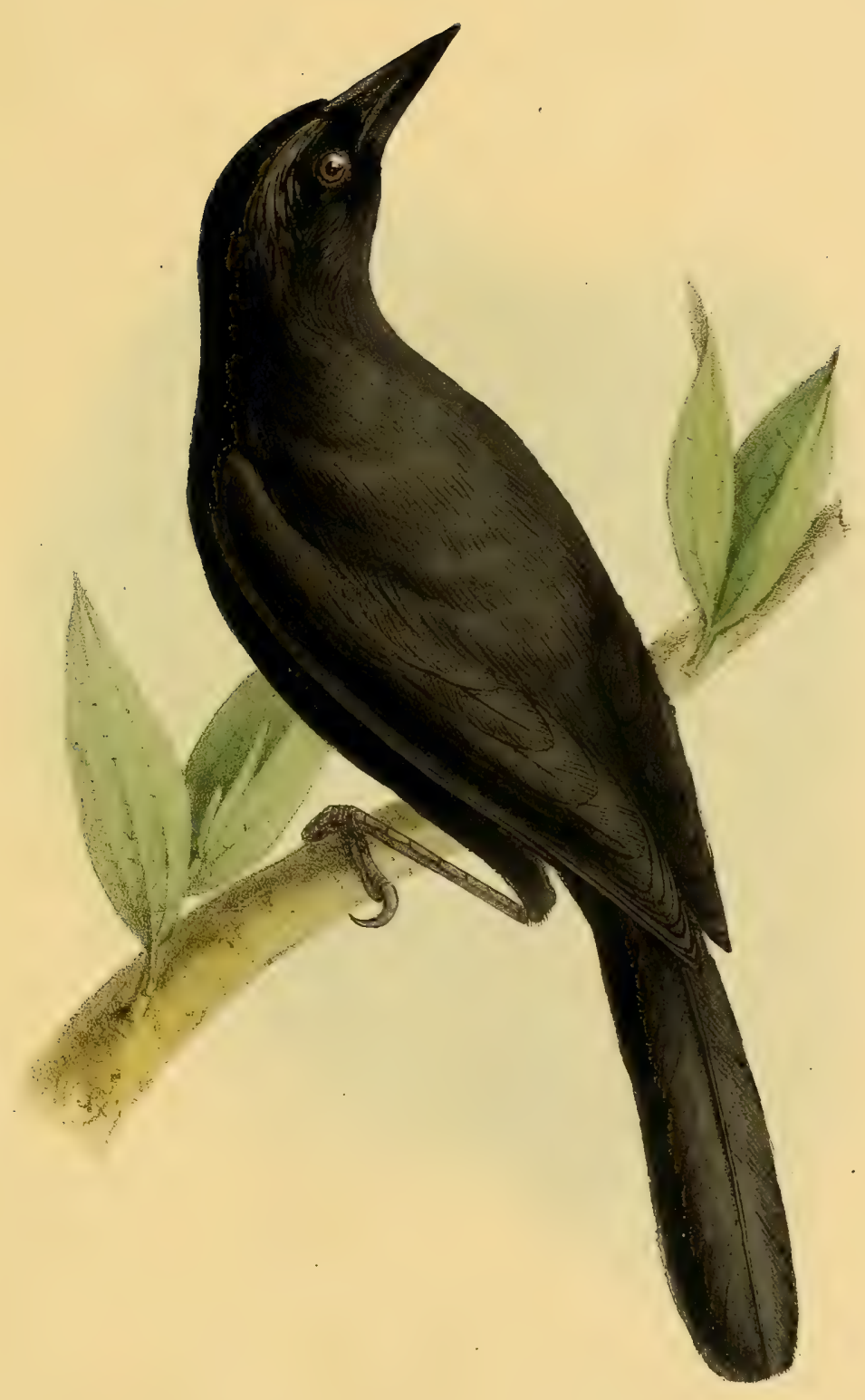

Pimple faced Oriole. (I. pustulatus.) 





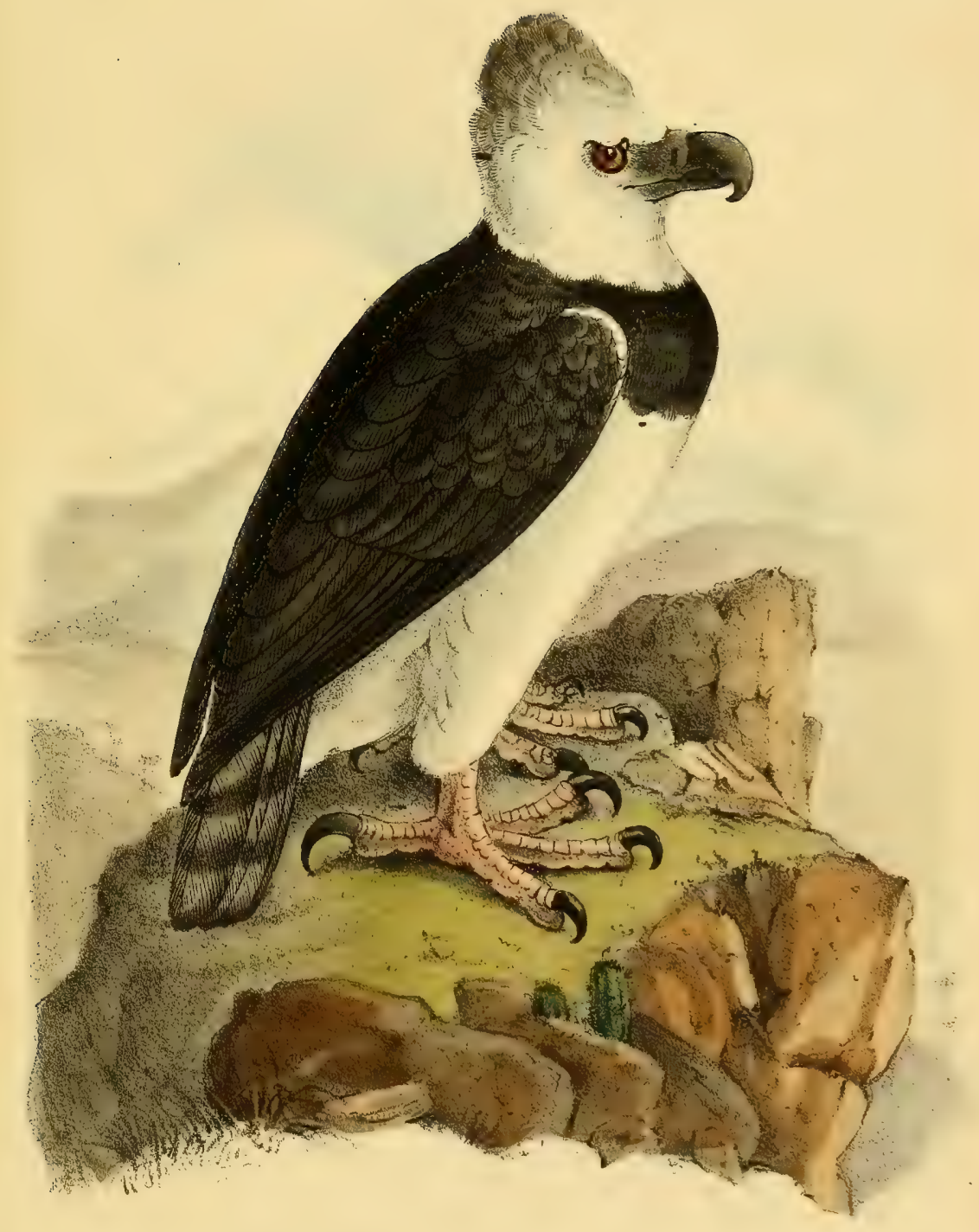

Mexican Imperied Eagle. 





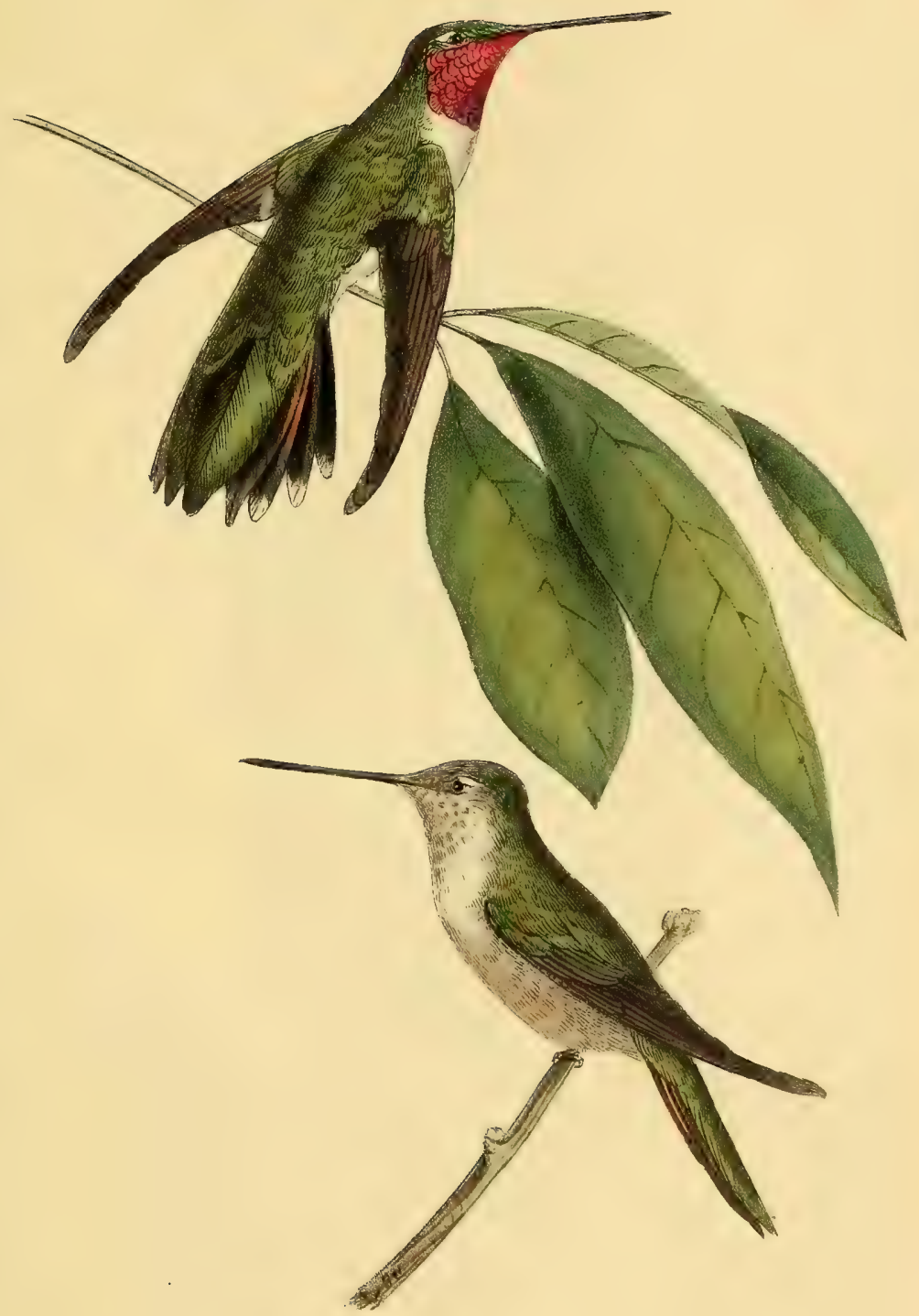

Mexican Amethyst Haird. 





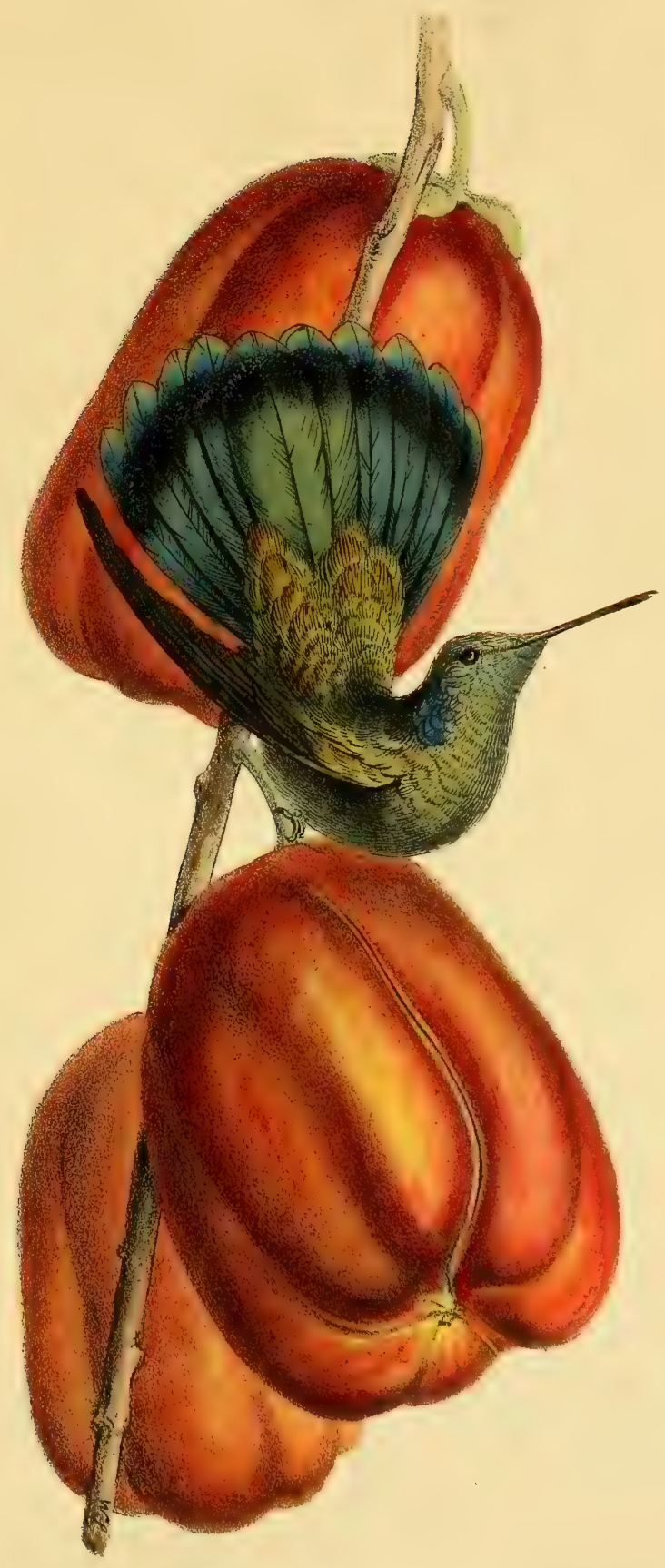

Green taild H.Bird. 





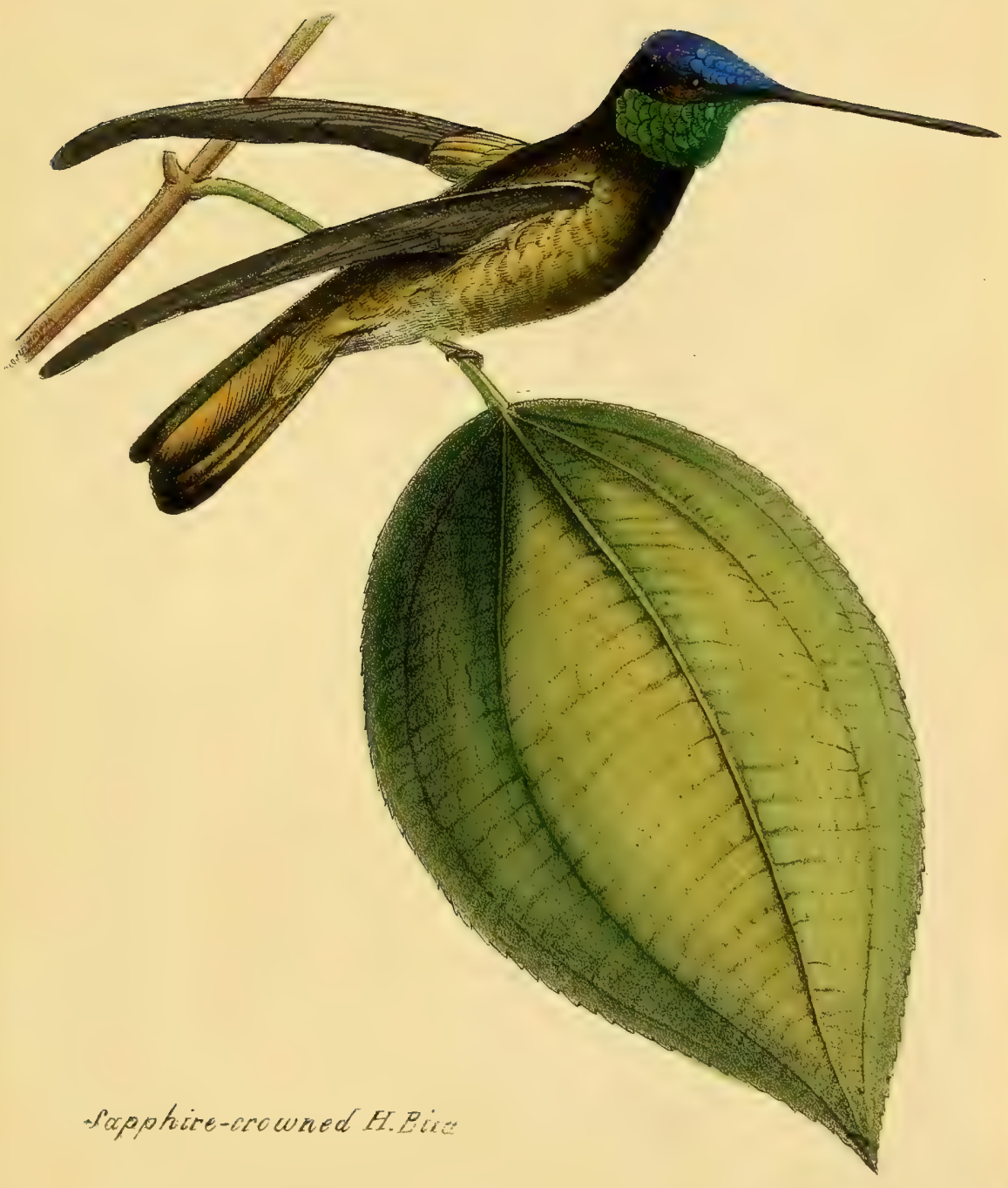







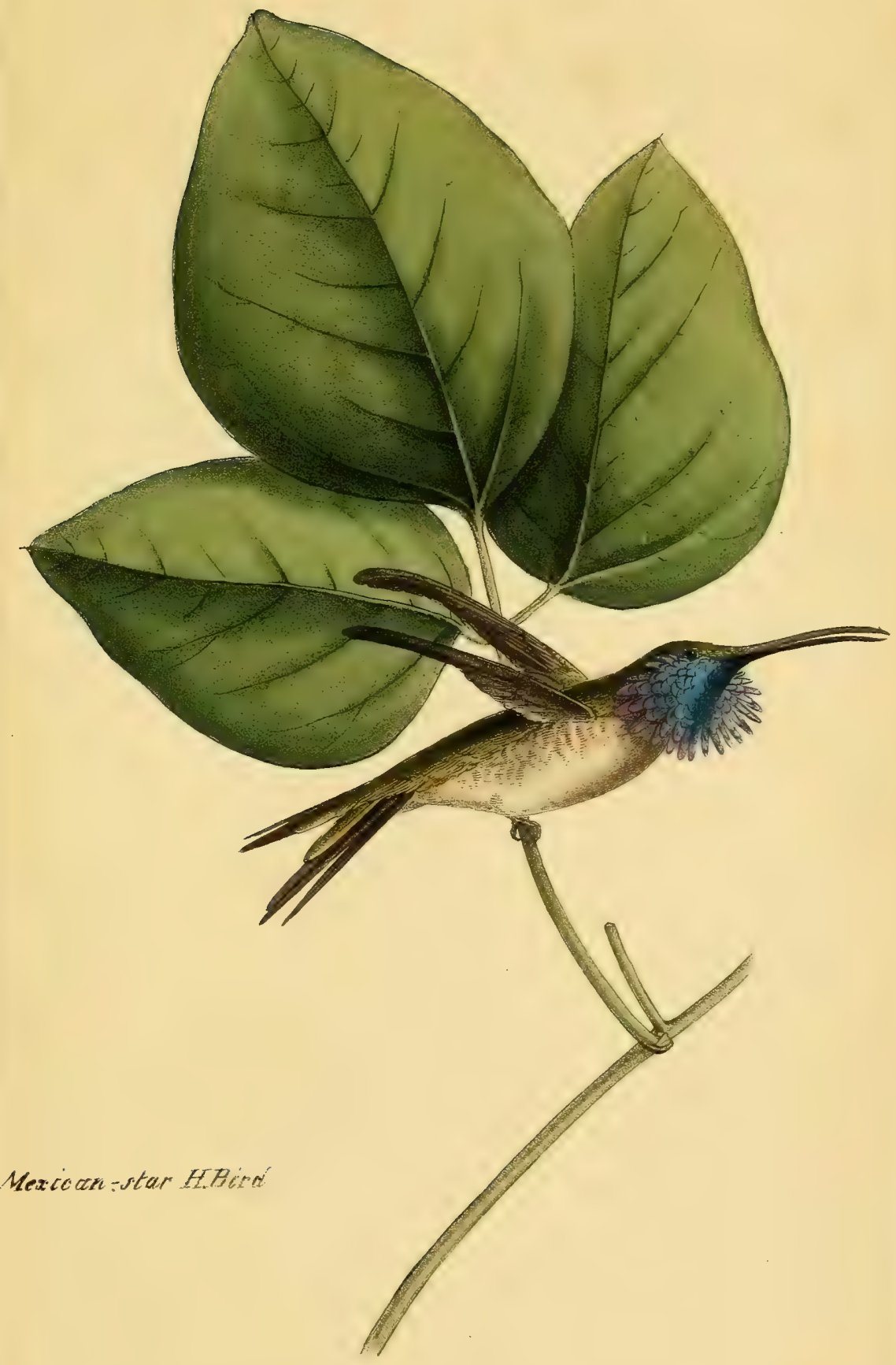






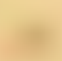

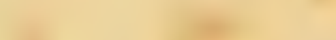

.

.

$\sqrt{2}+x^{2}$

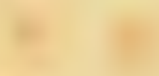

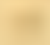

. 


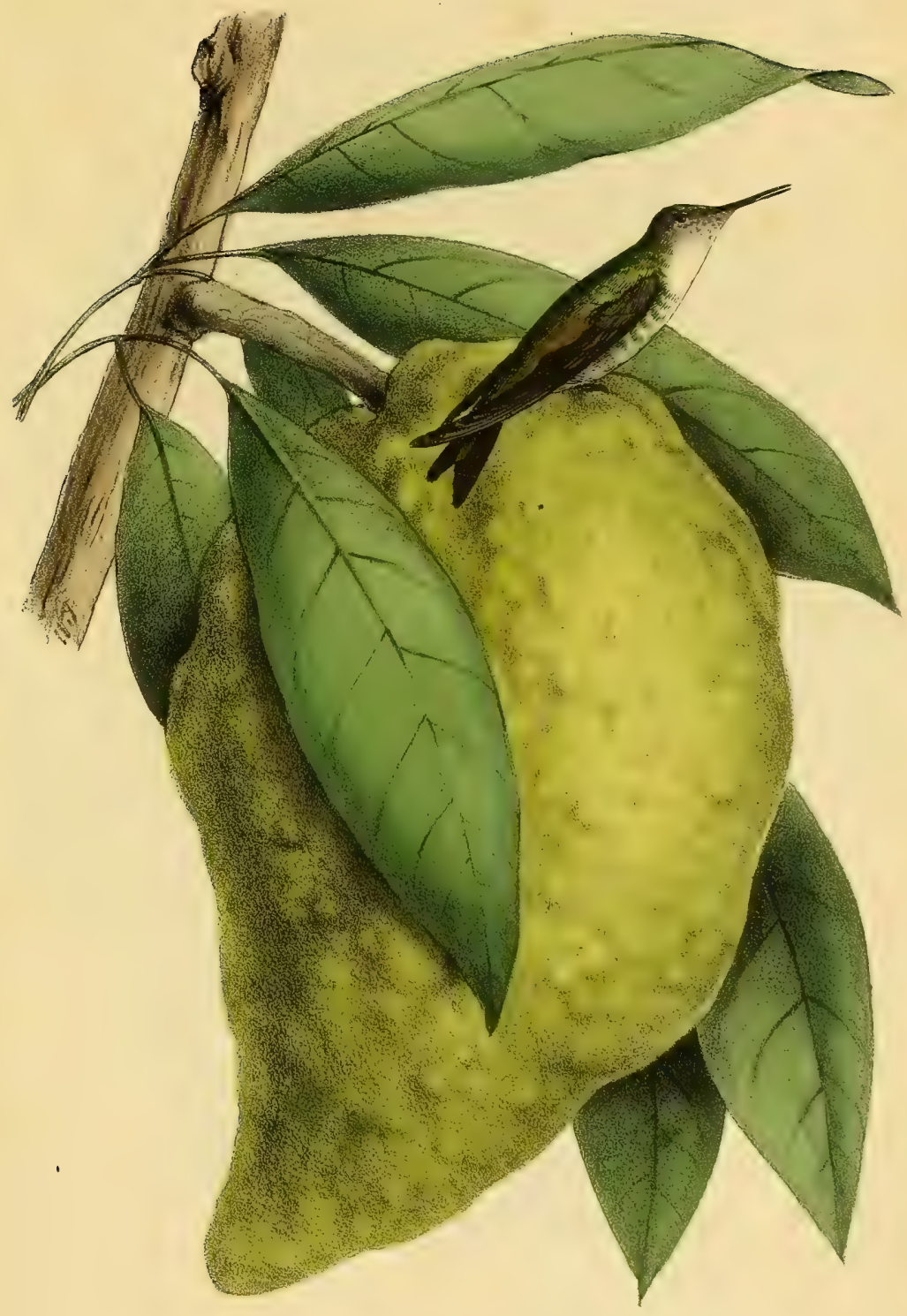

Pigmy Humming Bird 




